Chapman University

Chapman University Digital Commons

Education (PhD) Dissertations

Dissertations and Theses

Fall 12-2021

\title{
Searching for Balance: The Reading Choices, Experiences, and Habits of Women in Higher Education Leadership Roles
}

\author{
Laura Burns \\ Chapman University, burns178@mail.chapman.edu
}

Follow this and additional works at: https://digitalcommons.chapman.edu/education_dissertations

Part of the Educational Leadership Commons

\section{Recommended Citation}

Burns, L. A. (2021). Searching for balance: The reading choices, experiences, and habits of women in higher education leadership roles [Doctoral dissertation, Chapman University]. Chapman University Digital Commons. https://doi.org/10.36837/chapman.000319

This Dissertation is brought to you for free and open access by the Dissertations and Theses at Chapman University Digital Commons. It has been accepted for inclusion in Education (PhD) Dissertations by an authorized administrator of Chapman University Digital Commons. For more information, please contact laughtin@chapman.edu. 


\title{
Searching for Balance:
}

\section{The Reading Choices, Experiences, and Habits of Women in Higher Education Leadership Roles}

\author{
A Dissertation by \\ Laura Ann Burns \\ Chapman University \\ Orange, CA \\ Attallah College of Educational Studies \\ Submitted in partial fulfillment of the requirements for the degree of \\ Doctor of Philosophy in Education with a Leadership Studies Emphasis
}

December 2021

Committee in charge:

Whitney McIntyre Miller, Ph.D., Chair

Kelly Kennedy, Ph.D.

Lorri Sulpizio, Ph.D. 
The dissertation of Laura Ann Burns is approved.

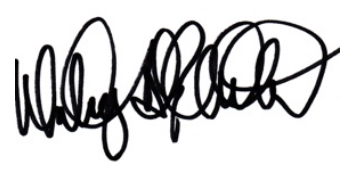

Whitney McIntyre Miller, Ph.D., Chair

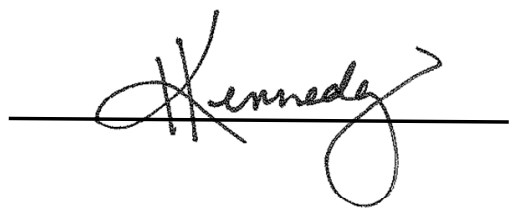

Kelly Kennedy, Ph.D.

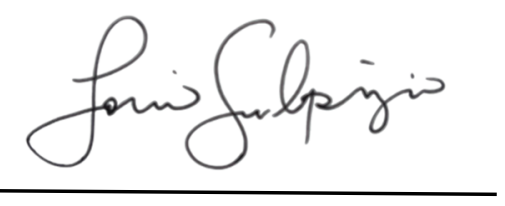

Lorri Sulpizio, Ph.D.

August 2021 
Searching for Balance:

The Reading Experiences, Choices, and Habits of Women in Higher Education Leadership Roles

Copyright (C) 2021

by Laura Ann Burns 


\section{DEDICATION}

\section{To my beloved parents, Jane and John Burns}

Thank you for nurturing my love of books and learning, and taking me to libraries and bookstores countless times so that I always had something to read. Thank you for your unconditional support and always believing in me. 


\section{ACKNOWLEDGEMENTS}

I would not have been able to complete this journey without the support and encouragement of my dissertation committee, family, friends, and colleagues.

I would like to thank my dissertation committee. To my dissertation committee chair and advisor, Dr. Whitney McIntyre Miller, thank you for your mentorship, encouragement, and feedback throughout the doctoral program. I could not have finished this without your insight and support. Thank you to Dr. Kelly Kennedy and Dr. Lorri Sulpizio for serving on my dissertation committee and for your invaluable guidance and feedback.

Thank you to the faculty and staff of Attallah College of Educational Studies for your support and encouragement as I navigated working full time while completing a doctoral program. I would especially like to thank Dr. Dawn Hunter for your kindness, support, and encouragement throughout my journey as a doctoral student. I would also like to thank the leadership faculty, Dr. Kris De Pedro, Dr. Angel Miles Nash, and Dr. Penny Bryan.

Thank you to my peers in the Ph.D. program for your support and friendship.

Thank you to the women in higher education leadership roles who participated in the focus groups for my research. My understanding of this topic was enriched by your contributions, and I am so grateful that you were excited to engage on this topic.

I am grateful to my family for their support throughout this process. Thank you to my parents, Jane and John Burns, for their love and support and for understanding my busy schedule. Thank you to the Burns family - DJ, Lauren, Cora, and Finley, and the Nelson family - Amanda, Tyler, Avery, and Savannah for your love and support. Thank you to my aunts, uncles, and cousins for cheering me on. 
A special final thank you to my dog, Bailey Burns, for sitting with me while I wrote, revised, edited, and completed this dissertation and conducted and transcribed the virtual focus group discussions. Thank you for being my constant companion throughout the doctoral program and through the pandemic. 


\begin{abstract}
Searching for Balance: The Reading Experiences, Choices, and Habits

of Women in Higher Education Leadership Roles

by Laura Ann Burns
\end{abstract}

Women in higher education leadership roles face complicated challenges in their professional roles, and struggle to maintain work-life balance, yet they make time to read for professional development and for pleasure. Utilizing grounded theory methodology, focus group methods, and grounded theory coding, this study examines the reading choices and habits of women in higher education leadership roles, delving into how they balance their reading between material tied to their professional interests and leisure reading material, and to what extent reading for pleasure contributes to their work-life balance. The study explores what reading materials women academic leaders consume, and where they acquire reading recommendations. The study also examines whether women had an early love of reading and when that began, and follows their reading choices and habits through K-12, college, graduate school, and their present lives. In addition, the study explores how reading has impacted women throughout their personal and professional lives, and how it has contributed to their current higher education leadership roles. Suggestions will be made regarding changes that can be implemented in curricula to better support and prepare young women to attain leadership positions and lead balanced lives once in these roles. 


\section{TABLE OF CONTENTS}

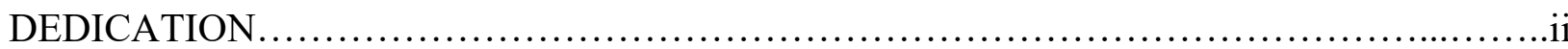

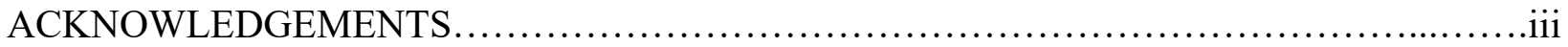

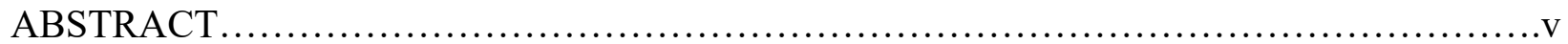

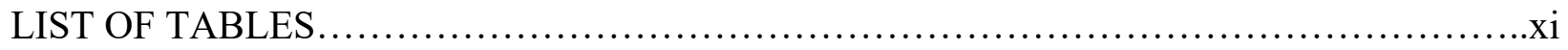

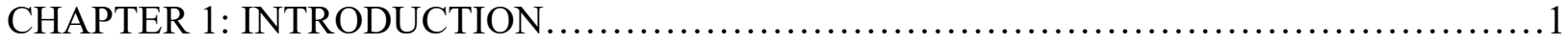

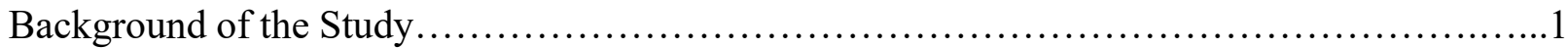

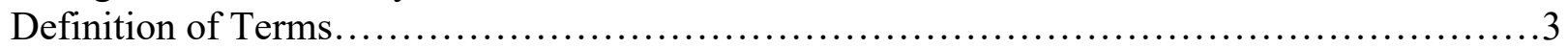

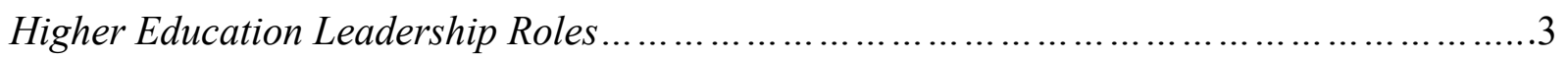

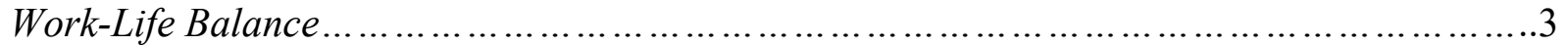

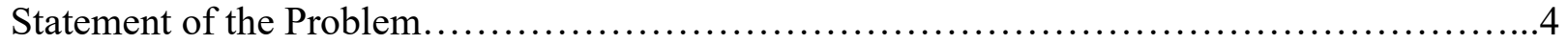

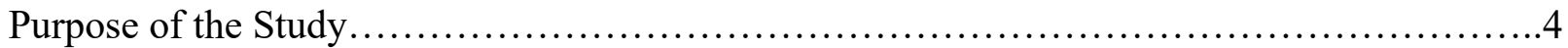

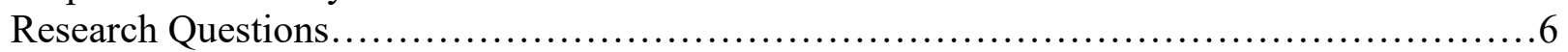

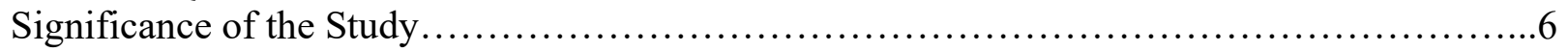

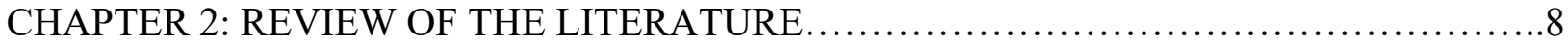

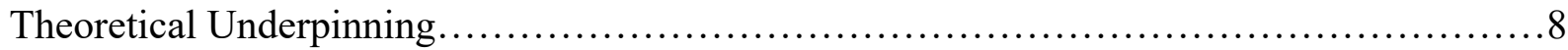

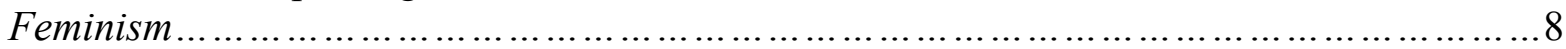

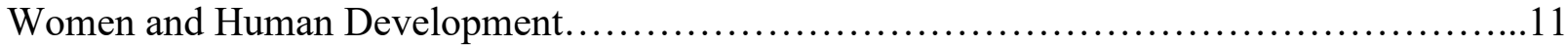

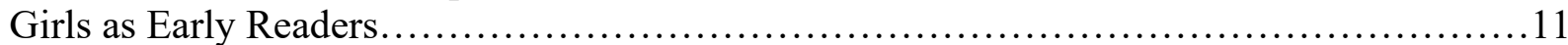

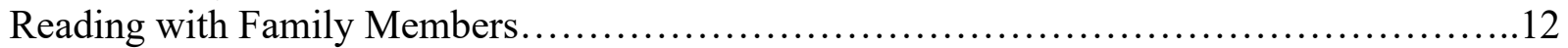

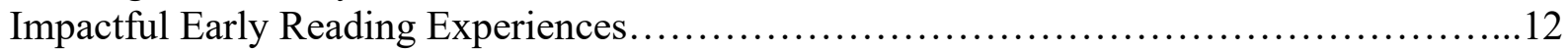

Importance of Personal Choice of Reading Materials..................................... 13

Importance of Gender Balance in the Classroom for Young Women............................13

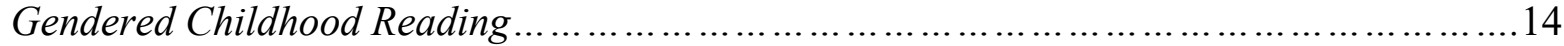

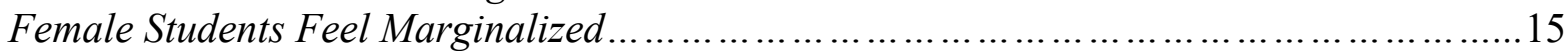

Identifying with Literature Helps Increase Students' Confidence ...............................16

Gender Balance in the Interest of Social Justice..................................................16

Counterbalance Negative and Stereotypical Portrayals of Women in Literature .................17

Gender Balance Benefits All Students - Male and Female ........................................ 17

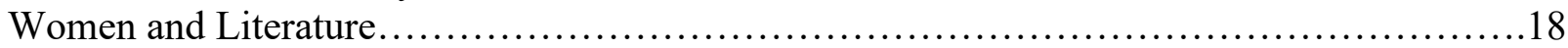

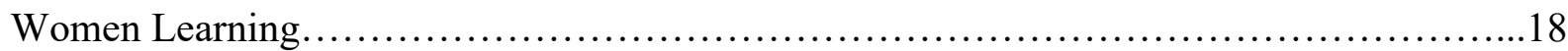

Gender Differences in Reading Comprehension.........................................18

Gendered Reactions to Difficult Subjects..................................................19

Muted Group Theory and Women's Understanding of Texts ..................................... 19

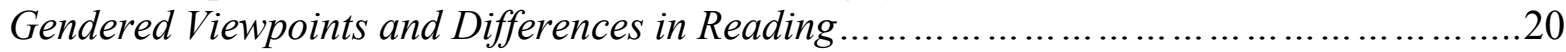

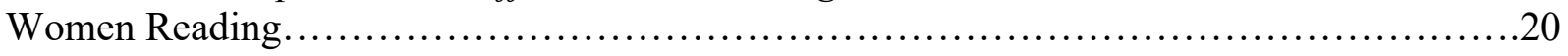

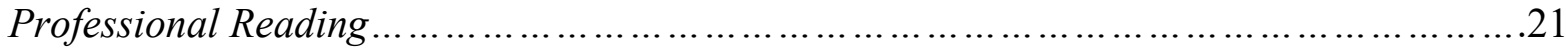

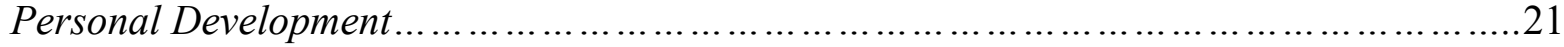

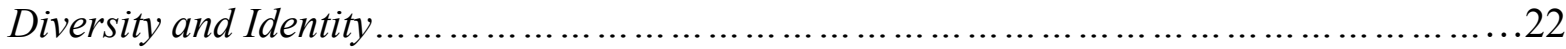

Leisure Reading for Escape and Fiction Genres Read by Women..............................22 


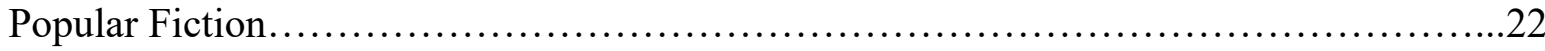

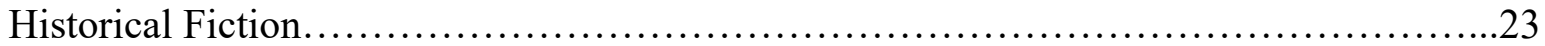

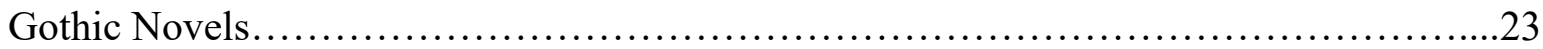

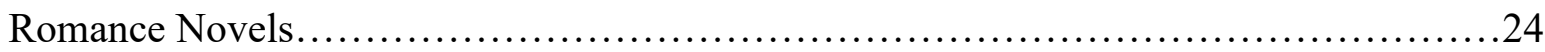

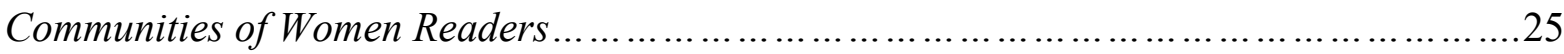

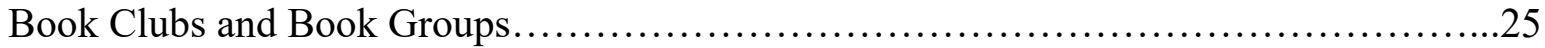

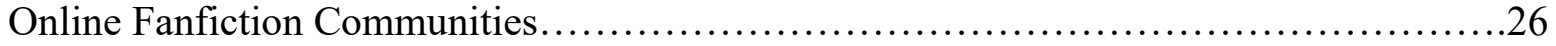

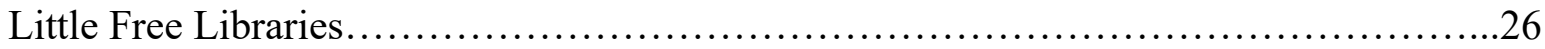

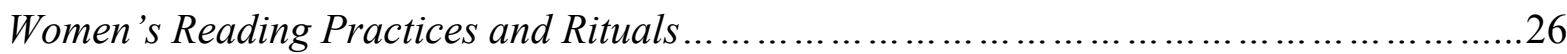

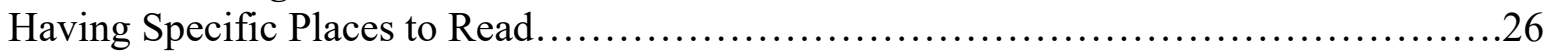

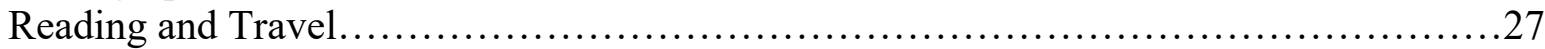

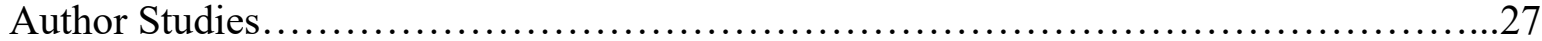

Women in Higher Education Leadership Roles........................................2 28

Life Balance: Personal Life Versus Family Life........................................28

Traditional Gender Norms and Power Dynamics....................................... 30

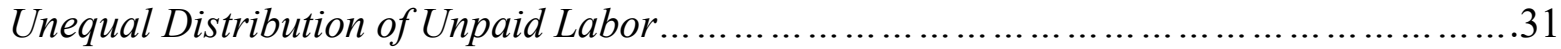

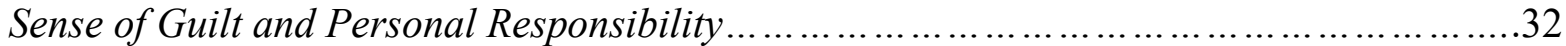

Women Leaders in Higher Education and Work-Life Balance..................................34

Balancing Strategies and Their Drawbacks............................................34

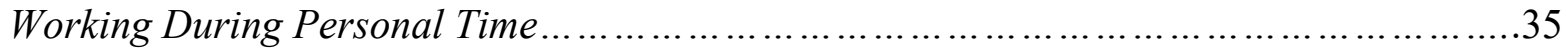

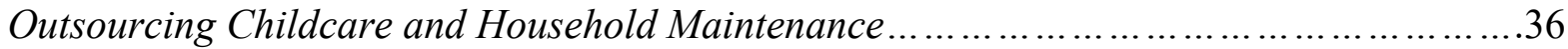

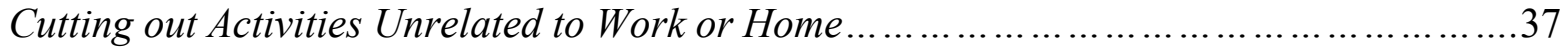

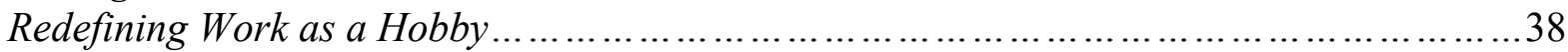

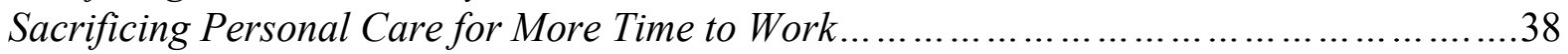

The Impact of Institutions and University Leaders on Work-Life Balance.....................39

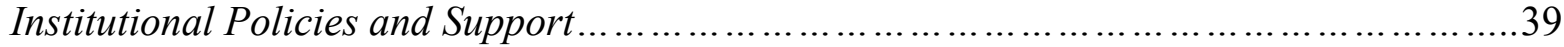

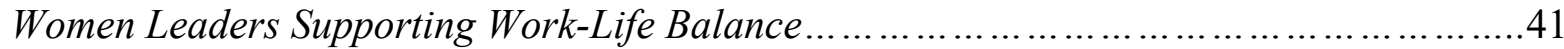

Women Leaders Modeling Work-Life Balance ...................................................... 41

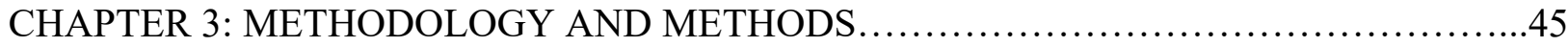

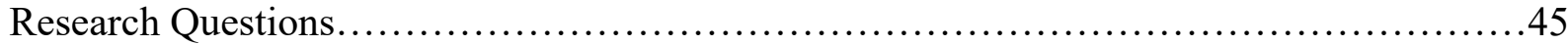

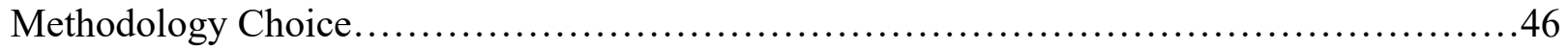

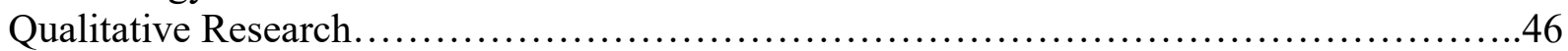

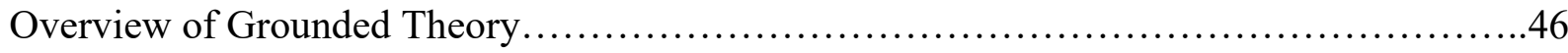

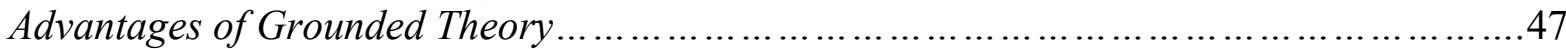

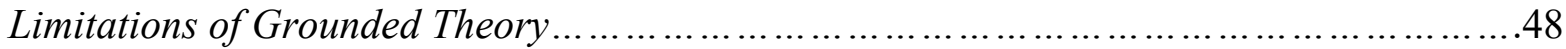

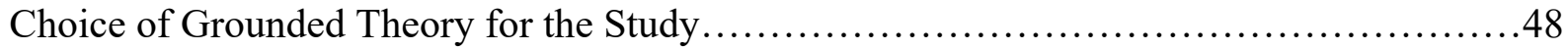

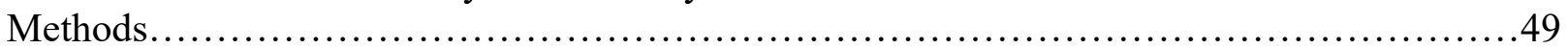

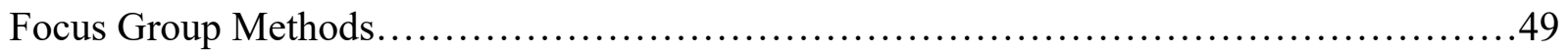

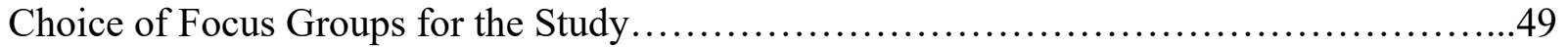

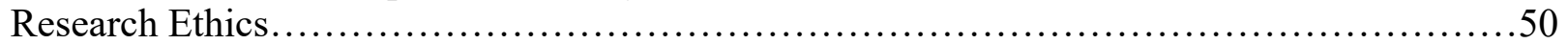

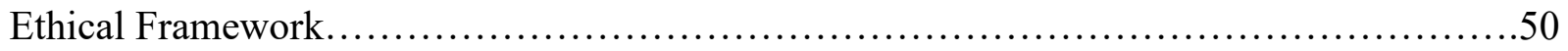

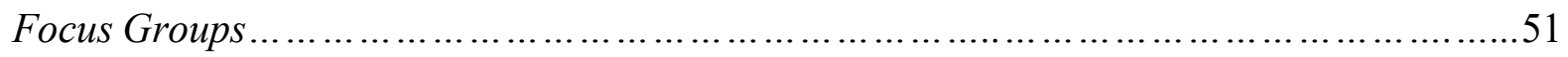

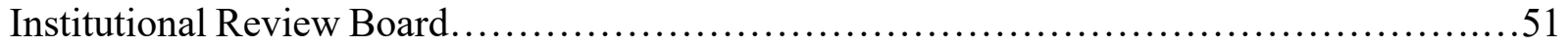

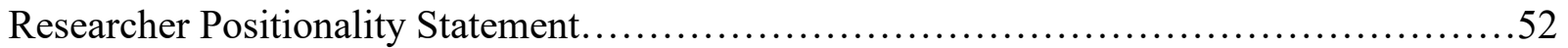

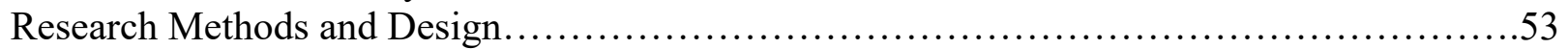




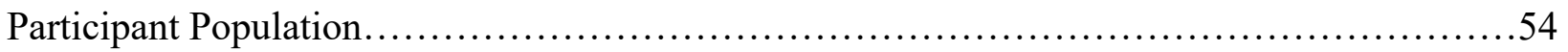

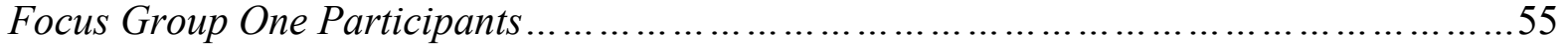

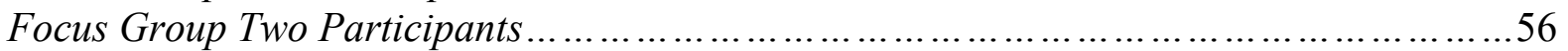

Focus Group Three Participants.....................................................5

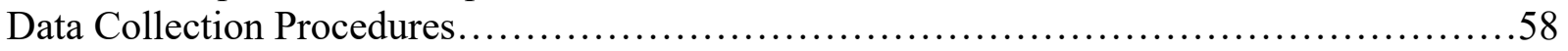

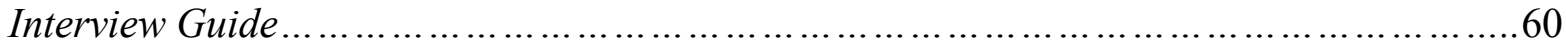

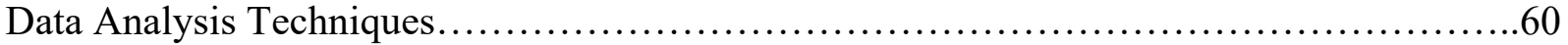

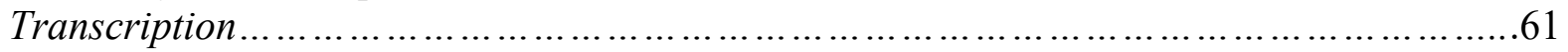

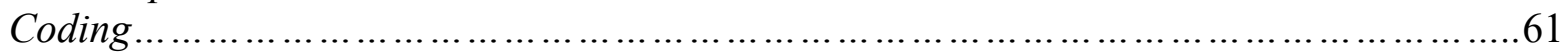

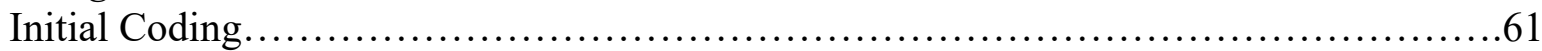

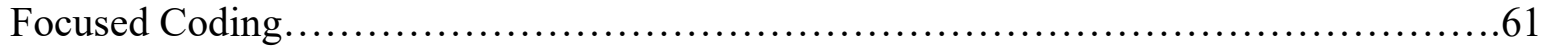

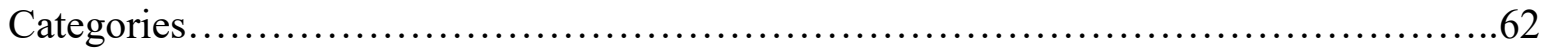

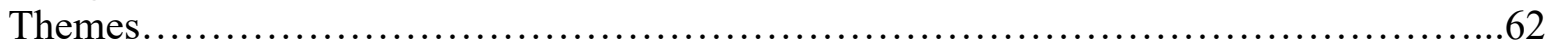

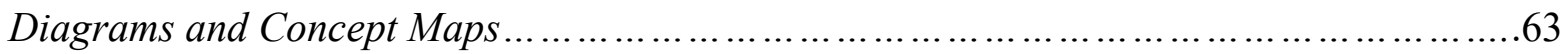

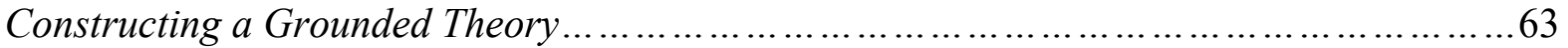

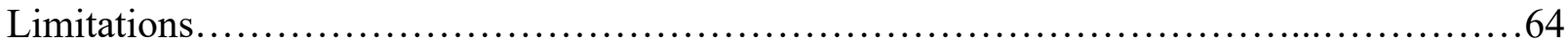

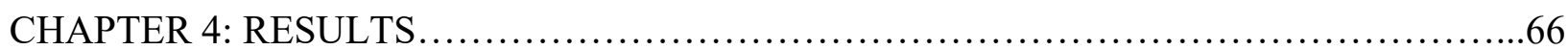

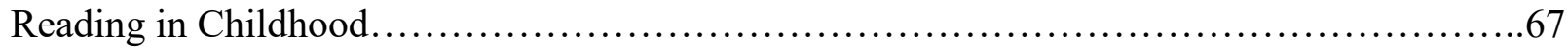

Early Readers with an Early Love of Books .......................................................6. 68

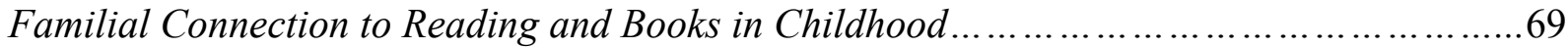

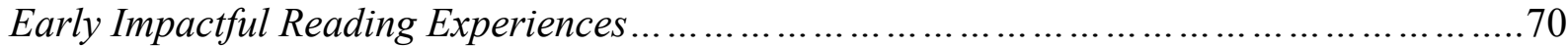

Early Reading Experiences Outside of the United States.......................................72

Importance of Personal Choice of Reading Materials ............................................... 73

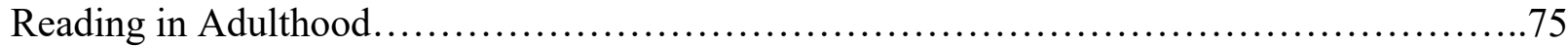

What Women Leaders in Higher Education Read .............................................. 75

Reading for Teaching, Research, and Theory Related to Professional Work................76

Connection of Reading to Teaching and Research Interests....................................76

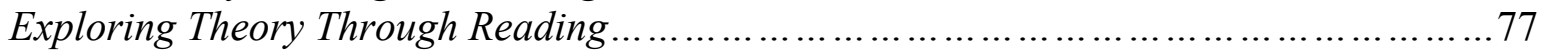

Reading for Diversity and Identity .................................................. 79

Importance of Representation in Books and Being Able to Identify with the Characters.....79

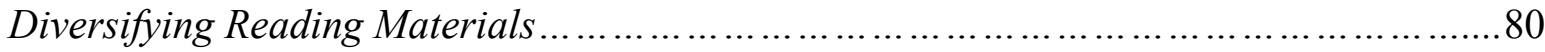

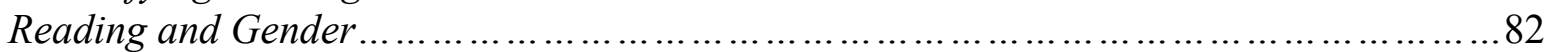

Exploring Relevant Intersectional Issues Through Reading ...................................83

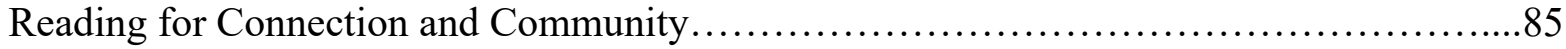

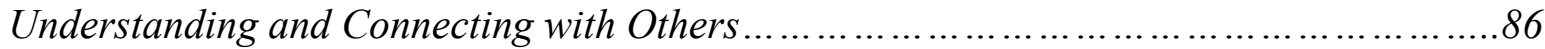

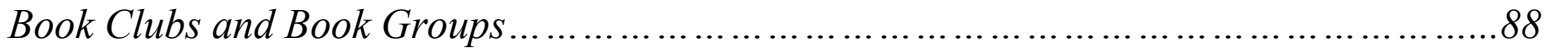

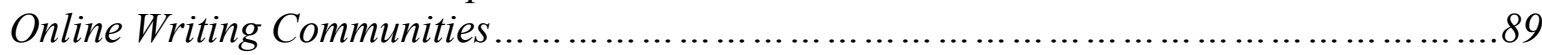

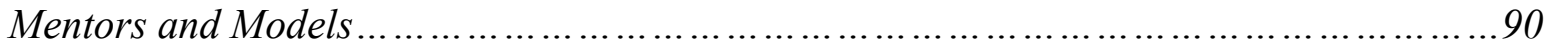

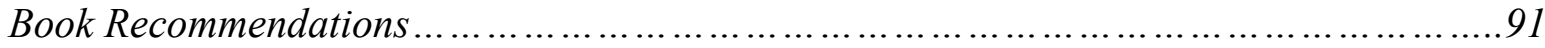

Reading for Personal Development....................................................99

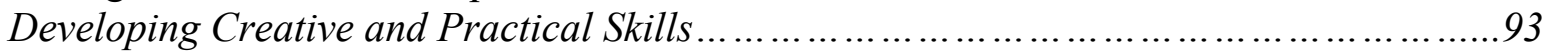

Developing Skills to Navigate Home and Workplace Roles.......................................99

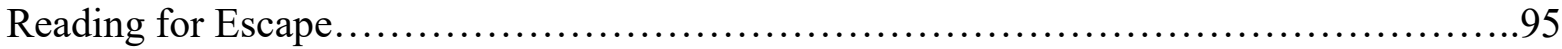

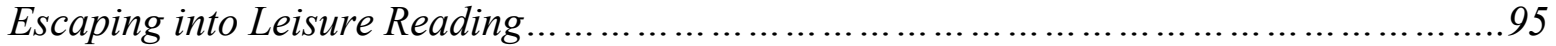

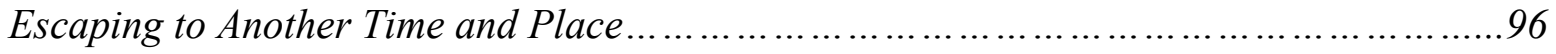


Escaping From Reality During the COVID-19 Pandemic ............................................. 97

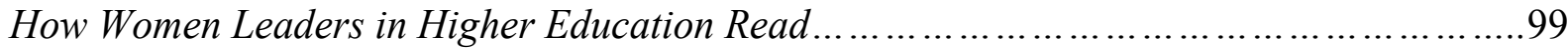

Having Specific Places to Read..................................................... 100

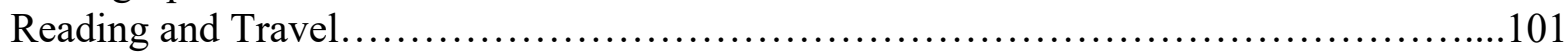

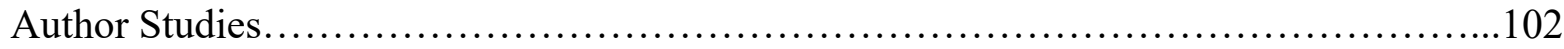

Technology Providing More Ways to Consume Reading..............................103

Reading and Balance.................................................................

Finding Balance Through Combining and Aligning Reading Interests ..........................105

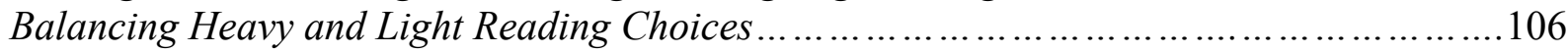

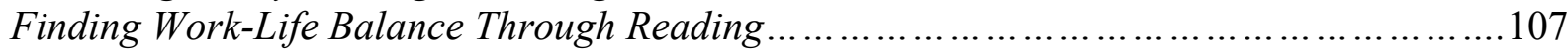

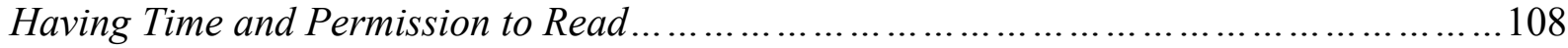

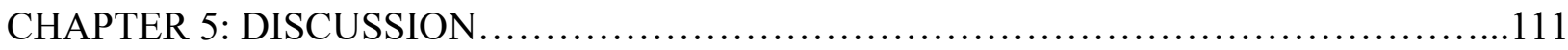

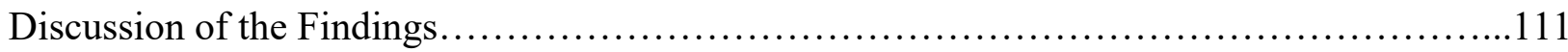

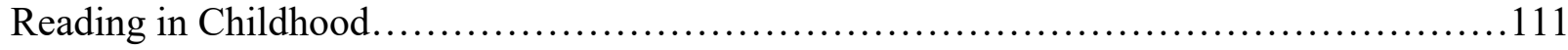

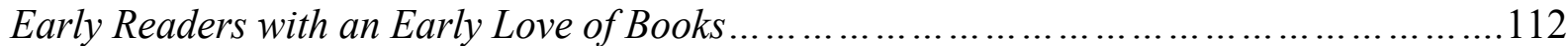

Familial Connection to Reading and Books in Childhood ...................................... 112

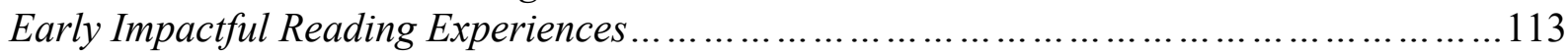

Early Reading Experiences Outside of the United States........................................... 113

Importance of Personal Choice of Reading Materials ............................................... 114

Reading in Adulthood.................................................................. 114

What Women Leaders in Higher Education Read ................................................115

Reading for Teaching, Research, and Theory Related to Professional Work...............115

Connection of Reading to Teaching and Research Interests..................................115

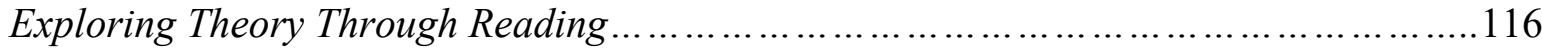

Reading for Diversity and Identity ................................................. 116

Importance of Representation in Books and Being Able to Identify with the Characters...117

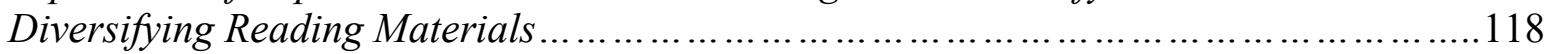

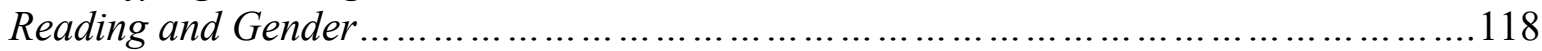

Exploring Relevant Intersectional Issues Through Reading...................................119

Reading for Connection and Community .............................................. 119

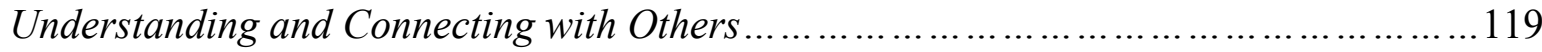

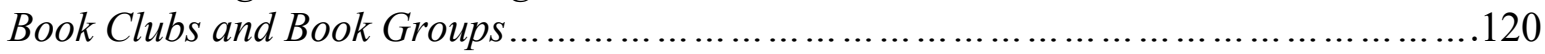

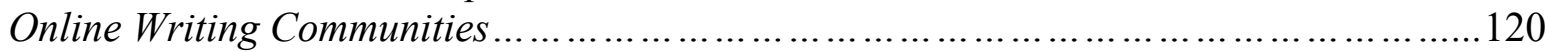

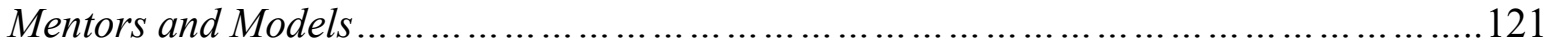

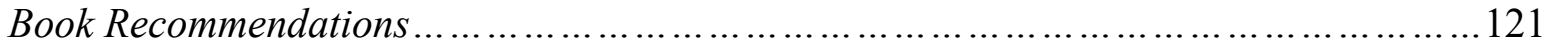

Reading for Personal Development................................................. 122

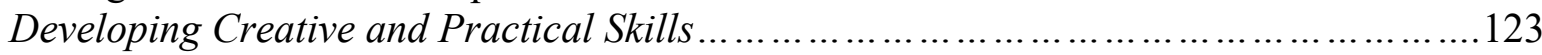

Developing Skills to Navigate Home and Workplace Roles.....................................123

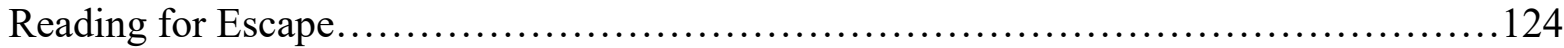

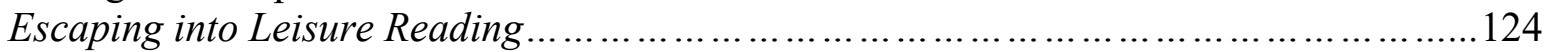

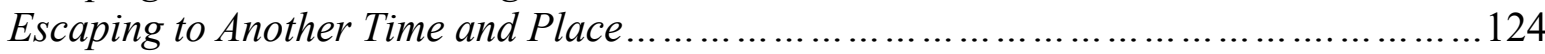

Escaping From Reality During the COVID-19 Pandemic ...................................... 125

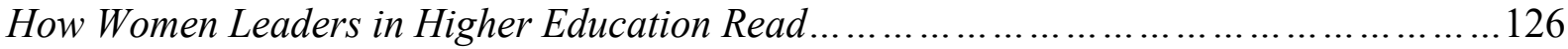

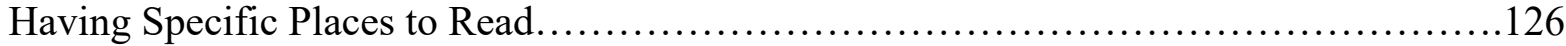

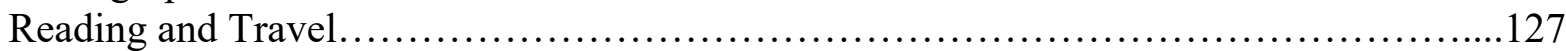




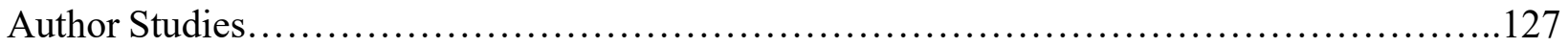

Technology Providing More Ways to Consume Reading .............................128

Reading and Balance............................................................ 128

Finding Balance Through Combining and Aligning Reading Interests ......................... 129

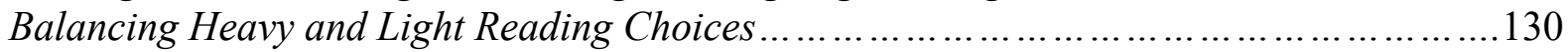

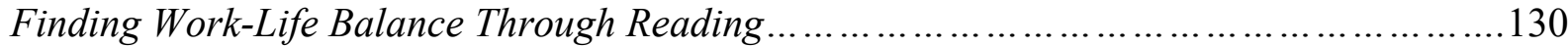

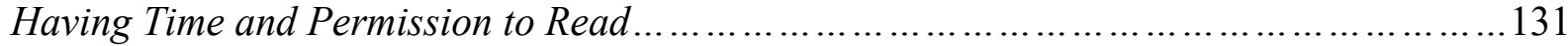

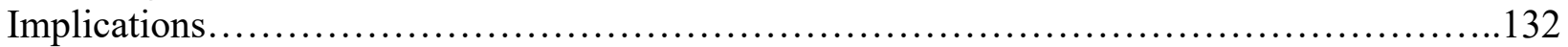

Parents of Childhood Readers......................................................... 132

K-12 Through Higher Education Educators...........................................133

Women Interested in Working in Academia........................................... 133

Women in Higher Education Leadership Roles.......................................... 133

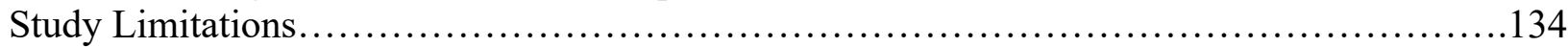

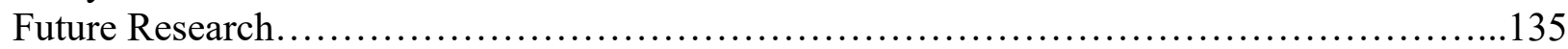

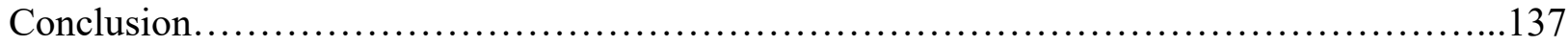

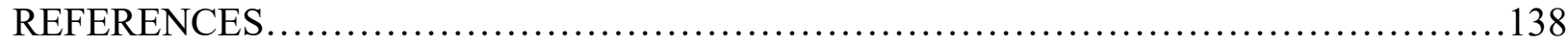

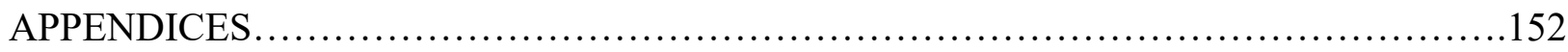




\section{LIST OF TABLES}

Table 3.1: Overview of Focus Group 1 Participants.......................................56

Table 3.2: Overview of Focus Group 2 Participants.....................................57

Table 3.3: Overview of Focus Group 3 Participants................................... 58

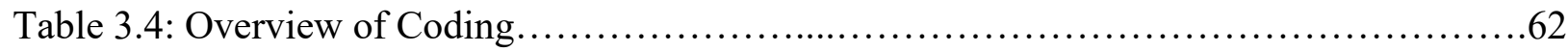

Table 3.3: Journey of a Quote...................................................63 


\section{CHAPTER ONE: INTRODUCTION}

Women leaders in higher education read throughout their educational journeys to reach their academic positions, but upon assuming their university roles they face complex challenges and struggle with maintaining work-life balance due to the rigor of their professional responsibilities (Cheung \& Halpern, 2010; Hertneky, 2010; Sallee \& Blakewood Pascale, 2012; Smidt, Pétursdóttir, \& Einarsdóttir, 2017). Whether they currently read to stay relevant and engaged in their field or make time to read for pleasure, the reading material that women in leadership roles in higher education choose to spend their valuable time consuming is of great interest and has inspired my research topic. This study examined the reading choices and habits of women in leadership in higher education and delved deeper into the types of reading material these women consume for scholarship and enjoyment, examined why they choose these reading materials, determined the impact of reading on their career trajectory, and explored how reading contributes to their work-life balance. My completed dissertation provides insight into the literature that impacts women leaders in higher education, how this literature has influenced their personal and professional lives, illuminates how to improve literature curriculums to better prepare women for leadership roles, and provides recommendations for how reading can bring balance to their busy lives once they are in these roles.

\section{Background of the Study}

As young girls develop, they are exposed to the literature provided by their parents and teachers and develop views of gender roles and attitudes through the books they consume (Cunningham, Buetel, Barber \& Thornton, 2005; Fan and Marini, 2000; Segel, 1986). As they continue through K-12 and college with a prescribed male-centered canon (Appleby, 1992; Greenbaum, 1994; Zeller Carlson, 1989), young women may begin to have more choice in the 
books they read in their leisure time. Their chosen course of study in college and graduate school exposes women to further diversity of reading material aligned with their intended field of employment. Upon entering the job field, women likely have full control over their reading choices and habits, and whether they spend their time reading for personal enjoyment, professional advancement, or most often both. While literature exists related to what young women read during K-12 and their undergraduate years, little relevant literature exists about the reading choices and habits of women in higher education and especially in leadership roles in academia. I was interested to discover if the reading that women in higher education leadership roles have consumed on their journey to becoming leaders has influenced and shaped that path in a significant way. This study also explores how women leaders' continued relationship with reading impacts their personal and professional roles, and their efforts to maintain work-life balance.

My love of literature and life-long interest in learning as much as possible through reading has had a great impact on my understanding of the world, educational journey, choice to continue through higher education, and decision to pursue a career in academia. The core literature curriculum studied throughout my elementary and secondary education consisted of predominantly male authors and male protagonists, and I supplemented this prescribed reading with personal reading choices that often included works written by women and about women. The canon taught in my bachelors and masters English literature courses was also heavily populated by male authors and male protagonists, though through the choice of elective literature courses and personal reading I was exposed to more female authors and protagonists during this chapter of my academic life. In the ten years that I spent working in publishing between my masters and doctoral programs, the leisure reading that I chose was heavily comprised of female 
authors and protagonists. I recognize that there are many other cultural phenomena that shape the gendered perceptions of girls and women, including television, film, theater, and music, but I have chosen to focus on the reading of books for the purposes of this study.

Once I joined the doctoral program, my personal experiences with the reading choices that I made in response to the literature curriculums I was obligated to follow led to my research into the impact of gender imbalance in literature curriculums on the development of young women. In an introductory qualitative research methods course, I also interviewed several women in higher education leadership roles about their reading choices and habits and was fascinated by their feedback on the topic. I was interested to discover how an in-depth study on the reading choices and habits of women in higher education leadership roles would provide insight into how to better educate and prepare young women to become future leaders in academia and successfully balance their lives once in these roles.

\section{Definition of Terms}

Integral terms that will be frequently referenced throughout this study include higher education leadership roles and work-life balance, defined as follows:

\section{Higher Education Leadership Roles}

The term higher education leadership roles refers to administration roles within the academic units of a university. This includes roles such as: deans, directors, department chairs, and program chairs.

\section{Work-Life Balance}

The term work-life balance refers to the struggle that individuals face to maintain equilibrium between the amount of time they spend on their professional endeavors and on their personal responsibilities (Kinman, 2016; Smidt, Pétursdóttir, \& Einarsdóttir, 2017; Toffoletti \& 
Starr, 2016). This term is often used in higher education in reference to work/family employment policies ostensibly created to assist employees in creating a life with time balanced between work and home (Sallee, 2013; Toffoletti and Starr, 2016).

\section{Statement of the Problem}

Women leaders in academia face complex challenges in their university roles and struggle with maintaining work-life balance due to the rigor of their positions (Cheung \& Halpern, 2010; Hertneky, 2010; Sallee \& Blakewood Pascale, 2012; Smidt, Pétursdóttir, \& Einarsdóttir, 2017), which can leave little time for outside pursuits, such as reading for either personal or professional purposes. The lack of work-life balance leads them to face issues related to their physical and psychological health, such as burnout, fatigue, high stress levels, sleeplessness, and depression, and when these symptoms persist they affect their personal relationships and professional satisfaction (Cherkowski \& Bosetti, 2014; Kinman, 2016; Rafnsdóttir \& Heijstra, 2013). While research exists on what young women read as they develop, there is little existing research on the reading choices or habits of adult women or adult academics. I explored the reading material that women in leadership roles in higher education chose to spend their valuable time consuming and their reasons for choosing it and examined the impact that reading has had on their professional and personal lives to provide insight into the literature that informs and enriches lives of women leaders in academia and to illuminate how reading contributes towards women in leadership roles in academia achieving a better work-life balance and quality of life.

\section{Purpose of the Study}

The purpose of this study was to better understand what women in higher education leadership roles choose to read, how reading contributes to their personal and professional lives, 
and how reading contributes to their work-life balance. Another goal was to investigate the reading experiences that these women had over their lifetimes, from childhood through adulthood, and to learn more about their reading rituals and practices.

This study used grounded theory methodology to investigate the reading experiences, choices, and habits of women in higher education administration roles at a small, private arts institution in California. Participants were women in the following leadership roles within the university: deans, directors, department chairs, and program chairs. The women participated in one of three focus groups, which gathered data about their reading experiences, habits, and choices. The use of a semi-structured interview guide provided structure to the focus group conversation (Morgan, 2019). The data was transcribed and then analyzed using grounded theory coding practices (Charmaz, 2014; Morgan, 2019). By examining the qualitative data compiled through the study, I provided the comprehensive view of the impact of reading on women in higher education leadership roles that will be discussed throughout this dissertation.

For context on the significant events occurring at the time of this research study, it is important to note that the focus group discussions took place in May 2020, which placed them during a period of lockdown towards the start of the COVID-19 pandemic. Universities in California began sending home students, staff, and faculty in mid-March of 2020, so participants had been working remotely and teaching online for about two months and a vaccine was yet to be developed. Women in higher education leadership positions in academia were concerned with the health and safety of students, staff, and faculty, and were still adjusting to working under unprecedented circumstances. The focus group sessions also took place within days of the murder of George Floyd and the subsequent protests about social justice, racial equity, and police brutality. While participants did not directly speak about his death or the protests that followed, 
they were likely still processing it. These events were widely covered in the news and likely on the minds of participants as they detailed the reading that they were already doing in the areas of racism, social justice, equity, diversity, inclusion, and identity. The context of COVID-19 and George Floyd will both be important in Chapter 4.

\section{Research Questions}

Guiding this study was the following research questions:

- In what ways have reading choices, practices, and habits impacted the personal and professional lives of women in higher education leadership roles?

- What are the life-long reading experiences of women in higher education leadership roles and how do these influence their work and lives?

- What reading materials do women in higher education leadership consume and why?

- What are the reading rituals and practices of women in higher education leadership roles? Why do they engage in these rituals and practices and how do these influence their personal and professional lives?

- To what extent, if any, does reading contribute to women in higher education leadership roles' work-life balance?

\section{Significance of the Study}

Institutions in the sector of higher education have communicated a goal to hire diverse individuals and to address existing gender imbalance in positions of leadership. Despite these stated goals, the average percentage of women leaders in academia was 24.53 percent (The White House Project, 2013). By adding to the body of knowledge regarding the unique challenges faced, as well as the factors such as reading that contribute to the success and the 
work-life balance of women in higher education leadership roles, this study illuminates what it takes to become a female leader in academia today.

Most of the literature outlining studies involving what individuals choose to read and why they choose to read it are focused on youth; primarily grade school, high school, or undergraduate students. Some areas of the lives of women leaders in higher education roles have been explored, including the unique challenges they face, but there is very little literature related to what adult women or adult academics are reading, and even less on what women in leadership roles in higher education choose to read. Examining the reading choices and habits of women in higher education leadership roles addresses a gap in the literature and provides groundwork to lead to potential further future research in this area. The study helps inform what it takes to aspire to higher education leadership roles and how reading impacts the success of women in academic leadership roles by contributing to their work-life balance. 


\section{CHAPTER TWO: REVIEW OF LITERATURE}

This study explores the importance of literature to women in leadership roles in higher education in the areas of work-life balance, their personal and professional lives, and throughout their development. This literature has been divided into the categories of women and human development, women and literature, women in higher education leadership roles, and leadership and work-life balance. I approached the topics pertinent to this study through a feminist lens. This and a thorough review of the literature appear below.

\section{Theoretical Underpinning}

The theoretical underpinning foundational to this study is feminism, which will be explored below.

\section{Feminism}

I approached this study through a feminist lens, exploring how the existing systems and norms within education affect the learning experience of women throughout their educational pathway, and continue to affect those that reach positions of leadership within higher education. Launius and Hassel (2018) describe a feminist position as "adopting a feminist perspective or way of looking at the world" (p. 4). There are a wide variety of definitions attached to feminism, and the precise interpretation has changed over time. Authors such as Freeman (2007) provide a simple definition, positing that, "feminism is the belief that women have the same human capacities as men" (p. xi). Others such as hooks (2015) provide a more active definition, asserting that, "feminism is a movement to end sexism, sexist exploitation, and oppression" (p. xii). I identify most closely with the definition of feminism that Leavy and Harris (2019) aptly articulated, explaining that "beginning with the status of girls and women, but not ending there, feminism is an engaged human rights position that seeks to expose and remedy gender 
inequalities" (p. v). Leavy and Harris' (2019) definition leaves room for both research and practice, focusing on the importance of feminist activism to discover solutions to gender inequalities, and enlarging the scope to include the human rights of all individuals facing gender inequities in addition to addressing the issues affecting girls and women.

There are also a variety of preconceptions attached to feminism. As hooks (2015), explained, mainstream patriarchal mass media continues to be the initial space where individuals learn about feminism, but much of the information they receive through this medium is destructive. As Launius and Hassel (2018) echoed, both popular culture and mass media undercut feminism by disseminating misconceptions and stereotypes about feminists and feminism, resulting in young women being hesitant to call themselves feminists even if their beliefs align with feminist ideology. In believing the negative portrayals of feminism and being reluctant to identify as feminists, women and men maintain the patriarchal status quo, for as hooks explains, "we are all participants in perpetuating sexism until we change our minds and hearts; until we let go of sexist thought and action and replace it with feminist thought and action" (p. xiii).

I used a feminist lens to explore how the existing systems and norms within education affect the learning experience of women throughout their educational pathway and continue to affect those that reach positions of leadership within higher education. Reading literature that has been written by a woman and with a female protagonist at each stage in a woman's life influences her perception of herself and the world around her at these crucial developmental stages. When authors and protagonists of their gender are not featured in the canon of literature that schools and educators have deemed to be significant, women are given the message that the thoughts and actions of women are not as important as those of men. 
The message that the stories of girls and women are not important begins at an early age with sexist, gendered books for young girls and is reinforced throughout the gender imbalanced curriculum of K-12 schooling. As hooks (2015) explains, the sexist preconceptions introduced in children's books were condemned at the height of the feminist movement, but over time this sexism has reemerged in children's literature. Young children are still developing their personalities and opinions, so children's books are an ideal space to include feminist education for critical consciousness (hooks, 2015).

Though as hooks (2015) asserts, the "feminist movement created a revolution when it demanded respect for women's academic work, recognition of that work past and present, and an end to gender biases in curriculum and pedagogy" (p. 21), much of the academy still has a long way to go until curriculums achieve greater gender balance. When women reach higher education, they finally have the flexibility to enroll in women's studies courses or literature courses featuring female authors in their undergraduate or graduate courses. At this level, they may have limitations due to the course sequence for their chosen career path, as well as financial concerns in that they may not be able to take additional courses that do not satisfy specific requirements. If the few courses highlighting the achievements of women and featuring works by female authors do not fall within the coursework for their majors, women may still not be exposed to these courses during their undergraduate or graduate programs. Men do not need to enroll in additional men's studies courses to be exposed to authors and perspectives of their gender, so until women's stories and perspectives are more integrated into the curriculum at all levels, education will not be free from gender bias.

By the time that women acquire higher education leadership roles, they have had to read gendered literature selected by parents and teachers in their early childhood and learn through a 
gender-imbalanced literature curriculum focused on male authors and male protagonists throughout their K-12 education. It is unlikely that these women had the same experience of closely identifying with the characters featured in the literature canon or the authors who wrote these novels as their male colleagues. If they did they were performing the gendered labor that all women are forced to do in many contexts in life - to take stories written as a universal norm that are in fact from a male perspective about a male experience, and adjust their perspective in order to creatively envision how this might apply to the lives of women.

When individuals are able to see themselves in the books that they read and consume literature in which protagonists similar to themselves are brave, intelligent, and full of agency, readers are better equipped to envision how they can achieve these positive qualities in their own lives and it leads to higher self-esteem. Those that do not find themselves reflected in the literature they consume for assigned classroom reading may take it upon themselves to supplement their assigned reading with books written by women featuring female protagonists in order to envision and inform their pathway to leadership and bolster their confidence in acquiring and succeeding in their leadership roles.

\section{Women and Human Development}

This section explores the learning and development of young women, and how it relates to the literature they are exposed to throughout their formative years. At key points in their development, young women form attitudes and beliefs about identity, agency, and gender roles, and their early reading experiences and education aid in the formation of these ideas.

\section{Girls as Early Readers}

Girls who are early readers with an early love of reading are often high performers once they enter school. Early readers that enjoyed reading at home were prone to better reading 
comprehension upon entering school (Leppänen, Anola \& Nurmi, 2005; Willingham, 2017).

Coles and Hall (2002) further related that building connections between children's literacy background in their homes to "the school literacy environment encourages confident, wellrounded readers who have a strong sense of their own agency and independence" (p. 104). Visiting libraries and reading frequently as children also led to young women becoming leisure readers when they entered adulthood (Moyer, 2007). Willingham (2017) also explained that positive reading experiences in childhood contributed to enjoyment of reading in adulthood. Girls who were early readers with an early love of books were set up for confidence, academic success, and an enjoyment of reading throughout their lives.

\section{Reading with Family Members}

Another reading practice that contributed to girls' early love of reading was family members sharing books and reading with them. Children with parents and family members who read with them and tell them stories at home were prone to greater reading growth and higher levels of literacy achievement (Boonk et al., 2018; Van Voorhis et al., 2013). Connecting with family members through a love of reading and books was significantly related to academic success and language performance (Boonk et al., 2018). as well as social emotional development (Baker, 2013). Girls who read with their family members in childhood were further well-placed for academic success and well-being.

\section{Impactful Early Reading Experiences}

Some books read in childhood particularly stand out, and young women remember these K-12 reading experiences throughout the rest of their lives. Some books that are impactful for young readers are related to issues of importance to their everyday lives. Issue-based books on topics such as bullying, prejudice, racism, refugee experiences, or sex are a growing area of 
reading for adolescent readers (Hopper, 2005). Impactful reading experiences in early reading contribute to girls' continued interest in exploring their connections to the experiences of others and the world around them as they progress in their development as readers and scholars.

\section{Importance of Personal Choice in Reading Materials}

Children who were provided with the opportunity to choose their own reading materials had a greater enjoyment of reading and were more likely to continue to enjoy reading throughout their lives. Hopper (2005) noted that adolescent students preferred to read books chosen by themselves or recommended by their peers to books that parents or teachers wanted them to read, and that providing them with personal choice of reading materials leads to both the development of critical skills and the appreciation of texts. When children have autonomy of choice and are provided with the opportunity to read what they like and select their own books, they have higher literacy achievement and are more engaged (McClung, et al., 2019). Reading choice also contributes to equity in the classroom as children are able to consume books that "reflect their lives, values, interests, discourses, and cultures" (McClung, et al., 2019, p. 169). As Miller (2009) explains, providing students with choice in their reading materials and validating those choices also supports their interests and culture in a way that mandating book selections does not. Girls who have the opportunity to choose and connect with their reading materials are more engaged and successful readers and students.

\section{Importance of Gender Balance in the Classroom for Young Women}

The relationship between adolescent development in young female students and gender imbalance within the curriculum has raised concern in educators who might not have questioned the core curriculum when they were young students. Shore's (2000) article on educating girls struck a compelling chord in her discussion of the problematic messages conveyed to young 
women through literature. As the author asserted, "the educated woman who teaches may come to her profession many times divided against herself. She is expected to teach the very texts her life may have taught her to question" (Shore, 2000, p.133). Confessing that she was ashamed to admit that after many years of teaching, Shore (2000) recognized the lack of gender balance later in life, and taught her students from the traditional male-centered canon for many years of her teaching career. Shore (2000) had since researched the topic of gender imbalance and found that female students were not only discouraged by a lack of female subjects within literature, they were also dismayed by the power construct within the classroom which has served to silence female students.

To counteract the prevalence of gender imbalance within high school English curriculums, women can supplement their reading of the predominantly male canon with their leisure reading of female authors, writing about female protagonists, but research shows that students of both sexes benefit from reading books written by and about women (Greenbaum, 1999; Zeller Carlson, 1989). While changes to the traditional literary tradition are slow to be widely incorporated, exposing young men and women to reading material from diverse points of view is important to their formation of a nuanced perspective at a key time in their development.

\section{Gendered Childhood Reading}

"One of the most obvious ways gender influences our experience as readers is when it determines what books are made available to us or are designated as appropriate or inappropriate for our reading. Nowhere is this fact so apparent or its implications so disturbing as in childhood reading" (Segel, 1986, p. 165). Dividing books into books specifically tailored to girls or to boys has set up a problematic precedent, where qualities such as agency or bravery are prescribed to be only of interest to young men and stories more centered on feelings and relationships are 
deemed to only pertain to young women (Segel, 1986). Gendered division of children's books is exacerbated by the attitudes displayed towards girls reading books geared towards boys, which is deemed harmless, and attitudes towards boys reading books geared towards girls, which is deemed shameful or unmanly, reinforcing gender norms that prioritize the male over the female experience and story (Segel, 1986).

The most disturbing factor in the division of gendered childhood reading is that adults are responsible for the publishing, marketing, purchasing, and provision of this reading material to young men and women, and are complicit, if not fully accountable, in the continued reinforcement of problematic gender norms (Segel, 1986). This has a long-reaching impact, because individuals form their opinions about suitable gendered behaviors in their early years of reading, so the materials that they are exposed to will have more of an impact than the diversity of reading material they may be exposed to once they have agency over their reading choices (Segel, 1986).

\section{Female Students Feel Marginalized}

At a critical age where their identities are forming, it is difficult to engage students in the classroom if the materials they are studying make half of them feel excluded and less important than their fellow classmates. As Zeller Carlson (1989) related, by leaving female protagonists and authors out of the curriculum, female students felt marginalized and "invisible," in a similar way that those of minority races may have felt when presented with a predominately white palette of characters and authors. Maintaining a curriculum narrowly focused on white male voices did not allow for a sense of belonging or inclusion for any of the students that did not fit within that category (Appleby, 1992; Greenbaum, 1994). Students that were unable to identify 
with the characters in the novels that they studied in school felt left out, causing a loss of agency, and it eroded their self-confidence (Zeller Carlson, 1989).

\section{Identifying with Literature Helps Increase Students' Confidence}

Educators stressed that examining novels featuring characters that they could personally identify with helped their students see their problems as universal and feel more confident in their abilities to resolve them (Miller, 1993; Zeller Carlson, 1989). The results of The Literature

Project of 1993, which used specific literature selections of strong female characters overcoming life struggles to help at-risk adolescent females gain perspective and confidence in themselves, revealed the importance of young women being able to relate to the protagonists and authors within their high school literature curriculum (Miller, 1993). The students identified with the characters, and Miller found that they felt more positive and hopeful after reading about these female protagonists facing similar challenges with courage and independence.

\section{Gender Balance in the Interest of Social Justice}

Literature instructors have the opportunity to better prepare their students to be socially responsible citizens by encouraging thought-provoking discussions about diversity and inclusion. According to St. Pierre (1999), English instructors have historically taken on the responsibility to remove prejudice and gender discrimination from society by exposing their students to the viewpoints of women and other cultures. Bender-Slack (1999) spoke of the need for representing the voices of previously underrepresented perspectives in the high school curriculum in order to ensure that female students and students of different cultural and financial backgrounds did not feel excluded from what is considered to be the authentic American experience. 


\section{Counterbalance Negative and Stereotypical Portrayals of Women in Literature}

Many of the female characters portrayed within the male-centered canon were supporting characters, with little agency, and unlikeable character traits. Thus, educators also saw gender balance in the curriculum as an opportunity to expose students to female characters with the opposite qualities: strong, goal-oriented women with likeable characteristics. As Benjamin and DeVitis (1998) related, the female characters depicted in the literature studied in high school classrooms mainly emphasized the traditional supporting caretaker roles. The lessons female students learned from these texts were in direct opposition to the messages that educators and parents claimed to be imparting upon young women: that they could aim for professional careers and be agents of change in the world (Benjamin \& DeVitis, 1998).

\section{Gender Balance Benefits All Students - Male and Female}

The male and female thought process and voice are different, and both genders benefit from being able to acquire fluency in interpreting and understanding reading material in each voice. As Zeller Carlson (1989) relates, gender balance within the curriculum would benefit the male students as well as the female students, because currently the male students are also lacking in the opportunity to learn from literature written from a woman's perspective, and to have the chance to better understand the female issues faced by classmates, relatives, and other women in their lives. It is necessary for male and female students to be exposed to literary role models of both genders in order to provide them with the inner strength and confidence to grow intellectually (Zeller Carlson, 1989). Greenbaum (1999) relates that exposure to literature portraying each gender leads students to discover more similarities between the male and female characters and themselves. Experiencing life vicariously through the viewpoint of each gender in 
literature is an opportunity for both male and female students to gain clarity into the concerns and priorities of all of their peers.

\section{Women and Literature}

In this section, the literature related to women and learning, as well as women and reading, will be explored. Both how women learn through reading and what women choose to read have an impact on their relationship with literature. There are critical differences in reading comprehension between male and female readers, due to the power dynamics set up in both the language used and the engagement of the reader with the text. Women readers consume a variety of reading genres, but there are a few key genres that tend to be predominantly read by female audiences.

\section{Women Learning}

How women read may be as important to the understanding of the effect of literature on women than what women read. Women have been educated to read like men, to identify with characters with a male point of view, normalizing misogyny as well as a male value system in the process (Schweickart, 1986). As Schweickart maintained, "androcentric literature is all the more efficient as an instrument of sexual politics because it does not allow the woman reader to seek refuge in her difference. It solicits her complicity in the elevation of male difference into universality and, accordingly, the denigration of female difference into otherness without reciprocity" (p. 42).

\section{Gender Differences in Reading Comprehension}

Men and women respond differently to reading texts when they encounter interpersonal verbs and generic masculine pronouns (Crawford \& Chaffin, 1986). As Crawford and Chaffin (1986) explained, in one study women read interpersonal verbs as reflecting emotion, while men 
interpreted the same interpersonal words as reflecting power, revealing a distinct difference in the understanding of the same text. Historically, the masculine terms "he" and "man" have been used to denote a neutral, universal, or generic interpretation in texts, which includes men and women, but male and female readers do not necessarily interpret it in the same way (Crawford \& Chaffin, 1986). While modern texts have started to move away from this tradition, readers of both sexes still interpret "he" or "man" literally rather than generally, so women expend more effort in understanding this generic language to include them (Crawford \& Chaffin, 1986). "For women....discussing people and what they were doing. Thoughts, emotions, senses, other peoples, negations, and verbs in present and past tense figured high on the list of words that women used more than men. For men...external events, objects, and processes...discussion of occupation, money, and sports...numbers, articles, prepositions, and long words.”

\section{Gendered Reactions to Difficult Subjects}

Flynn (1986) found in her study of college-age male and female readers, that when confronted with difficult characters and plotlines, the male readers in her course tended to reject characters or events and would make hasty judgments. Flynn's (1986) male readers also dominated the text, which happens when a reader is resistant to a disturbing or unfamiliar subject and allows them to not have to learn anything or change their perspective through the reading experience. The women readers in Flynn's (1986) course were better able to critically detach from the text in order to try to understand the difficult characters or situations and were more likely to find meaning in the reading experience.

\section{Muted Group Theory and Women's Understanding of Texts}

In circumstances where there is a power differential between two groups, "members of the muted group are disadvantaged in articulating their experience since the language they must 
use is derived largely from the perceptions of the dominant group" (Crawford \& Chaffin, 1986, p. 21). The long-standing power differential between men and women creates a dynamic in the literary realm where women writers are obliged to utilize the language and literary conventions originally constructed by men, which can alter the meaning when women tell their own stories (Crawford \& Chaffin, 1986; Turner, 1992).

\section{Gendered Viewpoints and Differences in Reading}

Similar to children's books specifically tailored to boys and girls, adult reading material tailored to a male or female point of view has a distinct effect on readers. While both men and women are used to reading material written from a male point of view, by both male and female writers, the same is not always true in regards to literature written from a female perspective (Crawford \& Chaffin, 1986). Women are conditioned to mentally code-switch and understand the plights of male characters as they have been consistently exposed to them throughout their lives from within the traditional literary canon, while men have the option to get through much of their educational and personal reading material without being asked to consider life from a woman's perspective very often. Through this conditioning, women are able to read and enjoy texts written from a male point of view without feeling that their femininity is threatened, whereas male readers who do not often read books from a female perspective feel uncomfortable identifying with a woman and view their own success with empathizing with the female characters as a threat to their masculine identity (Schweickart \& Flynn, 1986).

\section{Women Reading}

Women in higher education leadership roles are reading about teaching, research, and theory related to their professional work, for personal development, diversity and identity, 
understanding and connection with others, and various genres of fiction for escape. These categories will be discussed in the sections below.

\section{Professional Reading}

Women frequently read to continue to develop knowledge in their professional field. Women in academia are passionate about their research and teaching subjects and reading about them is enjoyable and allows them to continue to work towards their purpose in their free time. Coker (2020) explained that honing in on the areas of her professional work that she was most interested in, and pursuing her work from a place of passion and purpose, provided her with purpose for maintaining work-life balance. Reading related to their teaching and research interests keeps their knowledge base relevant and allows them to engage with the latest research, so it is valuable that they are passionate about their subject and enjoy reading about it in their leisure time.

\section{Personal Development}

Books to develop skills to navigate home and workplace roles were also another category of women's chosen reading materials. Women read books with advice on parenting strategies and succeeding in the workplace as a woman. One key skill women read up on was negotiation, a key skill needed by women leaders that is not often taught to them in the workplace (Scandura, 2020). In academia especially, women leaders need to be able to negotiate salaries, negotiate disputes between individuals, negotiate resources for themselves and others, and negotiate positions for schools and departments, and reading up on this skill is necessary (Seltzer, 2015; Scandura, 2020). Reading up on personal development topics allowed women to feel better prepared to address the challenges they faced at home and in the workplace. 


\section{Diversity and Identity}

Books that explore diversity and identity were another key category of reading that women in higher education leadership roles were consuming. As Kohn-Wood (2020) stated, "it is imperative to have in higher education a diversity of thought borne of having engaged individuals with vastly differing lived experiences, intellectual and cultural traditions, and perspectives and conceptual lenses" (p. 29). By reading about a wide variety of diverse identities and exploring their own, women in higher education prepared to better understand themselves and others and to provide their students with diverse reading selections.

\section{Leisure Reading for Escape and Fiction Genres Read by Women}

Research into reading choice and selection has revealed that some genres are more likely to be read by female readers than others. The genres that women are drawn to read also tend to be genres that include a predominance of female writers, writing from a woman's point of view, and that allow women an escape from their everyday lives into a fictional world. Women are drawn to fiction because they tend to be reflective and interested in exploring the inner lives of other women (Taylor, 2020). As Miner (1986) asserted, “variations of a specific 'women's story' continue to motivate the sales of texts sold primarily to women" (p. 191). As women tend to leisure read in order to learn about different people, perspectives, countries, and cultures, they are also drawn to books that help them escape to another time and place (Moyer, 2007). Some of the main fiction genres that center around women's stories, transport them to a different place, and help them understand and connect with others include popular fiction, historical fiction, gothic novels, and romance novels.

Popular Fiction. In her study of the personal reading habits of women students, Jarvis (2003) found that regardless of their age or situation in life, most of the women relied on their 
female friends and family for reading recommendations, and often read similar types of books as the women they were closest to rather than the men in their lives. While some may view the reading of popular fiction as upholding dominant values and concerns, others interpret the reading of popular fiction "as an act of resistance against dominant cultural ideas and forms" (Jarvis, 2003, p. 265). The women studied saw reading as an escape, and in choosing popular fiction over other potentially more taxing or aspirational genres; it was a pleasant escape that helped them make sense of their identities and of the world around them (Jarvis, 2003).

Historical Fiction. Written with the benefit of hindsight, historical fiction provides readers with targeted insight into the human issues that impact the lives of individuals in a specific place and time, as well as the human issues that remain relevant today (Heilmann \& Llewellyn, 2004). Historical fiction can provide readers with an escape from their contemporary concerns, and immerse themselves in another time and place, as well as provide the opportunity to explore the unique experiences of historical figures that are not traditionally written about by male authors of that time period, such as women and minorities (Heilmann \& Llewellyn, 2004). As Heilmann and Llewellyn (2004) explained, "historical fiction has a strong political resonance especially for women and ethnic writers: the imperatives behind female and ethnic (re)writings of history are inescapably different from those of white men" (p. 142).

Gothic Novels. Gothic novels as a genre historically tend to become more prevalent and compelling in times of crisis and the shifting of power (Johansen, 2016). The gothic and horror novel genres explore the elements of society that cause discomfort in audiences, teasing out their deepest fears and revealing what awful events would occur if they came true, bringing relief when these fears are put to rest through the plot (Wisker, 1999). As Wisker (1999) related, the fears explored in these books often threaten traditional societal values and the patriarchy, and 
then subsequently reinforce these values with the defeat of a villain in the end, to the relief of the audience.

Gothic novels typically feature unsettling locations such as gloomy castles, estates, or monasteries to set the stage for dark events to occur. Gothic novels also contain the common gothic trope of a heroine falling in love with the "hero-villain, " a partner that assists the individual in avoiding danger but ultimately also poses a threat to them (Wheatley, 2002). As Russ (1973) related, the heroine is both drawn to and scared of this type of hero, unsure of both her feelings for him and his feelings for her, creating great anxiety and tension on her side of the pair. This ties directly to the concept of the "spectacle of male dependence" wherein the hero shows his vulnerability and need for the support of his mate and his previous aloofness and indifference turn out to be love (Wheatley, 2002).

As Holland and Sherman (1986) relate, the writers of gothic fiction are primarily women, although there are a few men writing under female pseudonyms, and the readers of gothic fiction are predominantly women in their thirties and forties. The protagonists in gothic novels are also principally women, and male readers can find the themes and issues explored in this genre cause them to feel uneasy and threatened (Schweikart \& Flynn, 1986). Themes related to resisting the traditional patriarchal structure, and tropes revealing the main male character to be powerless without their female counterpart, unsettle male readers and cause them to be less likely to enjoy the gothic genre, for the same reasons women are drawn to gothic fiction.

Romance Novels. Romantic fiction continues to have a wide popularity with millions of female readers, regardless of their age, race, nationality, class, or level of education (Owen, 1997). Owen (1997) learned through his study that women read romantic fiction with irony, humor, complexity, and at many varied levels. Though the central plot is romantic and 
emotional, romantic fiction contains an underlying story where the problems in the main female characters' lives are resolved in an ideal and uplifting manner and reflect the heroine's survival of a patriarchal society (Owen, 1997). As Owens (1997) explained, "The books are an escapist daydream. But the daydream is an active reworking of the possibilities of the women's lives" ( $p$. 540). The formulaic nature of romance novels also provides readers with a freedom to actively engage with the text because the plot is often a variation on a familiar story, allowing readers a flexibility to compare the character's actions, feelings, and decisions with their own. (Owen, 1997).

\section{Communities of Women Readers}

Women engage with each other and form reading communities around book clubs and book groups, online fanfiction communities, and Little Free Libraries. Each of these reading communities will be explored in the following sections.

Book Clubs and Book Groups. Throughout their lives, women who love to read become participants in book clubs and book groups. Women in book clubs found value in having the opportunity to explore the books they were reading by making connections to their personal experiences, sharing these connections with others, and getting to know each other better (Alsop, 2015; Beach \& Yussen 2011). As book club members became familiar with each other's knowledge and experiences, they anticipated what particular book club members would be drawn to in the books that they were reading and looked forward to discussing books with them and hearing their insights (Beach \& Yussen 2011). Alsop (2015) further noted that book clubs and book groups also allow women to network with other readers with similar reading tastes. Women in book clubs value having an outlet for discussing books, sharing about each other's lives through book discussions, and forming a community around books. 
Online Fanfiction Communities. Women readers also engaged with others interested in the same genres through online fanfiction communities where amateur writers write about their favorite television shows and are provided with feedback by other members of the online community. Fanfiction provides a creative outlet for readers and writers to connect around their favorite television shows, adding plotlines they wished they could have seen, continuing storylines, and exploring characters they enjoyed, while developing creative writing skills or providing feedback to other writers (Vinney \& Dill-Shackleford, 2018). Online fanfiction forums are updated in real time so they can provide an immediate and ongoing source for new reading material.

Little Free Libraries. Neighbors and local friends have the opportunity to connect around book selections and recommendations through the use of Little Free Libraries. Building community is one of the core missions of the Little Free Library organization, and it works on a local level by creating a meeting point where neighbors that previously had no connection are gathering, discussing, and sharing books (Kozak, 2017). Little Free Libraries also provide an outlet for discovering new authors, genres, and topics that readers might not be exposed to otherwise.

\section{Women's Reading Practices and Rituals}

Some reading practices and rituals shared by women are having specific spaces in which they read different genres of reading materials, reading rituals related to travel and vacation, and the practice of conducting author studies. Each of these reading practices and rituals will be discussed in the sections below.

Having Specific Places to Read. A ritual that women have around reading is to read different reading materials in different locations, moving throughout the house as they transition 
from one reading subject to another throughout the day. Taylor (2020) described how some readers have "Upstairs" and "Downstairs" reading selections, reading fiction upstairs and nonfiction downstairs. Women stash different genres of books in various locations in their home depending on the subject, and different types of books are saved to be consumed in the mornings, afternoons, or evenings, which is also dependent on the topic and the necessary level of concentration (Taylor, 2020). A favorite space for women to relax with a leisure reading book or work of fiction is their bed in the evenings (Taylor, 2020). Changing reading subjects through changing the space that they read in is a practice that can help women switch their mental perspectives.

Reading and Travel. Reading while travelling and on vacation is another popular reading ritual. Women tend to look forward to reading fiction when they take a holiday or vacation (Taylor, 2020). As Taylor (2020) explained, having a break from their everyday responsibilities and routines offers additional time to enjoy a work of fiction. Reading itself provides an escape similar to a vacation (Taylor, 2020). Readers describe looking forward to finding a coffee shop to read in or reading to pass the time while travelling by plane, train, bus, or car on a trip (Taylor, 2020). Making reading an anticipated travel ritual provides women with a way to get excited about their trip and choose what books they will bring to read.

Author Studies. Readers conduct author studies through exploring all of the books written by an author and following their career. Author studies have commonly emerged out of K-12 education, providing readers with the opportunity to draw connections between an author's books and lived experiences and recognizing themes across an author's various books (Kennedy, 2012). In author studies, students will read something about the author, then read several pieces of their work, and critically analyze connections, similarities, and differences (Calkins, 2001). As 
Kennedy (2012) noted, adults in her college courses were just as engaged in conducting author studies as her students in the K-12 classroom. Author studies informally translate to adult reading habits, as readers consume the same author's books because they know that they enjoy their work, have an idea of what to expect from their writing, are interested in the recurring themes in their work, and are excited to see what other stories they come up with.

\section{Women in Higher Education Leadership Roles}

This section explores the unique challenges faced by women in higher education leadership roles. The titles of the literature related to the challenges faced by women leaders in academia to uphold their responsibilities reveal the high tension in these roles, with authors using strong phrases such as, "working hard to relax" (Buettner, Shattell, \& Reber, 2011), "living on barbed wire" (Christman \& McClellan, 2008), and "walking on broken glass" (McCutcheon \& Morrison, 2017). This literature revealed that women in leadership roles in higher education faced greater challenges that impacted their work-life balance than men in the same roles (Aiston \& Jung, 2015; Beddoes \& Pawley, 2014; Kloot, 2004; McCutcheon \& Morrison, 2017; Sallee, 2013). For those with families and caretaking responsibilities in their personal lives, women academics tended to take on a greater share of personal duties, whereas men in the same positions, who spent the same amount of time and effort on their work duties, tended to rely on their female partners to manage obligations at home (Aiston \& Jung, 2015; Beddoes \& Pawley, 2014; McCutcheon \& Morrison, 2017).

\section{Life Balance: Personal Life Versus Family Life}

Much of the literature related to women in higher education and how they balance their roles focused on the compromises necessary for those in academia to devote an equitable amount of time to their career and to their family, and primarily defined family responsibilities as caring 
for young children (Roebuck, Smith, \& El Haddaoui, 2013; Sallee, 2008b). While this definition of the personal side of work-life balance described some women's situations in academia, it limited the consideration of other women who used their personal time in caretaking roles for spouses, parents, friends, grandchildren, and other loved ones, or for other personal commitments (Roebuck, Smith, \& El Haddaoui, 2013; Sallee, 2008b). Women who advanced to leadership roles in higher education were also found to be just as likely to be single, childless, or have grown-up children, especially once they reached higher roles such as university president, so defining work-life balance as a problem largely faced by women with young children provided an inaccurate portrayal of the sacrifices required to fulfill leadership roles (Cheung \& Halpern, 2010; Hertnekey, 2010; Penney, et al., 2015).

This led to the question of whether leadership roles in academia have been attracting women with less personal commitments because they had more time to devote to these highly demanding roles, or if the requirements for fulfilling these leadership roles have proved to be so all-consuming that the women who reached these positions found it difficult to have time to devote to personal relationships? If the latter were true, then a similar ratio of men in leadership roles in higher education would also be single and childless, but according to The White House Report (2013), 90.1 percent of male presidents in academia were married and 90 percent of them had children, while in comparison 71.6 percent of female presidents in academia were married and 72 percent of them had children.

Getting married and having children has not been seen as a liability for male academics, and in fact has added to their career success, while negatively impacting female academics and their progression in their careers (Aiston \& Jung, 2015; Watanabe \& Falci, 2017). The differences in statistics for each gender illuminated that the reiteration of traditional gender 
norms has aided men in succeeding in leadership roles in higher education because their partners conventionally took on the bulk of personal responsibilities, while women in leadership roles in higher education had to maintain a delicate balance between the high expectations of their university positions and managing the majority of the responsibilities in their home life. (Beddoes \& Pawley, 2014).

\section{Traditional Gender Norms and Power Dynamics}

Despite serving a student population with a higher female demographic than male, higher education is still a predominantly male-led field, and the women in leadership positions face unique challenges due to the existing gender norms and power dynamics in place (Madsen, 2011). As reported in The White House Project (2013), while women students earned 59 percent of all degrees conferred in the 2009-2010 academic year, the average percentage of women leaders in academia was 24.53 percent, compared to 64.7 percent of men in leadership roles.

Women in positions of leadership encountered impediments that men did not face and could not conceive of in their everyday experiences as leaders (Eagly, 2007; Elmuti, Jia, \& Davis, 2009; Growe \& Montgomery, 1999; Sallee \& Blakewood Pascale, 2012). Universities reinforce institutionalized gender norms because traditional university structures have been designed around the life course of men according to the traditional gender binary (McCutcheon \& Morrison, 2018; Sallee, 2013). Women in positions of leadership were often held to higher standards than their male counterparts and were obligated to provide proof of exceptional performance to be seen as competent (Eagly \& Carli, 2003; Eagly, 2007; Growe \& Montgomery, 1999; Kloot, 2004). Women's drive to prove their proficiency by outperforming male colleagues in similar leadership roles contributed to their difficulties in maintaining work-life balance. 
As Rosser (2003) explained, cultural assumptions about how men and women operate as leaders has impacted the opportunities available for women in academia to move into positions of leadership. Once they reached leadership roles, women in higher education have followed varied approaches to leadership that either reinforced these traditional gender stereotypes or transcended them. Women leaders were compelled to walk a fine line between not being assertive enough to be seen as an effective leader and being so assertive that they were rejected as unfeminine and unsuccessful (Eagly, 2007; Eagly \& Carli, 2003; Kloot, 2004).

Since their gender had proved to be an obstacle to success in the past, some women leaders tried modeling a traditionally masculine leadership approach focused on aggressiveness, completing tasks, and achieving goals, based off of the logic that embodying male leadership traits caused others to see them as effective leaders (Elmuti, Jia, \& Davis, 2009; Growe \& Montgomery, 1999; Kloot, 2004). Others have embraced traditionally feminine leadership characteristics such as communication, facilitation, collaboration, and nurturing relationships (Cheung \& Halpern, 2010; Eagly \& Carli, 2003; Growe \& Montgomery, 1999; Hertneky, 2010; Kloot, 2004). Successful women leaders in academia utilized the most effective strategies and characteristics from both the traditionally masculine and feminine leadership traits and honed their own unique leadership approach (Christman \& McClellan, 2008). Regardless of their approach, women still faced judgment based on biases against women leaders and the double bind of gender norms (Christman \& McClellan, 2008; Madsen, Longman, \& Daniels, 2012).

\section{Unequal Distribution of Unpaid Labor}

As Sørensen (2017) explained, gender inequality has had an impact on the choices available for women in relation to work-life balance. A significant result of pervasive traditional gender norms was the unequal distribution of unpaid familial responsibilities to women, for 
despite their high level of education and complex responsibilities in their academic positions, women were still expected to primarily manage their households and care for their children (Beddoes \& Pawley, 2014; Dubois-Shaik \& Fusulier, 2017; Kinman, 2016; McCutcheon \& Morrison, 2017; Penney, et. al., 2015; Rafnsdóttir \& Heijstra, 2013; Roebuck, Smith, \& El Haddaoui, 2013; Sallee, 2008a; Sallee, 2008b; Sallee, 2013; Sallee \& Blakewood Pascale, 2012; Toffoletti \& Starr, 2016). Men in academia have received more help from their partners in managing responsibilities at home than their female colleagues (Beddoes \& Pawley, 2014; Kinman, 2016; Rafnsdóttir \& Heijstra, 2013). After completing equitable hours of work as their male academic counterparts, women typically put in 75 percent more time into childcare than men, and women also performed about 75 percent of care for parents and elderly relatives (Roebuck, Smith, \& El Haddaoui, 2013; Sallee, 2008b; Sallee, 2013). This left a wide disparity in the amount of time that women in academia had for their own research and personal time, while their male colleagues were free to pursue research to further their careers or spend leisure time on activities they enjoyed (Beddoes \& Pawley, 2014).

\section{Sense of Guilt and Personal Responsibility}

Women were found to be more likely than men to feel a personal sense of responsibility for maintaining a work-life balance in higher education, and to feel guilty when their personal responsibilities were given less attention in favor of their work obligations, and vice versa (Penney, et al., 2015). Women in academia were used to negotiating how much personal time they could sacrifice to meet university commitments but felt guilty when they did not have enough time for their partners, children, and other loved ones (Kinman, 2016; Smidt, Pétursdóttir, \& Einarsdóttir, 2017; Toffoletti \& Starr, 2016). Women also felt guilty when they turned down additional work obligations in order to set boundaries to protect their personal time, 
recognizing that their colleagues might be tasked with completing the extra duties (Kinman, 2016). Women were so wary of placing undue burden on their colleagues and anxious about utilizing work-life balance resources that might cause coworkers or university officials to think less of them, that many women did not take advantage of family leave policies provided to them through their universities or only used them partially (Sallee, 2013; Sallee \& Blakewood Pascale, 2012).

Women in academia were more likely than men to feel uncomfortable communicating that they were having a difficult time maintaining a work-life balance, because they considered that it was their individual choice to take on their personal responsibilities or to have children (Rafnsdóttir \& Heijstra, 2013; Sørensen, 2017; Toffoletti \& Starr, 2016). As Beddoes and Pawley (2014) explained, the academics they interviewed believed that women who decided to have children had to accept facing additional barriers and harming their careers due to their choice to start a family. Men were less likely to be concerned by whether or not they maintained a work-life balance or were perceived as balancing their work and personal lives, because they found it acceptable to have their identities defined through their work (Rosser, 2003). Women viewed their identities as complex and preferred not to be solely represented by their professional roles, were more concerned with maintaining work-life balance, and were more likely to judge themselves when they were unable to maintain that balance (Christman \& McClellan, 2008; Madsen, 2011; Rafnsdóttir \& Heijstra, 2013, Rosser, 2003). This is one reason that, as Kinman (2016) related, women in higher education reported higher levels of work-life conflict than their male colleagues. 


\section{Women Leaders in Higher Education and Work-Life Balance}

This section explores the relationship that women in higher education leadership roles have with work-life balance. Women in higher education leadership roles often have a lot of flexibility as to when and where they complete the bulk of their work, however this flexibility can lead to a lack of boundaries in their personal and professional lives. The flexibility afforded by providing academics with the ability to choose their hours and work from home was often one of the key advantages that attracted talented and educated women to accept positions in higher education (Sallee, 2008b; Smidt, Pétursdóttir, \& Einarsdóttir, 2017; Rafnsdóttir \& Heijstra, 2013). As they moved up in their careers and took on more responsibility, women in leadership roles found that the flexibility in their position assisted them in carving out more time in the day for their professional obligations, rather than creating more space to be present for their personal responsibilities (Kinman, 2016; Rafnsdóttir \& Heijstra, 2013). Presenting flexibility as an advantage to working in academia masked that the freedom to choose where and when to work provided ambitious women in leadership roles an opportunity to blur the boundaries between their personal and professional lives (Cheung \& Halpern, 2010; Sallee \& Blakewood Pascale, 2012; Smidt, Pétursdóttir, \& Einarsdóttir, 2017). As Sallee and Blakewood Pascale (2012)

related, often this encroachment of work on their personal time led women in higher education to feel as if they never fully committed to either of their roles as academics or as parents.

\section{Balancing Strategies and Their Drawbacks}

Women in leadership roles committed much time and energy to balancing their work and personal lives, but most balancing strategies they employed created more time to devote to their professional obligations and infringed upon their personal time (Hertneky, 2010). Technology has provided women leaders with the ability to work from anywhere at any time, but this has 
often led to further blurring between work and personal time as they were easily able to both work at home during family time and handle personal concerns while at work (Penney et al., 2015; Roebuck, Smith, \& El Haddaoui, 2013). This had negative impacts for some, who felt tethered to their work all day by technology to the detriment of their personal lives (Roebuck, Smith, \& El Haddaoui, 2013). This lack of boundary between work and life, while challenging to balance, also had positive outcomes, for as Cheung and Halpern (2010) explained, some women in academic leadership roles were able to unify "their work and family roles in ways that enabled them to harmonize both" (p. 190).

\section{Working During Personal Time}

By integrating their personal and professional lives, women in leadership roles in higher education created more time to work by bringing their children to work and taking them with them on work-related trips, which also afforded them more time with family (Cheung \& Halpern, 2010). Another solution that women in leadership roles in academia deployed to combat the lack of time to complete their work obligations was to continue their work from home during family time and in close proximity to their family while their loved ones were doing other things like eating, playing, or watching television (Penney, et al., 2015). Modern technology offered women in leadership roles the ability to take advantage of any free moment they could to accomplish work responsibilities, and they often found themselves using their laptops in shared family spaces to continue working during personal time so that they could be near their families even if they did not have their attention (Kinman, 2016; Rafnsdóttir \& Heijstra, 2013; Roebuck, Smith, \& El Haddaoui, 2013). A drawback to the integration of personal and professional obligations was that being around family while working was distracting and did not always produce their 
best work, and women were also not engaged or present in family activities during the time they spent working near their loved ones.

\section{Outsourcing Childcare and Household Maintenance}

Women in leadership in higher education around the world have recruited a village to aid in raising their children, including partners, extended family, and outsourcing childcare. Social support was crucial to assisting women in finding a work-life balance (Cheung \& Halpern, 2010;

Christman \& McClellan, 2008; Kinman, 2016; Sallee \& Blakewood Pascale, 2012). Many relied on their partners to assist with childcare, but this hinged on the partners being both supportive of their wives' demanding careers and secure enough in their identities to face potential judgment for performing duties socially and culturally considered to be feminine (Cheung \& Halpern, 2010; Sallee, 2008b). Women who were raised in cultures that were supportive of collective familial duties often had more success in finding childcare assistance from their extended families, while others struggled to find extended family members with the time or ability to assist with childcare (Cheung \& Halpern, 2010).

Women in leadership roles in academia without partners, with working partners, or who lived far from family needed to find outside support, and as Sørensen (2017) reported, they have utilized paid childcare more frequently within the last decade. While some expressed guilt when leaving their children with professional caregivers, those that were more successful at maintaining a work-life balance reframed their concept of being a good mother to mean that spending all of their time with their children was not as important as the quality of that time and being involved and engaged in their children's lives (Cheung \& Halpern, 2010). Women leaders faced similar challenges when responsible for providing elder care for their parents or their 
partner's parents, securing paid care to ensure their loved ones were cared for while they fulfilled their responsibilities in their university roles.

In addition to outsourcing child and elder care, women leaders in academia found balance by hiring help for any other areas of their lives not directly tied to spending time on their work or personal commitments, including hiring cleaners to maintain their homes, prepare meals, and shop (Cheung \& Halpern, 2010). The drawback to this solution for maintaining a feasible worklife balance was that not all women in leadership positions in academia had the financial resources to outsource caregiving and home maintenance, so this introduced class and privilege into the discussion of women leaders who maintained a work-life balance (Rafnsdóttir \& Heijstra, 2013; Sørensen, 2017). Those with financial limitations did not always have supportive or local partners or relatives able to step in and assist them with juggling their professional and personal responsibilities, so outsourcing as a balancing strategy could only be employed by women leaders in academia that were well-compensated enough to afford the assistance.

\section{Cutting out Activities Unrelated to Work or Home}

Another balancing strategy used to find enough time to devote to both their work and personal lives was for women in leadership roles in academia to remove time for leisure activities and self-care from their schedules and replace it with additional work or family time (Aiston \& Jung, 2015). As Hertneky (2010) related, the women's personal relationships aided them in finding balance and in order to nurture these connections, women in leadership roles in higher education often had to forego any activities that did not directly relate to their work obligations or their personal relationships.

While this was a satisfactory compromise for some women in leadership roles, others placed importance on their personal time and were dissatisfied when they were unable to find 
time to devote to other pursuits. Some of this was found to be generational, as Roebuck, Smith, and El Haddaoui (2013) revealed in their cross-generational study of perspectives on work-life balance. Generation Y or Millennial women leaders placed a high value on being able to have hobbies, take vacations, and maintain commitments to church or volunteer groups as part of their personal lives, but Generation X and Baby Boomer women leaders did not discuss outside interests or commitments as being important to them and focused solely on finding a work-life balance that allowed for caregiving for children and parents (Roebuck, Smith, \& El Haddaoui, 2013).

\section{Redefining Work as a Hobby}

Similar to cutting out all activities not directly related to personal relationships or work obligations, some women in leadership roles have chosen to reframe their work as a hobby so that spending a large portion of their personal time on their work could be seen as an enjoyable choice. While women in academia find satisfaction and enjoyment in their work, reframing work as a hobby allowed them to work during leisure time without actually getting the benefits that usually occur when enjoying leisure activities (Rafnsdóttir \& Heijstra, 2013). While this reframing may serve to alleviate anxiety that women academic leaders are not maintaining a work-life balance, it does not create more balance between their work and personal lives in reality.

\section{Sacrificing Personal Care for More Time to Work}

When questioned about the top strategies that they used to free up more time to complete their work obligations and family responsibilities, women in academia often confessed that they gave up valuable self-care time, foregoing sleep, exercise, and leisure activities (Kinman, 2016; McCutcheon \& Morrison, 2017; Rafnsdóttir \& Heijstra, 2013). As Buettner, Shattell, and Reber 
(2011) related, work and personal demands "tend[ed] to crowd out time for other meaningful experiences" (p. 269). The danger in this strategy was that without true breaks from their work and personal responsibilities, despite functioning at a high level of achievement in both areas, women's psychological and physical health deteriorated, with symptoms such as high stress levels, fatigue, burnout, sleeplessness, and depression (Cherkowski \& Bosetti, 2014; Kinman, 2016; Rafnsdóttir \& Heijstra, 2013). If these symptoms persisted over time, it affected personal relationships as well as their satisfaction with their professional position (Cherkowski \& Bosetti, 2014).

\section{The Impact of Institutions and University Leaders on Work-Life Balance}

Institutions and their leaders have an important impact on the implementation of policies and resources related to work-life balance. The manner in which they roll out and announce these policies and resources to faculty members, their own use of these policies and resources, and their response to others using these policies and resources all impact whether or not faculty feel comfortable and supported in utilizing policies and resources related to work-life balance.

\section{Institutional Policies and Support}

While many universities have recognized the need for faculty to maintain a balance between their work and personal lives, and have created policies and resources to assist them with that balance, they have not always made faculty aware of these policies and have often put the responsibility on individuals to figure out how to utilize them (Sallee, 2008b; Sallee, 2013; Toffoletti \& Starr, 2016). Policies and resources such as having access to flexible work hours, working from home, family leave, the opportunity to take a semester off from teaching or delay

the tenure clock when having a child, and having on-site childcare were all advantages meant to assist faculty in maintaining a work-life balance, but academics were often wary of using them 
(Sallee, 2008a; Sallee, 2008b; Sallee, 2013; Watanabe \& Falci, 2017). The divide between policy and practice provided the mixed message that universities supported such policies by creating them, but did not necessarily support faculty in taking advantage of them by not providing adequate information or support staff to assist faculty in utilizing these resources.

While institutions often framed work-life balance as a gender-neutral concept, this just "disguise[d] the reproduction of gender inequalities in academia" (Sørensen, 2017, p. 298). More equitable leave policies related to personal responsibilities and having a family need to be employed, because policies to date have focused on women, and more specifically mothers (Sallee, 2008a; Sallee, 2008b). There are few work-life balance policies related to men, and men are less likely to use them in institutions where they are available due to institutional and cultural biases about gender roles, further distancing women and men in their efforts to balance personal and work responsibilities (Sallee, 2013). In not providing options or support for fathers, adoptive parents, or same-sex couples, universities have reinforced inequalities in splitting up duties between academic partners, perpetuated archaic gender roles, and have placed an unequal share of personal obligations on women (Sallee, 2008a; Sallee, 2008b).

While support often varied as much between each university department as it did between different universities, institutions truly interested in recruiting diverse talent projected a university message that faculty were encouraged to balance their work and personal lives and also supported this in practice, especially through those in leadership positions (Sallee \& Blakewood Pascale, 2012). The support of presidents, deans, assistant and associate deans, department heads, chairs, and assistant and associate department heads and chairs were crucial to creating a campus climate where faculty felt safe and supported in using policies and resources to facilitate a work-life balance (Kinman, 2016; Sallee, 2008a; Sallee, 2008b; Sallee, 2013; 
Sørensen, 2017). It was especially important to support and encourage female academics as they faced additional challenges to maintaining balance between their work and personal lives.

\section{Women Leaders Supporting Work-Life Balance}

It was particularly crucial for women in leadership roles in higher education to show their support for initiatives created to promote work-life balance for themselves and their colleagues. Communicating that they supported female faculty in leading balanced lives and that they would not be penalized for using university programs to support work-life balance fostered a healthier campus climate and a better working environment within departments (Sallee, 2008a; Sallee, 2008b; Sallee, 2013). Women gained confidence and inspiration from seeing other women thrive in their chosen field of discipline, and connecting with networks of women built bridges in all phases of an academic career (Rhode, 2017). With few women in positions of leadership, women struggled to find mentors to provide them with examples of how to navigate the challenges they faced (Elmuti, Jia, \& Davis, 2009; Kloot, 2004). Women often "lack the multiple mentors and sponsors that are critical for advancement" (Rhode, 2017, p. 108). The struggle to find women academics to mentor them was even more difficult for women from underrepresented groups, who often had to find one set of professional connections and a second set of women outside of higher education for cultural support (Seltzer, 2015). Providing sound advice on maintaining work-life balance as a part of their mentorship of women under their supervision was an important service that women in leadership roles in academia could provide to bolster the success of their institutions and their mentees.

\section{Women Leaders Modeling Work-Life Balance}

Some of the most important actions that women in leadership roles in higher education could take were to model the use of university policies or resources related to work-life balance 
themselves (Sallee, 2013). If women leaders spoke in support of such policies but were not seen to utilize any of them, then the women who worked under their supervision interpreted this as an unspoken message that these resources and policies were available but that it was frowned upon to take advantage of them. Women in academia already faced concern that their male and female peers would potentially judge their commitment to their position if they took advantage of policies related to work-life balance (Beddoes \& Pawley, 2014; Sallee 2013). When women in leadership roles reinforced this message, female academics were even less likely to feel comfortable utilizing the university resources that might aid them in creating a more balanced life. In not taking advantage of work-life balance policies to add balance to their own lives, women in leadership in higher education reinforced traditional gender norms and power imbalances by making it more difficult for women under their supervision to envision how to lead a balanced life within the academy.

Through the review of literature on the development of young women, women as learners, women as readers, women in higher education, and leadership and work-life balance, a common thread is the unique experience of learning and advancing as a woman within systems and structures set up to the advantage of men. What women read in their childhood and throughout their education influences their attitudes and beliefs about gender roles, individuality, and agency, and the lack of gender balance in the current core literature curriculum has a direct impact on the development of young women. Primarily examining books written by men and about male protagonists sets young women up on a lifetime journey of identifying with masculinity as the more important point of view, reinforcing problematic gender norms and patriarchal ideas. Consequently, being raised with this curriculum teaches women to read and to 
think like men, and to accept generic masculine pronouns as an ordinary part of their experience as a reader.

Women read and think differently than men, and are interested in reading different genres as well, often leaning towards fiction in their leisure reading in order to escape the concerns of their everyday lives. Popular fiction, historical fiction, gothic novels, and romance novels are especially popular reading choices for women. Popular fiction offers a means to make sense of themselves and the world around them, and to connect with their female friends and family members interested in the same types of books. Historical fiction provides the opportunity for women to read about the untold stories of historical figures such as women and minorities that have been left out of the historical accounts originally transcribed by men in power. Gothic novels afford an unsettling threat to traditional societal values and the patriarchy, while romance novels allow women to relax and reflect on how to survive a patriarchal society.

Women who have attained leadership positions in higher education have overcome significant barriers to reach their roles (Christman \& McClellan, 2008). Women leaders in academia face challenges that their male colleagues do not have to contend with, because universities were traditionally constructed to support the life trajectory of male academics according to the traditional gender binary. Women leaders in academia are held to higher standards, and are more harshly judged in their leadership approaches, than their male counterparts. In attaining work-life balance, women leaders take on the bulk of unpaid labor, retaining the majority of caretaking duties for children and parents, while facing a sense of guilt and personal responsibility whenever they struggle to maintain a balance between their professional positions and their personal responsibilities. The flexibility offered in academia serves to create less balance as women in higher education leadership roles have the flexibility to 
complete work tasks outside of office hours at the expense of time with family and friends, selfcare, leisure, hobbies, and their personal research agendas. Women struggling with work-life balance have employed various balancing strategies, including working during personal time, outsourcing childcare, eldercare, and household maintenance, cutting out activities unrelated to work or home, redefining work as a hobby, and sacrificing personal care for more time to work. University work-life balance policies or resources have a stigma attached to them if the university does not make it easy or accessible for women to use these options, or if the culture is such that women in leadership roles do not utilize these resources or model a healthy work-life balance.

I used the knowledge gleaned through this review of the literature surrounding women developing as readers and women in higher education leadership roles to inform the construction and the implementation of my research study, outlined in Chapter 3. 


\section{CHAPTER THREE: METHODOLOGY AND METHODS}

This study provided a comprehensive view of the impact of reading on women in higher education leadership roles. As the aim of this study was to gather data in order to best understand what women in leadership roles in higher education were reading and how that impacted the balance they found within their personal and professional lives, and because this topic did not have much of a presence within existing literature, grounded theory was the appropriate methodology to use for the study, and a series of focus groups was the appropriate method to gather the data. Data was solicited from women in leadership roles within higher education, such as deans, directors, department chairs, and program chairs. The methodology, methods, research ethics, and research design will be explained in further detail within this chapter.

\section{Research Questions}

Guiding this study was the following research questions:

- In what ways have reading choices, practices, and habits impacted the personal and professional lives of women in higher education leadership roles?

- What are the life-long reading experiences of women in higher education leadership roles and how do these influence their work and lives?

- What reading materials do women in higher education leadership consume and why?

- What are the reading rituals and practices of women in higher education leadership roles? Why do they engage in these rituals and practices and how do these influence their personal and professional lives?

- To what extent, if any, does reading contribute to women in higher education leadership roles' work-life balance? 


\section{Methodology Choice}

This section will discuss the choice of a qualitative research approach, in particular grounded theory methodology. An overview of grounded theory methodology will be provided, followed by a discussion of the advantages of grounded theory, the limitations of grounded theory, and the choice of grounded theory for the study.

\section{Qualitative Research}

Qualitative research is founded on the principle that meaning is "socially constructed by individuals in interaction with their world" (Merriam, 2002, p. 3). Out of the range of qualitative methods used to understand these constructions and interpretations, grounded theory is a method most often used to gain understanding of a phenomenon (Merriam, 2002). In choosing a research topic with limited existing data in the literature, the most appropriate framing of the study was through a qualitative research approach, in particular grounded theory methodology.

\section{Overview of Grounded Theory}

Grounded theory emerged out of a turbulent time in the 1960's when qualitative and quantitative researchers were at odds (Charmaz, 2014). In a shift towards positivism, quantitative methods and methodologists gained prominence over qualitative methods and methodologists, especially in the United States, and top department and editorial positions as well as funding were inordinately bestowed to quantitative researchers (Charmaz, 2014). As Charmaz (2014) clarified, the positivistic approach to research focused on technical aspects such as precise instruments, procedures, research designs and quantitative measures, which did not leave room or credibility for the human perspectives and issues being explored by qualitative researchers.

As Charmaz (2014) further explained, while qualitative sociological studies had transitioned from consisting primarily of life histories and case studies to participant observation 
decades earlier, the new methodology had not employed a consistent set of methods or analysis. Thus, Barney G. Glaser and Anselm L. Strauss' 1967 publication, The Discovery of Grounded Theory: Strategies for Qualitative Research provided a helpful and long overdue guide to outline their strategies for grounded theory methods and analysis (Charmaz, 2014). The most striking and innovative idea presented by sociologists Glaser and Strauss was their assertion that researchers should develop their "theories from research grounded in qualitative data rather than deducing testable hypotheses from existing theories" (Charmaz, 2014, p. 6). This was a large departure from the quantitative and positivistic approaches to research that validated existing theories, but rarely generated new theories from the data (Charmaz, 2014). Not only did Glaser and Strauss provide a logical and systematic approach to qualitative research, they also assisted in creating a strong and compelling argument for the use of qualitative methods in their ability to generate new theory (Charmaz, 2014).

\section{Advantages of Grounded Theory}

There are a number of advantages in choosing a grounded theory research approach, beginning with it being an appropriate method to choose when little is known about a particular topic (Birks \& Mills, 2015). By taking a grounded theory approach, researchers are able to have both focus and flexibility, keeping an open mind to data as it emerges, and allowing the data to inform their ideas in an iterative process (Charmaz, 2014). Grounded theory methods are conducive to collecting rich and relevant data (Charmaz, 2014). Finally, grounded theory methods provide researchers with concrete tools, guidelines, and strategies to complete a successful qualitative research project and generate an explanatory theory on a topic of interest to the researcher (Birks \& Mills 2015; Charmaz, 2014). 


\section{Limitations of Grounded Theory}

Potential limitations to consider were reflexivity, the "manner and extent to which the researchers present themselves as imbedded in the research situation and process" (Bryant \& Charmaz, 2007, p. 423). It can be difficult for a researcher to be truly objective and observe their participants without applying their own experiences and prior knowledge to their approach to the study (Bryant \& Charmaz, 2007). I addressed these concerns through thoughtfully considering and disclosing my positionality, through my continued study of the grounded theory methods critical to the approach of my study, as well as my continued consultation of the experts on my committee. This will be discussed in further detail in the sections below.

\section{Choice of Grounded Theory for the Study}

Now that grounded theory research has been defined and the advantages and limitations of grounded theory research have been explored, I will explain my choice of a grounded theory approach for this study. As Johnson and Onwuegbuzie (2004) explained, the best way to choose a research method is to examine which method will best answer your research question. I recognized that due to the lack of existing research and literature on the topic of the reading experiences, choices, and habits of women leaders in higher education, grounded theory methodology would be an appropriate approach for this study because my aim was not to prove an existing theory but rather to construct a new grounded theory based on the data collected.

In addition to considering what would best answer the research question, I reflected on the advantages of a grounded theory research approach and concluded that the strengths outweigh any possible weaknesses for this study. The advantages, including being able to use a focused and flexible qualitative method with concrete tools, guidelines, and strategies to yield rich data and construct a grounded theory to explain a phenomenon of interest to me which has 
not previously been studied, all resonate as significant reasons to choose grounded theory for the research approach in this study.

\section{Methods}

In this section, I will introduce focus group methods and explore the choice of focus groups as the method paired with grounded theory methodology and grounded theory coding for this study.

\section{Focus Group Methods}

"Focus groups are a research method that collects qualitative data through group discussion" (Morgan, 2019, p. 4). As Morgan (2019) asserted, "what makes focus groups unique as a research method is the use of the participants' discussions to produce data that would be less accessible without that interaction" (p. 5). Focus group discussions reveal the ideas and opinions of the participants within a social setting, and allow participants to be prompted or reminded of topics they may not think to discuss if they were questioned by the researcher in an individual interview (Morgan, 2019). Morgan (2019) related that focus groups allow participants to share and compare their thoughts and practices, and that by doing so they often relate how their ideas and experiences are similar and different, which allows the researcher to learn more about what individuals think about the chosen topic and why they form these opinions.

\section{Choice of Focus Groups for the Study}

I recognized that holding multiple focus groups would allow me to gather data from a healthy sample of participants while the small number of people in each group would allow greater depth and meaning to emerge from the discussions than I might have gleaned through other methods. As Birks and Mills (2015) explained, there are specific advantages to focus groups which make them helpful to a grounded theory study, including the ability to highlight 
the varied experiences and perspectives of people with similar interests, which is important in the development of categories. Having a common area of interest is particularly helpful in engaging participants in conversation, which allows participants to feed off the information that each of them share, yielding more data (Birks \& Mills, 2015). Also, per Morgan (2019), one of the common methods used to analyze focus group data is grounded theory coding. Using grounded theory methodology and grounded theory coding paired well with using focus group methods for this study. The process of conducting focus groups will be discussed in further detail in the data collection section.

\section{Research Ethics}

In this section, discussion will include the ethical framework for this research study and for the focus group discussions, the consultation and approval of the Institutional Review Board (IRB), and my positionality statement as a researcher.

\section{Ethical Framework}

The ethical framework for this study aligned with the ethical principles laid out in the federal regulations influenced by the 1979 Belmont Report. Participation in this study was voluntary and participants had the ability to withdraw from the study at any time. I disclosed the purpose and procedures of the study to the participants and informed and reminded the participants of their rights throughout the course of the study. Communication for the focus group was provided both verbally and in writing. I explained the role of the researcher, followed ethical interview practices, adhered to confidentiality standards, and did not use deceptive or misleading practices. 


\section{Focus Groups}

I conducted three focus groups with a small group of four to five women in higher education leadership roles in each group. Ethical concerns I considered for focus group research included being mindful of potential power dynamics within the focus group as well as privacy concerns (Marshall \& Rossman, 2015). Morgan (2019) stressed that researchers keep in mind that while the researcher chooses the topic of discussion and serves as a moderator, the focus group members are the ones that produce the data through their conversation. I made it a priority to balance my data collection goals with the interests of the focus group participants.

I was transparent about my inability to ensure full confidentiality due to the nature of a focus group discussion but encouraged the participants to respect each other's confidentiality and not divulge what was shared within the focus group conversations (Morgan, 2019). While the questions in the interview guide related to reading choices and habits did not include sensitive topics, I acknowledged the possibility that such topics could emerge in a group discussion and I was prepared to moderate responsibly and maintain a safe environment (Morgan, 2019). If a stressful topic had occurred, I would have reminded the focus group participants that their participation was on a voluntary basis and that they were free to leave at any time (Morgan, 2019). Fortunately, I did not need to make this statement as none of the discussions became stressful.

\section{Institutional Review Board}

This study was reviewed by the university's Institutional Review Board to ensure that all potential risks were adequately considered within the research plan. It was important to seriously consider all aspects of the study related to the ethical treatment of human research participants to be sure that the study was conducted responsibly. As Fowler (2014) noted, "a good researcher 
also will be attentive to maximizing positive outcomes of the research process" (p.140). I completed a CITI training refresher and was fully apprised of the necessary protections for human research subjects. As I was not working with a vulnerable population for this study, it only required an expedited IRB review. I submitted and received approval for an amendment to my initial IRB submission once the COVID-19 pandemic emerged and it became necessary for me to hold my focus groups virtually via Zoom.

\section{Researcher Positionality Statement}

As a female doctoral student holding a bachelor's and master's degree in English literature, and with research interests including gender studies, feminist studies, leadership studies, and higher education, I have a particular interest in the reading habits and selection of women in higher education leadership roles. I am currently pursuing a doctorate in education with an emphasis in leadership studies, and am employed at a university where I provide administrative support to a master's level leadership program. I have been employed in the field of higher education for eleven years, and worked in the publishing field for eight years. I was born and have lived the majority of my life in California, which is the geographic area of focus in this study. My undergraduate and doctoral coursework was also completed at institutions located in California. Given my extensive background in working in higher education and in proximity to leadership studies, as well as in researching in the fields of literature and feminist theory, I recognize that there was the potential for bias in the interpretation of the data for this study.

My research interests led to my study of gender imbalance in high school English curriculums, and the effect that this has on the development of young women. Though I was in honors and advanced placement courses throughout my K-12 education, I was not exposed to 
many female authors or feminist theory until I began taking women's studies courses in college and purposefully choosing more female authors in my personal reading. I was embarrassed to realize that in my early years, though I was an avid reader, I was preoccupied with reading all the books considered to be literary classics, which included few female or diverse authors. I recognize that this was likely influenced by living in a fairly affluent neighborhood in California which was not especially diverse in the 1980's and 1990's as I went through public school. I have spent the past two decades rectifying this initial imbalance and incorporating female and diverse authors into my personal reading as much as possible.

My research interests further led me to explore the impact of reading on the personal and professional lives of women in higher education leadership roles in this study for my dissertation research. Women I respected in academic leadership roles all seemed to be avid readers when time allowed for leisure reading, and I wanted to learn more about what they read, how it shaped their path to higher education leadership roles, and how they were able to balance their time to be able to read. I went into this study with assumptions that over the years, like me, they had needed to look outside of the assigned curriculum and seek out their own reading materials to help shape and inform their reading journeys on the way to becoming leaders in higher education.

\section{Research Methods and Design}

In this section, I will discuss the participant population, data collection procedures, and the interview guide. Then I will explain the data analysis techniques, including transcription, coding, diagrams and concept maps, and constructing a grounded theory. Finally, I will discuss limitations. 


\section{Participant Population}

The target population for this study was individuals who self-identify as women and hold leadership roles in higher education. The types of leadership roles held by women who would be eligible to participate in the focus groups included presidents, deans, assistant and associate deans, department heads, chairs, assistant and associate department heads and chairs, and other women in supervisory roles in higher education. I identified potential participants for the focus groups through a detailed analysis of publicly available information on the website of a small, private liberal arts institution in California. As Morgan (2019) asserted, the initial step in finding suitable research participants is to create a list of eligible individuals. The contact information for women who had held higher education leadership positions within the last five years was systematically collected and compiled into a database that was used to solicit the focus group participants. A recruitment email, as seen in Appendix A, was crafted, which clearly laid out the details of the focus groups and why their participation was needed, including the topic, time commitment, that it would be recorded, and it was sent to all of the potential participants from the database (Morgan, 2019). Those that were interested in participating in the study answered the email, and I responded to any that had questions and answered them. Upon receipt of agreement emails, I then sent out follow up emails to schedule the focus group session dates and times (Morgan, 2019). Once the dates and times were confirmed, I sent out reminder emails a few days before the focus group sessions, confirming attendance and including the consent forms, as seen in Appendix B, for participants to sign and return (Morgan, 2019).

Intentional or purposive sampling, in which "participants are carefully selected to meet the research criteria," was used to gather a small cohort of women in higher education leadership roles in a small private university in California for inclusion in three focus group sessions 
(Morgan, 2019). A sampling of participants was invited with a range of disciplines and leadership roles through a large initial email inquiry, with a subsequent follow up email to those interested in participating. Typically six to eight participants are used in a focus group, although some only include four to five in order to facilitate higher levels of engagement (Morgan, 2019). Participants were sorted into the focus group sessions based on their availability. Four to five participants were included in each of the focus groups that I conducted in order to provide ample speaking time for each participant and facilitate maximum engagement. I conducted three focus

group sessions as two to three focus groups are necessary to ensure that the themes that emerge from a group are similar across groups (Danner, Pickering \& Paredes, 2018).

\section{Focus Group One Participants}

Participants in the first focus group, as seen in Table 3.1, included "Sarah," who was in the field of leadership studies, had a role at the Coordinator level. Sarah also had experience in teaching in K-12. "Mary" held a position at the Director level and came from the field of religious studies. Coming from a disability studies background, "Elizabeth" was in a role at the Director level. "Julia" held a Senior Administrative level role, and came from the field of teacher education, with a background in teaching K-12. 


\section{OVERVIEW OF FOCUS GROUP 1 PARTICIPANTS}

\section{PARTICIPANTS}

Participant 1

Participant 2

Participant 3

Participant 4
PSEUDONYM

Sarah

Mary

Elizabeth

Julia
ROLE

Coordinator

Level

Director Level

Director Level

Senior

Administrative

Level
FIELD OF

SPECIALTY

Leadership

Studies

Religious Studies

Disability Studies

Teacher

Education

Table 3.1

\section{Focus Group Two Participants}

The second focus group, as seen in Table 3.2, included "Rebecca," who was in the field of law and held a role at the Director level. "Nicole" held a position at the Coordinator level, and came from the field of teacher education, and also had experience in teaching in K-12. Coming from a film and media arts background, "Heather" was in a Director level role. "Melanie" was in the field of disability studies and held a Director level role. "Andrea" held a Director level role and came from the field of law. 


\section{OVERVIEW OF FOCUS GROUP 2 PARTICIPANTS}

PARTICIPANTS

Participant 5

Participant 6

Participant 7

Participant 8

Participant 9
PSEUDONYM

ROLE

Rebecca

Nicole

Heather

Melanie

Andrea
Director Level

$$
\begin{gathered}
\text { Coordinator } \\
\text { Level }
\end{gathered}
$$

Director Level

Director Level

Director Level
FIELD OF

SPECIALTY

Law

Teacher

Education

Film and Media

Arts

Disability Studies

Law

Table 3.2

\section{Focus Group Three Participants}

Participants in the third focus group, as seen in Table 3.3, included "Jennifer," who held a Senior Administrative level position, and came from the field of law. Coming from the field of applied psychology, "Lisa" held a position at the Coordinator level. "Erica" was in the field of leadership studies and held a role at the Senior Administrative Level. Coming from the field of education, "Amanda" was in a Director level role, and also had experience in program assessment and improvement. "Stephanie" held a position at the Director level and came from the field of history. 


\section{OVERVIEW OF FOCUS GROUP 3 PARTICIPANTS}

\begin{tabular}{|c|c|c|c|}
\hline PARTICIPANTS & PSEUDONYM & ROLE & $\begin{array}{l}\text { FIELD OF } \\
\text { SPECIALTY }\end{array}$ \\
\hline Participant 10 & Jennifer & $\begin{array}{c}\text { Senior } \\
\text { Administrative } \\
\text { Level }\end{array}$ & Law \\
\hline Participant १1 & Lisa & $\begin{array}{l}\text { Coordinator } \\
\text { Level }\end{array}$ & $\begin{array}{l}\text { Applied } \\
\text { Psychology }\end{array}$ \\
\hline Participant 12 & Erica & $\begin{array}{c}\text { Senior } \\
\text { Administrative } \\
\text { Level }\end{array}$ & $\begin{array}{l}\text { Leadership } \\
\text { Studies }\end{array}$ \\
\hline Participant 13 & Amanda & Director Level & Education \\
\hline Participant 14 & Stephanie & Director Level & History \\
\hline
\end{tabular}

Table 3.3

\section{Data Collection Procedures}

Grounded theory begins with gathering rich data, which "reveal participants' views, feelings, intentions, and actions, as well as the contexts and structures of their lives (Charmaz, 2014, p. 23). Grounded theory can be constructed using several types of data, including field notes, memos, interviews, and information from records (Charmaz, 2014). For this study, I collected group interview data through holding multiple focus group sessions.

As Morgan (2019) specified, the practical aspects of conducting focus group research include the initial preparation of creating an interview guide, finding and contacting participants, arranging a mutually agreeable date and time, and securing a meeting location. Due to the 
restrictions of the COVID-19 pandemic, all of the focus group sessions were held virtually on Zoom. To provide some context, the focus groups were held in May 2020, which was towards the beginning of the COVID-19 pandemic. California was in a lockdown, and participants had been working remotely from their homes since mid-March. The university had transitioned from fully in-person to fully online instruction, and in their varied leadership roles, the participants were navigating the concerns of students, parents, staff, faculty, and administrators, while staying informed on the latest state and federal recommendations for health and safety. COVID19 related concerns and stressors impacted the reading habits of the focus group participants at the time of these discussions.

On the days that the focus groups met virtually, I was responsible for moderating the focus group, facilitating turn taking during discussion, and audio recording the discussion (Morgan, 2019). Some participants preferred that I not record the video of the discussions, so I recorded the audio only to ensure comfort in the focus group process to all participants. I recorded the audio on Zoom and also through my phone on an application called Otter to ensure that I had a back-up recording for each session.

Immediately following each focus group session, I spent 30 minutes writing memos to capture my initial thoughts and impressions of the topics and themes discussed. As Birks and Mills (2015) explain, "memos contain insights into your data and your analysis of your data" (p. 77). By noting my initial impressions on the interactions from the focus group sessions, I was able to glean insight into discussion points that may emerge in future focus groups or have also been highlighted in previous sessions. This provided me with initial ideas about emergent themes which would be further developed in the data analysis stage. 


\section{Interview Guide}

A semi-structured interview technique was used to help facilitate conversation in the focus group. I prepared an interview guide, as seen in Appendix C, organized by topics that contained a mix of more and less structured questions, and exercised the option to change the order of the questions when necessary for the flow of conversation and when the participants answered additional questions within an earlier answer (Bailey, 2007; Merriam \& Associates, 2002). As Terrell (2016) asserted, using a semi-structured interview technique "allows us to expand the type and amount of information that we collect" (p. 81). The interview guide included both discussion starter questions and wrap-up questions that I used to provide structure and flow to the focus group's conversation (Morgan, 2019). Questions were grouped in three categories: past experiences, current experiences, and recommendations. The semi-structured interview guide included questions about when their love of reading began, impactful previous reading experiences that they had, what they are currently reading, and how reading contributes to their work-life balance.

I was able to follow the interview guide closely in each group, which enabled me to collect data for each question I included in the guide. While not all participants in each group answered every single question, they each took turns responding regularly to the questions and I received multiple answers to each question in each focus group session.

\section{Data Analysis Techniques}

The qualitative data from the focus group was analyzed using grounded theory coding practices. Following each focus group, I transcribed the recordings, analyzed the transcripts, and wrote up the results (Morgan, 2019), each stage is outlined in detail in this section. 


\section{Transcription}

I utilized Zoom and Otter both of which translated the audio recordings into transcripts. I used both sets of transcripts and reviewed the audio recordings multiple times to create one comprehensive updated set of transcripts for each focus group. While the technology aided autotranscription sped up the transcription process and provided me with material to edit rather than transcribing from scratch, it still required focused attention to detail in correcting and editing the transcripts for accuracy. This reflexive process allowed me to deeply connect with the data which emerged from the focus group discussions.

\section{Coding}

Once the transcripts were updated for accuracy, I identified initial codes, focused codes, and categories within the transcripts, and developed themes from these codes and categories (Morgan, 2019). A large number of initial codes were pared down to five themes, as seen in Table 3.4. The original quote was translated to an initial code, then a focused code, then a category, and finally a theme, as exemplified in Table 3.5.

Initial Coding. I started with initial coding, looking at the transcripts line-by-line and breaking that up into a first level of short, simple codes which "stick closely with the data" (Charmaz, 2014, p. 116). Initial coding is also sometimes referred to as open coding. When initial coding, I was searching for actions in each section of the data and using gerunds (i.e., the noun form of a verb ending with 'ing') to code for the actions (Charmaz, 2014; Birks \& Mills, 2015).

Focused Coding. In the intermediate coding stage, I analyzed the initial codes, comparing them and looking for commonalities and frequency, in order to condense them into 
focused codes. As Charmaz asserted, "this type of coding condenses and sharpens what you have done because it highlights what you find to be important in your emerging analysis" (p. 138).

Categories. Once focused codes were established, I analyzed these to parse out a smaller set of categories. Some researchers call this third and advanced level of categorization axial or theoretical coding (Charmaz 2014).

Themes. I then refined the categories down further from categories to themes in a fourth round of coding. These themes helped narrow down and conceptualize the overall theory related to the study.

\section{OVERVIEW OF CODING}

INITIAL CODES

1,114
FOCUSED CODES

CATEGORIES

166

20
THEMES

5

Table 3.4 


\section{JOURNEY OF A QUOTE}

\begin{tabular}{|c|c|c|c|c|}
\hline ORIGINAL QUOTE & INITIAL CODE & FOCUSED CODE & CATEGORY & THEME \\
\hline $\begin{array}{l}\text { T can go to Italy for three } \\
\text { monthe and take my ipad } \\
\text { and have downloaded } \\
\text { what Im going to read..I } \\
\text { used to take a whole } \\
\text { suitcase of books" }\end{array}$ & $\begin{array}{l}\text { molbing a big } \\
\text { difference to } \\
\text { pock one ipad } \\
\text { instead of a } \\
\text { suitcose of books }\end{array}$ & $\begin{array}{l}\text { being able to } \\
\text { travel with more } \\
\text { electronic books }\end{array}$ & $\begin{array}{l}\text { technology } \\
\text { providing more } \\
\text { ways to consume } \\
\text { reading materials }\end{array}$ & $\begin{array}{c}\text { Practices and } \\
\text { Ritusls }\end{array}$ \\
\hline
\end{tabular}

Table 3.5

\section{Diagrams and Concept Maps}

Using the initial codes, focused codes, categories, and themes which emerged from the data, I created a series of diagrams or concept maps to visualize the interrelatedness of my data. As Bryant and Charmaz (2007) explained, diagrams can serve to assist the researcher in visualizing concepts out of the complicated mass of their data. Sometimes this serves solely as a means to aid the researcher in organizing their thoughts around their data, and sometimes the diagrams and concept maps can also assist in explaining the data to others. Charmaz (2014) asserted that constructing visual images of emergent theories is a critical component of grounded theory methods, as it allows researchers to envision the connections between data categories. As my understanding of the data developed, my diagrams and concept maps were updated to reflect my increased understanding of the relationships between the categories. Examples of these can be seen in Appendix D.

\section{Constructing a Grounded Theory}

Following the identification of the initial codes, focused codes, categories and themes and the visualization of these components in a series of diagrams and concept maps, I then integrated these themes into a comprehensive theory answering my research questions (Morgan, 2019). 
After going through several rounds of refinement and theoretical sampling, the data reached theoretical saturation and was ready to be built into a cohesive theory (Birks \& Mills, 2015). Birks and Mills (2015) defined theory as "an explanatory scheme comprising a set of concepts related to each other through logical patterns of connectivity" (p. 108). While one of the most challenging components of the grounded theory method was the construction of a unique and cohesive theory, it was also a valuable experience as a researcher and served as a contribution to the shared body of knowledge on the reading experiences, practices, rituals, and habits of women leaders in higher education.

\section{Limitations}

I studied a representative sample of women in higher education leadership roles within a small private university in California. A larger focus group study may yield differing results, especially if it included participants from a variety of institutions throughout the country and outside of the United States in order to gain insight into the impact of reading on the personal and professional lives of women in higher education leadership roles around the world. I believe that this study will leave ample opportunities to develop further related research into this area once I have earned my doctorate and found a position within the academy.

I chose a grounded theory research approach because it was the best fit to answer my research question. While some aspects of the lives of women in higher education leadership roles have been studied in detail, such as the unique challenges they face to maintain work-life balance, very little research has delved into their reading experiences, choices, and habits, making this an ideal subject for a grounded theory study. In addition to addressing a gap in the literature, the results of the analysis of these focus groups provided unique insight into what we can learn about women in higher education leadership based on their reading habits and the ways 
that reading impacts the personal and professional lives of women in higher education leadership roles. The details of these findings will be shared in the next chapter. 


\section{CHAPTER FOUR: RESULTS}

The focus group conversations revealed that the participants' reading fell into three different spheres: professional, personal, and community. Professional reading included reading student papers, sampling reading materials to potentially include on their syllabi, and reading academic articles to maintain knowledge of their field and further their research. Personal reading included reading as an escape from daily responsibilities, reading to take the reader away to another time and place, and reading for personal development and practical skills, such as sewing, quilting, knitting, and cooking. Community reading included participating in book clubs which provided connection to other readers through the choice and discussion of books, using Little Free Libraries to share books with neighbors and colleagues, connecting with professional mentors through the discussion of writing and academic careers, and keeping in touch with friends, family, and colleagues through book recommendations.

Each of the spheres have significant overlap, and at various times in their lives, women have put more time and effort into one area or another, focusing on professional reading at key points in their careers, on personal reading in times of leisure or of stress, and on community reading when feeling the need to share and connect with others about their reading experiences. The choices that women in higher education leadership make about what they read, the practices they put into place about how they read, and their decisions about when they read help to create balance between and among their professional, personal, and community reading lives. Women in leadership roles in higher education juggle a variety of responsibilities within each section of their lives and find that their reading choices and rituals contribute meaningfully to all of these areas. 
Participants shared their reading habits and experiences from their childhoods and adulthoods. Childhood reading habits and experiences included an early love of reading; their introduction to books and stories by family members; early impactful reading experiences, including for some an exposure to the United States through reading while growing up abroad; and their discovery that they preferred reading materials that they personally chose. In adulthood, women leaders in higher education consumed reading materials in categories which included teaching, research, and theory; diversity and identity; connection and community; personal development; and escape. In reading these materials, participants adopted reading rituals and practices such as reading in different places for different topics, reading and travelling, conducting author studies, and using technology to increase the ways they could read. Participants strived for balance in their lives, and while balance was not something that any of them felt they had achieved, they recognized that incorporating reading into their daily practices was something that contributed to feeling like they had better work/life balance.

\section{Reading in Childhood}

We began the focus group sessions with a discussion of participants' early reading memories and learned that most of the women remembered being able to read at an early age, and many also loved reading from a young age. They recalled being read to by family members and teachers and sharing books and stories with loved ones. Some of the most impactful reading experiences shared were from childhood when they read a book that really resonated with them or caused a strong emotional reaction. For the participants that grew up outside of the United States, reading books about America was also an impactful experience. Participants also shared that from an early age, a key factor in whether or not they enjoyed their reading experiences was if they were able to choose their own reading materials. Several women leaders in higher 
education mentioned that their love of reading truly began in earnest once they were able to select their own books.

\section{Early Readers with an Early Love of Books}

Most participants shared fond memories of their early love for and interaction with books. As Stephanie related "I actually can't remember a time that I didn't read. So, you know, little kid in the library and reading, staying up all night with a night light, and it's just...always been a...really important part of my life." Sarah agreed that reading has always been a special part of her life since her earliest memories, explaining:

I was an early reader and...reading came easily to me... and that became a wonderful...escape to another world. I learned character, sense of place... It was fiction that really grabbed me and was a big part of my life growing up, and still is...It's like having a friend. It's a companion, and I still have trouble getting rid of books, trying to lighten the library because every time I pass by those spines, I know those stories and those characters, and I love living with them. It's been a part of my life [for] as long as I can remember.

Erica also spent time engaging with her books as companions from an early age, sharing that: I remember people would give them to me as gifts...I remember being so proud of being able to read what was not a picture book and I would draw on the on the real books too...I would spend so much time with the books I would take my coloring pencils and I would just color everything...that I wanted to see, so they kind of became my constant companions.

Amanda was so excited to read that she started out pretending to read her mother's favorite books. As she shared: 
I remember being way too little to understand the books but pulling them off the shelves and trying to read them and pretending like I was reading them. I was flipping the pages and they have pictures of me very small with these big fancy Sherlock Holmes series books and just pretending like I was reading them.

Happy memories of childhood reading created a lifelong love of books for many of the participants.

\section{Familial Connection to Reading and Books in Childhood}

Participants described being introduced to reading and stories by family members, and their relationship with reading was often impacted by these familial connections to reading. As Mary shared, "I'm the daughter of an English teacher, so I can't ever remember a time when I didn't love English and reading. That was just a part of our family." Lisa agreed that she remembers always sharing a love of books with her family. As she explained:

I don't remember when I started to love books, but I know it was from very tiny. I would always carry books around with me. I loved to read at an early age...I liked funny books and I would share them with everyone in our family and sort of walk around and talk about them and try to write my own books. So it started pretty young.

Heather remembered that sharing her love of reading with her sister took on a mischievous side, especially in the case of a favorite childhood book, Goodnight Mr. Tom. She related that:

My sister and I...we had to share it...we would share the reading and we will be reading it at the same time. And as siblings, especially sisters are wont to do, sometimes we would get on each other's nerves. So as punishment, we would hide the book from each other, or we would threaten each other with telling [each other] we would read further ahead if you don't be nice to me. I'll tell you what happens in the story. 
Amanda's grandfather encouraged her love of reading, providing her with reading materials and asking her thoughts on what she read. As she shared:

As a kid, my grandpa was very instrumental in my reading...now I think back he started me when I was really little, with the...comics in the newspaper and that would lead to a discussion about an article in the newspaper. And then he would provide me with books on world issues and history and we would talk about them... as soon as I can learn to read, and he would help me sort of read through them and then later he would give them to me, and I would read them and then we would talk about it.

Having family members share in their enjoyment of reading contributed to participants' childhood connections to reading.

\section{Early Impactful Reading Experiences}

Stories read as children which particularly impacted participants continued to stand out years later after they had read much more widely. The childhood book that still personally resonated with Sarah was The Diary of Anne Frank, particularly as it touched upon her own cultural identity. As she related, "I very much identified my own history, my own culture with...her story and so that...made an impact that has stayed with me.” Andrea periodically rereads The Great Gatsby, a book that stood out to her in high school, explaining:

I'm not quite sure what it was about that book, but I have multiple copies of it. I still reread it every few years. And I feel like every time I go take something different away from it...That's one book that stuck with me, just because it covers so many different facets of...society, relationships, looking into yourself.

Nicole first began to recognize the possibility of becoming a female writer through reading Louisa May Alcott's Little Women and seeing Jo model her journey as a writer. As she related: 
I would say that it was Jo March and Little Women and...I thought a woman can be a writer...I was...11 years old and that was such a novel sign for me...I think that was really formative in terms of imagining myself as a writer, that a woman could be a writer...I think that idea stayed with me throughout...my different career paths. Jennifer was also affected by childhood reading about possible career paths for women, explaining that:

I read a lot of biographies, nonfiction. I read a lot about suffragists, first female lawyer, first female doctor... admitted to practice. And I think just being so shocked that that [had] happened less than 100 years before I was born really had a huge impact on me as a child.

Books that elicited a strong emotional reaction also stood out to participants as they recalled titles that particularly impacted them. Heather remembered reading her teacher reading A Bridge to Terabithia by Katherine Paterson to her fifth-grade class, and shared:

I remember that was the first time I think I had a very visceral emotional response to a story. I think it was certainly the first time that a character died in a book that I was reading. And I remember in front of everybody crying and...I was so in the story. And I still remember now the way that the story was, about Jesse running and...just crying about when the character died...but that was...I think still now is such a huge impact to me about that real genuine engagement with a story.

Being emotionally connected to early reading experiences contributed to participants' memories of reading always being an important part of how they interpreted and understood the world around them. 
Early Reading Experiences Outside of the United States. Focus group participants that grew up outside of the United States discussed being exposed to different books as children, and consuming American books when they were available to learn about life in America. Erica, who grew up in Australia, explained that:

Because I didn't grow up in the States, I read a whole lot of different kinds of books. Most of them were adventure books when I first started out, there was a whole series of things called Biggles. I'm sure you [Americans have] never heard of them. But I read things that were about kids and adults doing things that were really exciting and solving problems, that sort of thing.

Heather found that she was able to read American books easily as a child in Australia, and that she enjoyed this insight into living in a different part of the world. As she shared:

There were a lot of American books in Australia, which is very weird...that was one of the books that got me reading outside of the things...seeing other parts of the world, I realized you could read books that showed you all the things about other lives, other places, other countries that were very different from someone growing up in semi-rural Australia where there isn't very much written around about you or for you at that time. So, you get to see life from a different point of view.

Lisa tended to read British books in her childhood in South Africa, and integrated American books into her reading after arriving in the United States. As she related:

I also grew up in South Africa, so I had a lot of British influence in my books. So, I didn't have access to some of the same stuff as people do here, I think, it was more British focused. And then when I came here, I read a lot of stuff that sort of taught me about 
American culture. I can't remember the names of it. But this sort of like the teenage girl books.

Reading American books in childhood contributed to an understanding of American culture for those that did not grow up in the United States and added to the international reading experiences that several participants had in their youth growing up abroad.

\section{Importance of Personal Choice of Reading Materials}

While most participants were early readers, their enjoyment of reading was greatly impacted by whether or not they were able to choose their own reading materials. Participants indicated that they only found their love of reading once they experienced the joy of reading a book that they chose themselves and that truly interested them. As Julia explained:

I was an early reader. My parents attempted to encourage reading in a variety of ways. They bought a million of those Book of the Month Club things for me when I was in elementary school. I found all of those books stupid. I had absolutely no interest in them, didn't read them, told my parents they were wasting their money.... it wasn't until I was...in about the sixth grade that I guess my parents then thought it was okay for me to read more adult literature. And then I started to read....and then I started to be taken to the library every week and...got more control over my reading materials. So, until I had control over my reading materials, I had no interest in reading whatsoever.

In Mary's case, she was resistant to read books urged upon her by others, even if she ended up liking the books when she decided to read them on her own. As she shared, "I remember my brother, who is seven years older, kept pushing me to read the Tolkien books and just because he was pushing, I didn't want to do it. And then I started reading The Hobbit 
and...then I had a Tolkien summer. That was pretty wonderful.” Elizabeth agreed that she also did not enjoy reading books chosen by family or teachers, relating:

I, too, was pushed to read the Tolkien series or the Harry Potter series and all of that and...I never enjoyed people pushing that on to me. I think that's probably why my enjoyment of reading...came to be when it was something that I selected as opposed to what was asked for me to do. And so, when it was like a story like To Kill a Mockingbird or assigned readings it was hard for me to.... really get into. I really sought out things that I wanted to read as opposed to assigned readings.

Erica shared that she often brought her own books to read in school because she preferred her own reading choices to what they were studying in class. As she explained:

We had the old fashioned kind of desk where it had a lid and...I would...open up my desk lid, and I had a reading book there, so I would tune [the teachers] out. I wasn't interested in what they were talking about, instead I wanted to read my books.

Sarah concurred, confessing that, "so much of my reading, it's not in school. I love reading books that I selected. I think the choice to me was really important.”

Julia agreed, sharing that in her experience as an educator and a parent, she observed that the Accelerated Reader program which began in the 1990's contributed to children struggling to love reading because their choice in reading materials was taken away. As she explained:

They started to tell children what books they could read and that those books had to be within this level. And that this number of points were assigned for this book and you had to amass this number of points within this time frame, they completely deconstructed what the construct of reading was for a child...they did it to an entire generation of 
children... and now that there are no points and now that there's no timeline...they do not engage in reading.

Sarah also had the same experience with young students early in her teaching career, relating that:

My first career was in language and literacy....and teaching in K-12 and I found students could read way above, whatever that arbitrary grade level was if they were interested, if you could get them engaged and get them interested. You would be amazed in the difficulty that they could tackle, but taking away choice, which takes away voice."

Making sure that children are able to choose what they read greatly impacts whether they will grow up with a love of reading or develop their love of reading later in life when they have full agency over their reading choices.

\section{Reading in Adulthood}

The focus group sessions next explored the participants' reading in adulthood. Discussions delved into what women higher education leaders choose to read, how they read in terms of the rituals and practices they have related to reading, and why they choose to spend their valuable leisure time reading. By examining each of these areas, participants shared insight into the impact that reading has on the professional, personal, and community spheres of their lives.

\section{What Women Leaders in Higher Education Read}

Through the focus group discussions, participants shared what they were currently reading. Current reading included reading for teaching, research, and theory; diversity and identity; personal development; and understanding and connecting with others. What they chose to read about in their professional, personal, and community reading influenced how they saw themselves and others and helped them provide this insight for their students in the classroom. 


\section{Reading for Teaching, Research, and Theory Related to Professional Work. For}

women in higher education leadership roles, professional reading has traditionally taken up a large share of their reading time and was prioritized over other reading. Professional reading included reading student papers, sampling reading materials to potentially include on their syllabi, and reading academic articles to maintain knowledge of their field and further their

research. It also included staying informed on relevant theories that intersected with their field of study.

Connection of Reading to Teaching and Research Interests. As participants explained, a happy side effect of choosing a profession where they were obligated to research a topic they were deeply interested in and passionate about was that professional reading was enjoyable and overlapped with personal reading. Elizabeth shared that while the bulk of her reading related to her profession, she was passionate about her work and took pleasure in expanding her expertise, explaining:

A lot of the reading I do, every book on...the shelf and then the shelf at home is...focused on disability... because that's my background. So, it's focused on disability, equity...education, special education, so [the] majority of my current reading is focused on the...professional, but I also enjoy it...I enjoy that type of reading and knowing that I'm expanding my current knowledge base in the area.

Sarah agreed, and related that this passion for exploring her research interests has continued despite her recent retirement from a full-time faculty role. As she elaborated:

I still read research journals and search articles, I still read books. I'm writing two books with some of my former...students...I'm reading and writing, and it doesn't end just because it's a lifetime kind of thing. So, I still get research journals. I still look through 
for the articles [that] are going to be relevant and meaningful to me and I just don't think that ends. I think it's a lifelong passion... reading everything on neuroscience and creativity and the creative mind...it doesn't end...if you're still curious and still want to know what's going on.

Heather found that incorporating popular reading that she has come across in her research can help illuminate the topic for her students in a more understandable way. As she related:

I'm reading something very popular to see how I can translate it for the students to make it palatable, manageable, exciting, and interesting and relatable for them because I appreciate not everybody likes reading that sort of style and dryness of writing at times. The books that really impacted Lisa were the stories of individuals that she might potentially be able to help in her chosen professional field. As she explained, the stories that stood out to her: Were autobiographies and people...experiencing struggle and...giving me a lens into the types of people I'd be supporting as a psychologist. So, I was thinking of A Long Way Gone, which is about a child soldier in Africa and sort of their resilience path and how they overcame that trauma.

Julia revealed that in addition to reading to stay informed on her teaching subject, part of her professional reading practice was to keep up with the latest news in academia. She stated that "I also read extensively for the class I teach...so that's... a big one for me...I have a practice...I read Inside Higher Ed...that's the first thing I do every single morning." Starting the day by reading up on the latest news in higher education contributed to keeping engaged in her professional role.

Exploring Theory Through Reading. Along with keeping up with the relevant literature in their chosen field of study, participants became well-versed in the work of theorists which 
informed their development as researchers and educators. Nicole was particularly affected once she discovered critical pedagogy, revealing that:

When I finally got into education... who influenced me in terms of what stance and what role I wanted to take in education was somebody like Peter McLaren. I read his work when I was a graduate student and for the first time in my life I remember somebody explaining social inequities that hadn't been explained to me at all before and it was such a visceral moment. I just remember...writhing in pain and crying because somebody said, it isn't you, it's social inequities that we have in society and that made me think that I've really got to go at my career in teaching and make a difference. And I frankly never aspired to be in higher ed...but I think because of that book that really had that critical edge to it that it really set me on a path towards critical education. Work by Michael Apple, [Michel] Foucault, and other critical pedagogy [authors] just that really have shaped my thinking and...helped me develop as a thinker.

Rebecca was drawn to political theory, stating that:

As I went into grad school, I became a lover of political theory. So Michel Foucault is one of my absolute favorite political theorists and bell hooks. I could not live life without bell hooks in my life... and then I love Gloria [Steinem] and [Simone] de Beauvoir's work on...speaking for others and just knowing my place and knowing my privilege and that really spoke to me.

Heather also found several theorists to be formative in her development as a scholar and as a leader. As she explained:

Simone de Beauvoir's The Second Sex...that was the one that made me...see marriage in a different way. For what marriage is and what it does to women and their roles...that for 
me was a very formative work. Similarly Michel Foucault as well. His work when I was an undergraduate and also...[Sigmund] Freud for me was a reader...they went hand in hand for me...Foucault is clear, but still complex, but for me Freud absolutely is someone that writes difficult ideas very clearly and so reading him shaped how I also wrote, but Beauvoir, in terms of leadership roles for sure.

In delving into the work of theorists, participants deepened their understanding of their areas of teaching and research.

Reading for Diversity and Identity. Focus group participants recognized that in their professional, personal, and community reading, it was important to read books where they were able to recognize characters or individuals with experiences and stories similar to their own and to aid others in this experience. It was also important to be able to choose their own reading materials and read books that were not chosen by teachers or family members. Whether this was choosing reading materials for their syllabus to be sure their students felt represented in the course materials, choosing books for their children that helped them see themselves, or choosing books that particularly resonated with what they were going through at various points of their lives, women in higher education leadership roles utilized reading materials to illuminate who they were and what was possible in their lives and to help others do the same.

\section{Importance of Representation in Books and Being Able to Identify with the Characters.}

Participants shared that some of the reading experiences that impacted them the most were when they identified with the author or the characters and could relate their experiences to their own. Conversely, some of their more frustrating reading experiences occurred when they could not relate to characters or see their lived experiences within the pages of a book. Nicole's reading experiences as a child did not mirror her lived experience, because the protagonists of the stories 
she read did not resemble her or her family. As she shared, "The children's books that I saw in... Dick and Jane books...all the...characters were...white and blonde and grandmothers have nice curly hair, and they bake cookies. And they look nothing like my grandmother." It was only when she was further in her academic journey that she found diverse female academics whose work allowed her to feel seen and also to see a potential path for her own career. As Nicole explained:

I have all these female authors on my bookshelf...I realized how important they are in guiding me and letting me know that a woman can do this work as well. That a woman can make such a monumental statement in the field. And especially being someone with a Mexican heritage, having somebody...who comes from that background has been so important to me in helping me see myself, not just as a woman, but as a person of color and as a person who's generally looked down [on] in society. So, I think that type of reading is vitally important in helping people see...themselves in certain roles. For me, as a...woman of color...those authors have been incredibly pivotal in my formation and I don't think I'd be here today if not for them.

Reading the success stories of women of color in academia contributed to Nicole's feeling of belonging in higher education and allowed her to provide similar lessons to her own students.

Diversifying Reading Materials. Participants found it important to aid their students and children in the experience of feeling represented in the reading material they consumed, choosing diverse selections for their courses and for their children to read at home. Stephanie made a conscious effort to diversify the books she read and chose for her classroom after realizing: I tended to read mostly the writings of white women, and I knew that I wanted to...diversify my own personal reading as well as bring some...into my classroom... so I 
just decided for the next foreseeable future I would just read books written by people of color.

To ensure that her students felt represented in the literature and were exposed to more diverse voices, Lisa explained that she thinks "about women, women of color, things like that as I build my syllabus and...letting our students see themselves represented in those books as well as learning more about people that maybe they don't know much about." Amanda agreed, relating she thinks "the same way about...including diverse people, a lot of more women in all of my teachings...for my students because in policy...the amount of women involved is so small that it's really important to elevate that voice and it changes the way we see, the way our society is structured." Erica shared that she thought it was important to for "teachers and curriculum designers and...instructors in higher education, anybody who's creating a syllabus for people to read" to intentionally diversify their syllabi, further elaborating that:

My sense is the best way to do that is to take a very thoughtful and deliberate stance on looking to see who's writing, what kinds of experiences of being reported, and making sure that you help whoever is reading, whoever you're interacting with, to get them the widest possible set of different kinds of experiences possible.

Participants also shared that they were committed to deliberately diversifying the reading choices they offered their children to ensure they saw themselves and other diverse voices in the books they read. As Amanda shared:

From a parent's perspective, I try to bring readings to my daughter...that highlight the role of women and the power of women and women's voices because I feel like that's also lacking. So often a lot of the adventure stories have been traditionally based around male characters, and so I've really tried to do that. And I do that for myself, not so much with 
the authorship, but definitely with the characters and somebody that I feel like can help me in my trying to elevate my, my own career and my own voice in the world.

Lisa agreed, relating that she was starting this practice early with her young boys. As she divulged, "I'm starting with my little ones, I have three boys... really trying to show them...the contributions of diverse people and women and how they can be a part of that. So, I think really getting the young to think about it would be helpful." Providing children with reading materials that help them see themselves along with other diverse perspectives ensures that future generations will value representation in literature.

Reading and Gender. The impact of the gender of the author and of the protagonist on the choice of reading materials differed between participants. While some participants agreed that gender did not factor in their choice of what to read and their interest was more tied to the topic or the storyline, for others gender was a critical part of their reading selection, especially if it was critical to their research. Gender did not come into consideration for Elizabeth, as she explained, "I don't have a focus on a particular gender, you know, I tend to...if I have... a favorite author then I will...continue to read...that same author, so I have several people that I follow their work. But it's not...particular[ly] either female or male." Whereas Heather, whose research and teaching directly involved feminist theory, shared that the gender of the author "certainly does make a huge difference to me when I'm reading something in my area of research.” Including women's voices within the reading materials discussed in the classroom was also important to Erica, who explained that "I looked for women's...experiences...because when I teach...methodology ...when I look at...qualitative methodology one of the things that I think it's really important is for us to be able to get into the understandings of other people." 
For some, reading books written by women and about women was a key component of being able to see themselves in the writing of others and to relate the challenges that the protagonist faced to their own experiences. Mary related that, "if I'm reading novels for pleasure, I really, $85 \%$ of the time go to women authors." Sarah agreed, saying, "I still read stories by women and about women, that's a lot of what I read."

Choosing books written by women and about women also helped address the lack of gender balance in the reading that had been assigned to them over the years in school. As Erica explained:

I did make a decision at one point. I decided, having had to read fiction mainly written by men, I would want to see what women do with similar kinds of things. And so, for a period there I made a conscious choice to read only books written by women in all genres...mystery, crime, stories of lives...And I would say at this point I don't necessarily look at the author anymore, especially if it's something that I really want to read about or know about. But I do gravitate more again like I said earlier to experiences that I'm not going to likely have in myself and often those happen to be women's experiences, whether it's about a protagonist or the author and mainly it's the author that I'm interested in.

Reading women authors contributed to participants seeing their own experiences and feeling represented in stories.

Exploring Relevant Intersectional Issues Through Reading. Staying informed of important intersectional issues and reading about theoretical frameworks linked to topics such as feminism, racism, and Lesbian, Gay, Bisexual, Transgender, Queer, Intersex, and Asexual $(\mathrm{LGBTQIA}+)$ issues contributed to participants' professional knowledge, their understanding of 
others, and added another layer of interest to participants if it also tied into their own intersectional identities and helped richen their understanding of themselves. Mary went through intense periods of reading on intersectional topics, beginning with feminism. As she explained: I went to college in the mid 70's, and grad school in the late 70's. And it was, it was just a really heady time for women. We haven't yet lost the ERA...we were just talking about women and who we are, who we could be... so I read Gloria Steinem and all, and then I also read feminist theology.

Continuing with feminist study, Mary also deeply studied racism, LGBTQIA+ issues, and the intersections between these topics. As she related:

I went through about 15 years where I read so much feminism stuff, and then I came out and I read a lot of LGBT stuff, and I'm in my racism phase, and I've been in there for probably six, eight years. And they're just similar kinds of analysis...but the times change. And then the dialogue in my head between all of these insights is something I love to think about and ruminate on.

Sarah began deeply examining democracy and politics through her reading and posed the idea that this partly emerged from her generational standpoint. As she shared:

It's interesting because we're different generations...I'm looking at the 60 's and ... we really thought the world was open...to change. And what if we have a war and no one came and...reading a lot about the Vietnam War right after that in the late 60's and the political turmoil and all of that...I just remember that was a focus of my reading. Melanie, also entering a formative time of study in the 60 's, found a lot of inspiration for the type of teacher she would like to become and how to help students develop their own critical perspective. As she discussed: 
I read things like Teaching as a Subversive Activity. A lot of work by Carl Rogers... a lot of psychology, Clark Moustakas, and Jung and some of the old guys... at that time. There weren't a lot of old women at that time around either that were doing a whole lot of writing, but it seemed like I liked the things that were saying let's do it different[ly]... Teaching As a Subversive Activity, I loved it and Malcolm X, and some of those books that were like, how do we do this, and how do we change things and books that were popular in the 60 's... Those were the things that really inspired me to...want to be a good teacher and I want to be a teacher that is going to do things differently and not be boring, like a lot of the teachers that I had. Wanted to make sure that people did have some kind of a critical consciousness and maybe I could help them be what they wanted to be, and who they were...meant to be in a way. And so, I guess it was those kinds of books that kind of influenced me, and still do in a lot of ways.

Integrating critical consciousness and reading on feminism, racism, and LGBTQIA+ issues added to participants intersectional understanding of their fields of expertise and also of themselves.

Reading for Connection and Community. Sharing and discussing books with others can be one of the most meaningful experiences of being an avid reader. Community reading, the third area of reading, often ties the first two areas together, bringing together individuals interested in the same professional or personal reading topics or genres. Some women in higher education leadership roles participated in book clubs which provided them with an experience of community in their choice and discussion of books, while others shared books with colleagues and neighbors through Little Free Libraries, connected with potential professional mentors by discussing their writing and academic careers, and bonded with friends, family and colleagues 
through book recommendations. In addition to bringing a social component to their reading, the community aspect of reading also helped women in higher education leadership roles learn about and better understand the experiences of others.

Understanding and Connecting with Others. Participants mentioned that one of the key aspects they hoped to glean from reading was a better understanding of other people and places outside of the context of their own lives. Stephanie found this early on with the supplemental reading packets she was assigned in elementary school, which opened a window into other cultures and locations around the world. As she explained:

My world was very small when I was growing up, but it taught me things about different places and people and history and the world. Like it made my world very big and I just...inhaled those...you were supposed to do three a week or something and I would just read them all because I recognized that reading opened all of these ideas for me that I just didn't have access to in my community context... it just gave me like a lens into places and people and experiences that I just didn't have in my context at all. So, I think for me it was...more like how can I access the world through reading and learn about other people, places that are very different for me.

Though it also relates to her research interests, Andrea shared that one of her current reads, Talking to Strangers, is primarily about understanding the experiences of others. As she stated: It deals with how to speak with people that we don't necessarily understand their story and how to deal with emotional people. How to understand and empathize with where they're coming from and how they engage in discussions with them that are beneficial and efficient with regard to problem solving and resolving disputes. 
Erica also prioritized reading materials which helped her better relate to the experiences of others with a life path unlike her own, sharing that:

I think it's really important...for us to be able to get into the understandings of other people. And I find that reading both biography and fiction helps us to do that, so...I want to read about people's experiences...that are really different from mine. So, one of the books that I read recently with the one by Nadia Morag I think it's called The Last Girl... I found that very insightful, very moving. Difficult to read, but that really stood out as something that helped me experience a world that is very different from my own privileged life. So, I have tried to read a couple of different ones like that.

Amanda tried to choose a variety of book topics to learn more about and understand the experiences of others, which could be quite harrowing when they depicted a brutal experience. As she divulged:

I try...to always find readings about places and people I would not ever relate [to] or experience on my own. And one of the most moving ones for me was one called Today We'll be Killed with Our Families, and it was about the Rwandan genocide. And it was really focused on how the leadership in Rwanda and the world let down Rwanda and the people there. It's a very difficult read.

For Jennifer, the books assigned in her college course on Politics and Literature provided her with lasting insight into how to see a situation differently once you have fully examined it from the other person's perspective through literature. As she elaborated:

I went...to college at the tail end of the Cold War, so between 1991 and 1995. This course focused on how...the rise of Communism and Bolshevism in Russia and...the Cold War that ensued and it was all through mainly fiction books and memoirs. And it 
was such a fascinating way to get an insight into...this...system that seemed like such an enemy...to us. Growing up, especially in the eighties...the Soviet Union was the enemy and taking this course and reading these books...gave me such a profound insight into...this different culture and political system. I never forgot that course and it had a profound impact on me. It's just like the power of books to...completely change your thinking about something.

Books have the unique power to immerse the reader deep in the perspective of another person and help them better understand their actions and motivations, unlocking the potential to change hearts and minds through reading.

Book Clubs and Book Groups. Book clubs or groups are a common way that readers can collaborate with other readers who like similar topics, genres, and authors. Book groups establish a unique sense of community as members relate what they are reading to their own life experience and learn about how books resonate with others' lived situations. Jennifer has been reading with book clubs since graduate school. As she explained, "I think the only time I didn't read consistently was my three years of law school, I was just too busy. But since then, I've always either been in a book club or just read for pleasure. Usually fiction but nonfiction as well." Andrea's book club helps her consistently read for leisure, as she related, "I am part of a book club. So we've been trying to be consistently on Zoom every five weeks or so and that keeps me going with reading for pleasure as well. We like to alternate between reading fiction or autobiographies or true crime.”

Stephanie emphasized that "the communities around books become very important for women, or at least that is my own experience. That's been really important to me." She further shared that: 
At every phase of my life [I] either have started a book group or joined a book group or participated in some way and nearly always...it tended to be women who participated, even if they weren't just women's groups and I think what ended up happening in those milieus ...there was a conversation about books, but there was a conversation about our lives as well and kind of having that empathetic interaction with each other around whatever book we're reading...[and] also gave me kind of models and a community of interesting people to interact with and ended up in many cases being very influential in my life and also lifelong friends that I have carried through. So, I think there was something about that catalyst of a book group that actually helped quite a bit to give me a community of interesting women to model on or to bounce ideas off of or to just be my support group...or just ...people you can relax and let your hair down and be yourself with if that wasn't the context you had at work or school or whatever.

Being a member of a book group meaningfully contributed to participants' sense of community and engagement with reading.

Online Writing Communities. With a busy academic career, Julia was able to find a similar sense of community online through her interest in fanfiction based on her favorite television show. She was also able to satisfy her passion as a teacher by providing feedback to other members of the writing community who were working on their writing. As Julia explained:

I don't have a lot of time to read...fiction, or novels. So, what I do actually is I read a lot of fanfiction...written by amateurs...Barbara Stanwyck was the ultimate female lady boss in The Big Valley and it's a family drama... that had a social conscience in the 1960's and did things that no other television show in the 1960's did and there's a whole 
fanfiction community around that show. And there are particular amateur authors that I adore who constantly produce new content. And I will tell you that pretty much every night, I read something before I go to bed on that fanfiction site. They publish in real time and it's also being part of a writer's community because they ask for feedback. So, the people who read those stories will post things back to them like...that was good, but here they can whatever...maybe it's the teacher in me...because I'm giving a writer...some feedback on their writing, but I find a lot of joy, being a part of that writer's community with amateur authors. And they all write under pseudonyms... but you kind of become familiar with them through their pseudonyms.

The online writing community created around fanfiction provides participants with the opportunity to connect with others with the same interests, generate their own stories, and help others in their development as writers.

Mentors and Models. Stephanie was able to find two different mentors and models for the type of academic research that she aspired to pursue through her reading. Explaining that she did not come from a background where she had examples of family members attending graduate school, she was inspired by Jill Ker Conway's book, The Road from Coorain, relating that "it's about her experience evolving as an academic coming from a very rural context in in a place in which she doesn't have a model for that. And there's other books like that I read as well." Continuing to seek models and mentors through her academic networks that had similar life experiences to her own and had succeeded in academia, Stephanie further explained:

I read a book by an author, her name is Laurel Thatcher Ulrich, and she's a historian who wrote a book called $A$ Midwife's Tale that won a Pulitzer Prize. It's a remarkable work of history, and it focuses on women's history specifically. And I had in my social context, 
the opportunity to become acquainted with that author and so she became a mentor to me as someone who'd had some similar life experiences to what I'd had.

Stephanie also recognized the importance of reading books that helped young women envision how they could engage in their careers. As she shared, "I think it is really important for women to have examples of whatever path they have for themselves and finding the appropriate examples is really important. And having mentors [that] can point those out."

Discovering mentors through reading in their field and engaging with their instructors provided participants with opportunities to engage with the literary community more deeply within their discipline.

Book Recommendations. Discussing books they enjoyed and providing recommendations to others was also a critical part of the community sector of reading. Participants gathered reading recommendations from a variety of sources, ranging from celebrities like Oprah and Barack Obama to suggestions from Amazon, Audible, Blinkist, and public radio. Some of the more personalized recommendations came from friends, colleagues, and independent bookstores. Lisa often gets recommendations from a friend who left academia to open a bookstore, as she shared, "she's really good because she has to read all day long, and she gets books before they're out, and so she's really great at giving me ideas." Similarly, Amanda has received great customized recommendations from:

A little bookstore in New York...right near my sister's house and they send the recommendations based on things that I've bought from them. And that seems to be the best for me because they know exactly what I'm interested in. And they just really seem to be able to funnel it to me perfectly and I feel like I'm contributing to keeping them going, as well as having the easy access of just getting them online. 
Stephanie received new reading materials often tailored to her preferences through books deposited in the Little Free Library she had in her yard, revealing that:

For a long time I had a Little Free Library in my front yard and so I would also just read what people were dropping by. And I used to live just two blocks from campus. And so sometimes other faculty would put books in there and they'd tell me you need to read this one. It was really fun actually to have that kind of social interaction around the Little Free Library space.

Heather used her love of reading to keep in touch with friends abroad who exchanged book recommendations through the mail. As she related:

The people who I share books with are still...my close friends in England, the women who...all had babies around the same time in our village. And to this day, we will still send books to each other like our own little resistant Amazon. We will say to each other about what we liked...because we've been friends for so many years, almost 20 odd years, you know what each other likes, even though it seems totally different. So, you know, a book will arrive in the post from her, and then I'll send her one.

Erica also kept up with friends abroad through sharing book recommendations. As she explained: One of the things, being in a country different from the one that I grew up in, is I still want to be reading what they're reading and I want to know what the current fiction is in Australia. I will just email people and say, what have you read in the last few weeks...or last few months, so I get a lot of recommendations that way.

Receiving personalized book recommendations from others kept participants connected to their communities throughout the country and around the world. 
Reading for Personal Development. Several participants enjoyed escaping into nonfiction books in their leisure reading time, reading books that contributed to personal development, as well as to further practical skills and creative pursuits. By consuming reading materials which expanded their techniques in cooking, quilting, sewing, and knitting, participants were able to clear their minds from the stresses of their day and focus on practical and creative skills they could employ in their down time. They also consumed books to further their personal development in areas such as parenting and being a woman in the workplace, looking for practical ideas to aid them in managing their busy schedules and balancing their lives.

Developing Creative and Practical Skills. Expanding their expertise in cooking, quilting, sewing, and knitting offered women leaders in higher education a practical and creative outlet in their leisure time. As Julia explained "I sew and so I read technical books on...quilting and construction and things like that," elaborating that "last week I was reading a book on a quilting method called Quilt as You Go, because that's... a technical thing. And I'm...working on my skills right now on that." Elizabeth also turned to instructive texts in her leisure time, stating that "I'm not someone who will...go to a store and just pick up any fiction book. I prefer something that's related to something that I am passionate about; I'm doing work in... whether it's sewing or knitting. You really want to understand it more and learn about it."

Julia, Melanie, Nicole, and Sarah all mentioned that they turned to cookbooks when they needed a break from academic reading. As Nicole related:

The other day I picked up a cookbook, not because I wanted to read, but I just needed the mental escape from the constant onslaught of news and the work that I'm doing at the university that it really was the space away from everything else... and I remember 
thinking, okay, I can do this for 20 minutes, before my next Zoom meeting...I had to allow myself that time because it's so easy to just spend like 10, 12 hours a day on stuff. Sarah explained that when she turned to cookbooks, it was not necessarily to prepare to cook, that:

Sometimes I'm not even going to be cooking but...I guess it's the creativity or the place or the culture or something. But I'll read cookbooks, the way other people would read some other kind of books and it's not only to think about that I'm actually going to make those recipes...I just like reading cookbooks.

By paging through cookbooks, the women were able to take a mental break, immerse themselves in other cultures, and embrace their creative sides.

Developing Skills to Navigate Home and Workplace Roles. In the area of personal development, participants shared that they gleaned a lot of helpful suggestions from books related to parenting, being a working mom, and navigating the workplace as women. Several participants recommended bell hooks' latest book, All About Love. As Rebecca explained. "The concept of self-love, it is so important... as we all know, coming into graduate school and being women leaders, we need to be tender with ourselves and we need to remember to be kind to ourselves." Jennifer shared that women in her field particularly benefited from:

Any kind of book that...helps women... say...I can actually choose a partner who... respects... a more egalitarian division of child rearing and family care. I think that's really important. I know...Cheryl Sandberg's book Lean In has...been criticized a lot as being...elitist, but I think that it sends a good message in the sense that, that's kind of what she did.

Lisa agreed, noting that while Lean In did come "from a very privileged position" it did help her: 
Frame my career and take ownership of my leadership roles at work. I'm still wiping butts in between meetings, but it gave me a sense of direction and a sense of like that I could do this, that this is possible and other people can do it...because I didn't have models for that either, I had a lot of...family members that weren't strong leaders or in academia.

Whenever the women in her life were looking for employment, Julia shared her recommendation of "Women Don't Ask: Negotiation and the Gender Divide by Babcock and Laschever. I hand it to every single person who's female before they go out in the job market."

Reading about how other women navigated the challenges of being a woman in the workplace and of being a working mother provided women in higher education leadership roles with examples of practices they could integrate into their daily lives.

Reading for Escape. Women in higher education leadership roles do not have abundant leisure time, so one of the key reasons that women choose to read in their free time is to escape. Participants shared that they enjoyed being able to take a break from the stress of their daily lives and lose themselves in a book. They particularly enjoyed reading books that made them feel immersed in another time, another place, or the life of another person. During the COVID-19 pandemic, participants found reading a helpful diversion to distract themselves after a long day of pandemic related news and stress.

Escaping into Leisure Reading. Cognizant of their need for a release from professional pressure, women in higher education turned to leisure reading to provide an escape. Melanie liked to escape into mysteries, sharing that she liked "the puzzle aspect...it was an escape...it wasn't hard. It was fun and I could figure things out and totally get into it and forget...the everyday things of my life." Jennifer related that fiction was usually her go-to escape when life 
became difficult, sharing that "I usually tend towards fiction and especially in times of stress, the lighter the better." Andrea explained that "at the end of the day, it's nice to come home and get away...I think I tend to read books that lend themselves to escapism...getting away from it all and just thinking about something else entirely and immersing yourself in something completely different." Rebecca agreed, relating that leisure reading at the end of the day helped her "to get away from the stress of what's going on at work and the roadblocks that you have that are thrown up in your research projects...I need to go somewhere else. I need to go to Neverland.” Escaping in a book in their free time allowed participants to reset and be ready for their next academic challenge.

Escaping to Another Time and Place. Participants shared that part of escaping into a book and taking a brief reprieve from the responsibilities of academia was becoming immersed in another time, place, or another person's experience. As Sarah related:

I do like stories or books where the place is a character where you really, if it's in New Orleans, you really get a sense of what New Orleans is like. Elena Ferrante did My Brilliant Friend, it was a series of four books, takes place in Naples. And Naples is totally, with all of its darkness and intrigue and myth and magic and just gritty, urban, the mafia. Everything is there and it's really a character in the book, so I feel like I know Naples better at that period of time because of her book, so they really become a character.

In a more personal experience, Sarah described feeling immersed in the neighborhood depicted in Anne Patchett's The Dutch House, explaining that the book was situated:

Exactly where I grew up. And I've never read...a story...that was from my neighborhood. So, it has the streets and the places, and the Central Church and I can locate everything. It 
was a very...strange feeling. I never had read a book like that. I grew up outside of Philadelphia and I don't know why she picked that, but...the sense of place is a character and it's where I grew up, so that latest book of hers really struck a chord.

Being able to fully visualize themselves in the setting of the books that they read added to the participants' sense of escape when reading.

Escaping from Reality During the COVID-19 Pandemic. The onset of the COVID-19 pandemic and the transition to working and teaching remotely had a significant effect on the reading habits of women in higher education leadership roles. While it was not possible to cut back on reading materials critical to their professional roles such as student papers, participants struggled to keep on top of reading academic articles to stay informed in their fields or to leisure read, finding that reading up on the latest pandemic news was taking up their reading time and draining them of the bandwidth needed to continue reading other materials. As Melanie explained, "I've been doing a lot of reading... on the virus and the pandemic and people's experiences throughout all of that and I have to watch it...because I can get so into it and then I start getting depressed and I have to just say, enough already." Sarah related to the feeling of COVID distracting her from her reading and writing, explaining that:

There's something about the pandemic and the layers...that seep in. And there are days I'm not productive or can't get to the writing or I can't get to the reading and it's hard to put your finger on...you're not as productive. And it's hard to, you know, actually explain why because it's not touching tangibly your material day, but it's there.

The shift to remote work and teaching also increased their usual amount of screen time, which impacted their desire to read, as Melanie shared: 
Since the COVID stuff has been going on with all the Zoom meetings and everything, I'm kind of ...visually overloaded and I kind of want to escape and not do anything visual at all...when I start to pick up something it's like too much for me. I'm on overload somehow. So, I'm hoping that that will settle down and we'll find a new normal. Mothers were especially affected by the changes brought on by transitioning to a remote lifestyle. As Elizabeth explained:

I'm having a more difficult time... since COVID to be able to do reading. I think partly because I have four kids at home and I'm trying to work full time and be their teacher and...make sure their assignments are turned in. So, I would say my reading has lessened and...I'm just trying to maintain at this point.

Lisa concurred, admitting "I have three kids under five and so by the time I get everyone to bed...I used to use that time to read...but now I'm just trying to keep humans alive....so I've lost a little of that." It was more difficult for mothers to justify reading in their leisure time, as they had to cede some of their professional time to supervising their children's online schooling and felt like they were constantly playing catch up.

Turning to leisure reading and reading with book groups and loved ones helped ease the uncertainty and pressure brought on by lockdown. As Nicole related, whenever:

I feel consumed with anxiety and worrying about what's going on, then I have to bring something else light into the mix. And that helps to light me up as well and to...give me hope again. So, I purposely look for books that are going to be those windows into... lightness and into other thoughts that aren't so virus related.

Andrea's book club brought normalcy, community, and variety into her newly remote lifestyle, as she explained "I am part of a book club. So, we've been trying to be consistently on Zoom 
every five weeks or so and...that keeps me going with reading for pleasure as well...We like to alternate between reading fiction or autobiographies or true crime." Reading with others was a practice that Rebecca also took up during COVID, sharing that the Harry Potter series was providing them with entertainment and escape. As she related "I'm actually reading them out loud to...myself and my sweetheart and...doing the character voices." Reading through the Harry Potter series was a popular COVID pastime, as Andrea shared, "I'm also reading Harry Potter in my spare time because I actually had never read the book before... and someone had given me the...entire set a few Christmases ago so I decided now was as good a time as any to pick that up." Reading contributed a sense of levity and escape during a time filled with anxiety and uncertainty for the participants.

\section{How Women Leaders in Higher Education Read}

Whether reading scholarly articles or student papers for work, a novel or cookbook for leisure, or a book for their book club, women in higher education leadership roles have several common reading practices and rituals in the professional, personal, and community spheres of their lives. Some have different physical spaces where they consume different types of reading materials in order to mentally shift more easily from one sphere of their reading life to another. Others have rituals around choosing books to read on vacation and to remember their trips around the world for conferences and for leisure. Still others have a habit of conducting author studies, where they follow the career of an author whose work particularly resonates with them and consume most, if not all, of the books that they have written, at times re-reading favorite authors' works multiple times. Technology has also provided participants with additional ways to consume reading materials through audiobooks and e-readers. The discussion of these shared 
rituals caused focus group participants to excitedly chime in that they had the same habits and find common ground in their reading practices.

Having Specific Places to Read. To successfully aid in the mental transition between reading directly tied to their field and teaching, reading related to their research interests, and reading for leisure and escape, women in higher education leadership roles change the physical space where they do their reading. Rebecca introduced this to the focus group discussion, explaining:

I'm changing mental habits and physical spaces in order to accommodate the different aspects of life and work...it really is kind of like...I'm going to put my hat on for this, and for this hour, this is where I'm going to be. Now, let me...take that hat off and...I even get into a different space... When I'm sitting at my desk, I'm working on mediation clinic stuff. When I'm sitting at my kitchen table I'm working on research, right? When I'm sitting in my living room, that's where I can cuddle up in my corner and I can do my...fun stuff.

This resonated with Nicole, who shared that she also has a separate space for her leisure reading, relating:

I have my chair in the living room that has sunlight in the morning. I think I just want to go and sit there and escape from everything and it's going to be reading unlike anything I am doing anywhere else in my life because that is my space. The other day I picked up a cookbook, not because I wanted to read, but I just needed the mental escape from the constant onslaught of news and the work that I'm doing at the university that it really was the space away from everything else. 
Erica, Melanie, and Lisa all mentioned that they tend to do their leisure reading in bed at the end of each day. Lisa especially noted that this helped her to transition from academic thinking and relax before going to sleep, explaining she thinks leisure reading before bed "helps me wind down versus if I'm working right until I fall asleep, and I'm still spinning about all the things I need to do. And when I read it sort of just shuts that down.” Moving from one space to another as part of their reading rituals seems to make a difference in their enjoyment and processing of their reading materials.

Reading and Travel. Another common reading practice among the focus group participants was making time to read for pleasure while travelling and on vacation. While the rigorous schedule during the semester did not always allow women in higher education leadership roles much time for leisure reading, they could justify making time for it when travelling to a conference or for vacation. As Lisa shared, between academic responsibilities and caring for her young children, often one of the only times she has to leisure read was, "if I'm going on vacation, like sitting by the pool or on a plane or whatever I could sit and read." Amanda agreed, lamenting that with the travel restrictions put into place by COVID-19, she was disappointed to not be taking a summer vacation in 2020. As Amanda explained, "that's the one thing for me, summer vacation means I get to read a pleasure book," and her travel ritual is to choose what books she will bring with her to enjoy on her annual summer vacation. Stephanie had several reading practices related to travel, sharing that in her frequent travel to conferences and for pleasure she does not read for work and makes sure to pick up an airplane book. Stephanie elaborated that:

I know all of the bookstores in the airports that I frequent, actually all too well. And one of the first things I do, especially when I'm traveling for pleasure, is I find a local 
bookstore in that place that I find myself and talk to the people in the bookstore and get great random recommendations or just browse until something jumps out at me. And I think having that as a kind of travel ritual there's a lot of pleasure in that for me.

After collecting books and bookmarks from the locations she has visited in her travels, Stephanie is able to further enjoy the experience, explaining that "when I have a stack of...books to read and I...put the bookmarks of the place... wherever I got the book and I'll kind of remember, it'll be part of the travel experience even. Where I got that book and the memories affiliated with reading it as I'm traveling."

Author Studies. Several of the participants shared that they did author studies upon finding writers whose work they enjoyed. Author studies was a term which was first introduced in the conversation by Julia, who explained, "by the time I got into high school...I would read a lot of the same author and I still do that...I do a lot of author studies." In an author study, readers consume all of the books from their favorite authors, eagerly awaiting new titles to come out from living authors and rereading titles that particularly resonate with them. As Elizabeth related, "if I have a favorite author then I will...continue to read...that same author, so I have several people that I follow their work." Sarah and Elizabeth started doing author studies in childhood by consuming all of the titles in a series such as The Boxcar Children, Nancy Drew, and The Babysitter's Club. Julia conducted author studies by consuming the work of other prolific writers such as Robin Cook, Steven King, and V.C. Andrews. Sarah mentioned that "I do have several favorites and I'll read whatever, like Elizabeth Strout. Olive Kitteridge and Olive, Again, those books I like very much." She added that she has also done author studies on Isabelle Allende, Barbara Kingsolver, Anne Patchett, Anne Tyler, Elena Ferrante, and Jodi Picoult. Erica revealed that she has "read everything Jane Austen ever wrote over and over again. It's got to a point 
where I say, oh, it's time for me to...go read them again" and that she has also "been making my way through all of the Kate Atkinson books. Some of them I had read years ago. Some of them I'm rereading." The practice of conducting author studies allows readers to engage with new titles that they anticipate they will likely enjoy because they have appreciated the author's previous books.

Technology Providing More Ways to Consume Reading. Time is a precious commodity for women in higher education leadership roles, and many have embraced technology to provide them with additional ways to consume their reading materials by providing ease of access or the ability to multitask while they complete other responsibilities. As Mary shared:

I just am really impressed with how the changes in technology allow us to read even more... You can read by listening to a book when you walk. You can...read in the car by yourself. There's so many different ways that...you can get more reading done than just sitting in your easy chair with a good book, so I just really love that.

Sarah agreed, explaining that her transition to reading on her iPad made a big difference while teaching annual travel courses. As she related:

I also made the switch to an iPad, which absolutely amazed me because I'm a reader but I'm very tactile as far as the arts go, I like the feel of books. I like the turn of...the pages. I like that whole tactile experience. And yet, I love the iPad. I can go to Italy for three months and take my iPad and have downloaded... what I'm going to read...Right now I'm home so it doesn't make a difference, but that switch happened by going to Italy and I used to take a whole suitcase of books... that were the basis of my lectures which once a year, I had to sort of pull together all of that information. So I use the iPad a lot for 
reading. I can change the font. I mean, there are many wonderful things about...technology.

Lisa and Mary mentioned that before COVID-19 hit they often listened to audiobooks on their commutes. Missing listening to her books through Audible while working remotely, Mary adopted a new practice, sharing "I've gotten back into exercise during COVID, and I walk almost an hour a day... and I use Audible....and it got me into got me into exercise again, which was wonderful to get out and just walk." Lisa enjoyed hearing directly from the author when she listened to audiobooks, as she explained, "I'm listening to Becoming by Michelle Obama. I really like listening to it because it's her...I think I like listening to books when you can hear the actual person reading it and telling the story." During her commute, Julia utilized an app to assist her in narrowing down which books she would read next, sharing that:

Blinkist takes nonfiction content, and it distills it down to 15 minutes for each book...that allows me to consume that content in the car on my commute in and back...I use Blinkist as my better preview...because it is actually summarizing the entire book in 15 minutes and I can decide if I want to buy it or not.

By consuming reading materials through audio, participants were able to multitask and incorporate more reading into their day.

\section{Reading and Balance}

Between their many professional, personal, and community reading choices, women in higher education roles found it difficult to balance their reading. While many were striving for better work-life balance and felt that incorporating reading into their routines allowed them to feel like they were leading a more balanced life, they were often successful in making time to read when life became hectic. Some found balance in creating division between their different 
types of reading, trying to complete professional reading earlier in the day so they could wind down with personal reading at night, or applying reading practices and rituals such as reading in different spaces for different purposes. Others found balance through finding ways to combine and align their different types of reading, balancing heavy and light reading choices, choosing leisure books that also related to their professional interests or ended up on their syllabi.

Participants had to allow themselves the time and permission to read in order to create a sense of balance in their lives and found it to be valuable when they did so.

\section{Finding Balance Through Combining and Aligning Reading Interests}

Some found that balance was difficult not because they did not make time to leisure read, but because they enjoyed their field of study so much that their personal and professional reading merged. These participants were able to find more balance in their reading lives by combining and aligning their reading interests. As Lisa confessed:

I have a weird overlap with some of my fun books [that] actually end up being related to my work and vice versa. So, I'm not very good at separating the two...I just read an autobiography....and I started reading it, just out of personal interest, but now...I think I'm going to include it in my class.

Amanda shared that her leisure reading also contributed to her study of elements she wants to bring into her professional life, explaining that:

I'm also always looking for ways to bring people together...The way I see my role both as an educator, an academic researcher, and as an administrator is that my job is really to bring people together and help to solve problems in that way. So I've been reading, most recently, Madeline Albright's...memoir...And I just find it very inspiring to see...a 
woman in that kind of leadership position and those are the sort of tools and techniques

I'm trying to draw from her to bring into my own career.

Participants were all passionate about their areas of expertise so it was common for their leisure reading to be on a subject that ended up being related to their research interests or being a book that they could potentially assign in their classrooms.

\section{Balancing Heavy and Light Reading Choices}

Another balancing strategy employed by the participants was balancing reading choices between heavy and light reading material. After reading on serious, weighty topics like racism or the pandemic, women would make sure to integrate a lighter reading choice into their reading rotation as a way to relax and keep their spirits up. Melanie explained that one of her lighter reading choices was “a book by Kevin Rafferty. He’s an Imagineer at Disney and it’s a very delightful, fun book and it makes me giggle." Despite feeling the need to balance their choices, women expressed being glad they made their way through weightier reads, with Jennifer sharing that they had just finished reading The Five, "which is research on the five women believed to be killed by Jack the Ripper...I didn't know anything about the topic before I started reading it...it was a fascinating read and...very much about their lives and how the system and society failed so many people." Jennifer noted that "The Five is an unusual book for me because I usually tend towards fiction...but this just looked really good and I'm glad I read it."

Heather similarly shared that they had just finished:

The Overstory...it depressed me... it was a very long book and in some ways very demanding book, and...even though I was supposed to be reading it for leisure, it felt like it was taking a lot more out of me...so I got through it, but it was a slog. I enjoyed it, but it was very sad. 
Amanda also likes to purposely stagger her reading choices, explaining that after reading a heavier book she tries "to always contrast these types of stories with other stories" and "for pure leisure I just finished a book called The Beneficiary by Janie Scott...about a woman who is part of the historic elite of America... and the way that disproportionate resources 150 years ago are supporting disproportionate outcomes in people and families today." Switching between heavy and light reading material in their leisure reading helps women keep a sense of balance in their reading choices.

\section{Finding Work-Life Balance Through Reading}

Other participants acknowledged that while making time for leisure reading or reading with their book clubs added to their happiness and provided more work-life balance, when time was short academic reading had to take priority. As Amanda related:

I don't have a good balance. I wish I did. And I always feel better when I have pleasure reading going on. I know that, but I don't always have time for it...It's probably the first thing that gets dropped off of my to-do list...And I realize it's important for my mental health...but the first thing, like I said, that drops off the to do list of all the things that need to be done in a day.

Lisa concurred, explaining:

Sometimes I feel like I need to be reading my work stuff if I'm going to be reading at all. But it does make me feel like I have a life when I get to sit down and read so I'm trying to make that a goal. Rather than prepping my class at night...instead I can....read before I go to bed.

Jennifer also agreed, acknowledging "I think like the other people have said, it's an important part of work-life balance for me." By prioritizing adding leisure reading to their schedule when 
they were able to, participants were able to feel that they were making a positive contribution to their self-care and mental health, and that they had better work-life balance.

\section{Having Time and Permission to Read}

With the competing pressures of their various professional, personal, and community responsibilities, women in higher education leadership roles shared that they needed to make a conscious effort to carve out time to read and to allow themselves that time to escape within the pages of a book. As Melanie confessed:

I've had to give myself permission to do that because, it's gotta read for work, gotta read for the profession, better read, gotta read. And right now it's like, give yourself permission to just screw off and have some fun and do something a little bit different and be light and it's okay. Don't feel guilty about that.

Nicole found that having so many interests made it difficult to find time to read everything she was interested in, explaining:

I can't read every single book that I want to read in this world...the problem is my mind just seems to go everywhere. Sometimes I really have to sort of narrow down and say, I['ve] got to get to this piece first, so focus here. Sometimes I have to leave these...books...in the wings and I know that they're there and I know that I could go to them. I feel like they're waiting there for me... I've never felt a loss for...titles. I just felt at a loss for time.

Some found it easier to allow themselves more leisure reading time once they reached a certain age or stage in their career. Mary felt more comfortable setting aside time for personal reading at the time of the focus group discussions than she had in the past, as she related "I hit 65 in April 
and...I am letting myself do more for pleasure than for work." Sarah similarly became more comfortable reading for pleasure once she retired from full-time teaching, admitting,

I thought I should wait because I'm retired. And I'm in reading heaven. One of the things that [I] said...was when I retire, I will have more time. And I read very widely...I read about the arts and creativity. So I have a whole section on that and if it sounds like a lot folks, it's because I'm now retired, and I can do that. I...had to give myself permission to say you can spend a part of each day now reading, just like you say you're going to do some exercise. I give my permission to just sit down and read and that's just a wonderful luxury.

Allowing themselves time and permission to read, while not easy for busy women in academia, provided them more work-life balance and a better quality of life.

As the focus group participants illustrated through their enthusiasm for reading in the professional, personal, and community sectors of their lives, women leaders in higher education create balance by the choices they make about what they read, the rituals and practices they put into place, and how and when they create space in their lives for reading. Their passion for their chosen field of research makes professional reading enjoyable and contributes to their being able to better prepare their students in that field of study. Personal reading provides an outlet, whether for personal development, practical skills and creative pursuits, or to escape the rigor of their everyday lives. Book clubs, book recommendations, fanfiction communities, and Little Free Libraries foster the social aspects of reading. Ultimately, reading helped the participants better understand themselves and others, improve their work-life balance, and enjoy their lives more fully. 
What women in higher education leadership roles chose to read about in their professional, personal, and community reading influenced how they saw themselves and others and helped them provide this insight for their students in the classroom. The reading practices and rituals that they enacted while reading allowed them to shift between the necessary headspaces for consuming materials in each area. Participants read to develop a sense of personal self, for connection and community, and escapism. Their efforts to prioritize and balance their reading, while ever-shifting and necessarily skewing towards professional reading in different times of the year and stages of their lives, contributed to their work-life balance and the feeling that they were leading a well-rounded life. 


\section{CHAPTER FIVE: DISCUSSION}

This study revealed that women in higher education leadership roles had reading experiences and developed reading habits that translated to what and how they read in adulthood, and to the choices and habits they made in the effort of balancing work for professional, personal, and community connectedness. This chapter will explore the value and importance of the findings for this study and what they mean for young readers, parents of young readers, educators for readers of all ages, and women aspiring to or currently working in higher education leadership roles.

\section{Discussion of the Findings}

The findings of this study begin with the participant's reading experiences in childhood, including an early love of books, family connections to reading, early impactful reading experiences, and personal choice of reading materials. Moving into adulthood, the findings explore what women leaders in higher education read, including reading for teaching, research and theory related to professional work; reading for diversity and identity; reading for connection and community; reading for personal development; and reading for escape. The next area of the findings reveal how women leaders in higher education read, including reading rituals and practices such as having specific places to read, reading while travelling, author studies, and utilizing technology for reading. Finally, findings around reading and balance will be discussed, including attaining balance through combining and aligning interests, finding work-life balance through reading, and having time and permission to read.

\section{Reading in Childhood}

Participant discussion began around the topic of reading in childhood, and the experiences that women had with books in their youth. Participants remembered being early 
readers with an early love of books, sharing childhood connections to reading with family members, having early impactful reading experiences, including for some reading books about the United States while growing up abroad, and the importance of being able to select their own reading materials. This section will discuss the findings related to the early reading experiences which shaped the childhoods of women leaders in higher education.

\section{Early Readers with an Early Love of Books}

Focus group participants shared that they had an early connection to books and to reading, considering books as friends that they carried with them through many of their childhood memories. They were so connected to their books that they wrote and drew in them and paged through them pretending to read long before they knew how to actually read. The literature reflected these experiences, stating that being an early reader that enjoyed reading at home contributed to stronger reading comprehension once they entered school (Leppänen, Anola \& Nurmi, 2005). Moyer (2007) further shared that reading and visiting libraries frequently as a child led to becoming leisure readers in adulthood. This is meaningful because having an early affinity towards reading sets children up for future success and a lifelong enjoyment of books.

\section{Familial Connection to Reading and Books in Childhood}

Focus group participants also shared having fond memories of reading with family members and being told stories during their childhoods, and this contributed to their lifelong love of books. Whether they were sharing books with siblings or having stories read by parents and grandparents, this comforting childhood connection with books started off a lifelong journey as avid readers. As Boonk, et al. (2018) explained, family members who read to children at home at an early age significantly impact their reading and language achievement in school. This is significant because parental and family involvement with early childhood reading also sets 
young children up for a successful academic future, as is the case for the focus group

participants, who all have successful academic careers.

\section{Early Impactful Reading Experiences}

Early impactful reading experiences resonated with the focus group participants throughout the rest of their lives. Reading books early on that impacted them emotionally revealed the power that literature has to not just entertain, but to give readers insight and empathy for the lived experiences of others. As Hopper (2005) explained, issue-based books are a growing area of reading for adolescent readers, who select books about issues important to teenage readers such as bullying, prejudice, racism, refugee experiences, or sex. This is important because by delving into these issues through their choice of reading materials, younger readers establish a practice of using their reading to learn more about the challenges that others face and engage in empathy for the experiences of others.

Early Reading Experiences Outside of the United States. A subset of focus group participants grew up outside of the United States, spending their early reading years in Australia and South Africa, which meant that their early reading materials included titles not common in America and that they also had more of a British influence on their early reading. These participants shared that they read books about America in the years prior to moving to the United States, with one participant sharing that American teenage girl book series provided some insight into what they might experience. A literature search did not yield pertinent articles on this subject, so further research and more literature review would be appropriate. It would be interesting to know more about how growing up with more British reading influences and initially experiencing American culture through reading materials shaped the American 
experience for those that grew up outside of the United States. This will be further addressed in the section on ideas for future research.

\section{Importance of Personal Choice of Reading Materials}

Some focus group participants did not truly find their love of books until they were able to make their own reading choices and select their own books. The books that parents and teachers supplied for them were not of interest, but when they were able to visit libraries and bookstores and select their own reading materials they found books, authors, and genres that resonated with their tastes and held their attention. We know from the literature that parents and teachers have a lot of control over the reading materials of young children and can contribute to the gendered division of children's books, where books tailored to boys display qualities like agency and bravery and books tailored to girls focus on feelings and relationships, when all children can find meaning in stories centered around any of those qualities (Segel, 1986). We also know from the literature that adolescents tended to choose their books based on peer recommendations and enjoyed being part of a "peer group cultural experience" which often diverged from their instructor's assigned or recommended reading selections (Hopper, 2005, p. 118). This is important because having a sense of agency over the selection of their reading materials makes a big difference in whether a child will grow up with a love of reading and books and potentially move on to a career in higher education, or whether they will only read what is assigned for class because they do not find a niche of reading that appeals to their tastes and preferences.

\section{Reading in Adulthood}

In examining the reading experiences, rituals, and practices of women in higher education leadership roles in adulthood, what they read and how they read emerged as two major areas of 
discussion. What women leaders in higher education read includes reading for teaching, research and theory related to professional work; reading for diversity and identity; reading for connection and community; reading for personal development; and reading for escape. How women leaders in higher education read includes reading rituals and practices such as having specific places to read, reading while travelling, author studies, and utilizing technology for reading. Each of these areas will be discussed in detail in the sections below.

\section{What Women Leaders in Higher Education Read}

In discussions of their current reading, women higher education leaders from the focus groups shared that their reading included reading materials for teaching, research and theory related to professional work; reading for diversity and identity; reading for connection and community; reading for personal development; and reading for relaxation and escape. Each of these areas will be explored in more detail in this section.

\section{Reading for Teaching, Research, and Theory Related to Professional Work. For} women in higher education leadership roles, reading is often centered around professional knowledge. Whether reading materials to potentially assign in class, reading student papers, or reading to stay informed of the latest advances in their area of interest, focus group participants shared that professional reading takes up a large portion of their reading time. This is meaningful because it reveals how critical it is for women in higher education to enjoy their field of study, as they will continue to read widely on the topic throughout their careers.

Connection of Reading to Teaching and Research Interests. Focus group participants made it clear that they are passionate about the topics of their research and teaching and enjoy sharing these subjects with students. They spend a lot of their reading time keeping updated on the latest literature on their subject of interest and enjoy these topics so much that the line 
between reading for professional and personal interest is often blurred. As Coker (2020)

explained, by pursuing her professional work from a place of passion and purpose and honing in on the areas that she was most interested in, it provided her with purpose for maintaining worklife balance. This is important because at times when professional reading must take priority, having a passionate interest in their teaching and research and focusing on their key areas of interest can help women leaders in higher education find balance and continue to derive enjoyment from their reading experiences and from enhancing their expertise in their chosen subject.

Exploring Theory Through Reading. In addition to staying informed on the most recent developments in their chosen area of study, focus group participants continued their study of theorists which furthered their growth as educators and researchers. Delving into critical education theory, political theory, and feminist theory all shaped participants' understanding of their fields of research and the way they look at the world. A literature search did not yield pertinent articles on this subject, so further research and more literature review would be appropriate. Nevertheless, this is significant because keeping up with the latest theories relevant to their field of study aids women leaders in higher education stay in the conversation within the academy and bring the latest knowledge to their students as well.

Reading for Diversity and Identity. It was important to focus group participants to have the opportunity to read literature that featured characters whose identities and experiences were similar to their own, and to be able to provide their students with the same opportunity by including diverse reading materials and books written by and about women in their class syllabi and choosing books for their children that included diverse and female characters. By incorporating diverse and female authors and experiences in their personal and professional 
reading choices, women expanded their thinking on identity and helped others do the same. This will be discussed in detail in the sections below.

It is important to reiterate that the focus group sessions occurred mere days after the killing of George Floyd. While the murder and the subsequent protests which began immediately in the aftermath were not directly discussed in the focus group sessions, social justice and issues of race were beginning to dominate the media cycle and several participants who were already doing the work of studying diversity and inclusion made sure to mention those reading choices. These reading choices stood out to me in reviewing, coding, and analyzing the responses of participants throughout the rest of 2020 and beginning of 2021, as protests continued and the New York Times Bestseller List shifted and readers purchased more books by African American writers and about social justice, equity, race, and racism (Harris, 2021).

Importance of Representation in Books and Being Able to Identify with the Characters. Focus group participants shared that reading experiences where they identified with the characters were particularly meaningful, while those where they had a difficult time relating to the characters were especially frustrating. In being provided with books where there were more female or diverse characters, women felt that their lived experiences were being valued and they could derive inspiration from seeing other women and individuals from diverse backgrounds achieving success. Identifying with characters within literature helps put situations into perspective and increases confidence, positivity, and hopefulness that one will be able to face and resolve challenges (Miller, 1993; Zeller Carlson, 1989). This is important because having the opportunity to see women like themselves represented within literature as becoming successful in higher education leadership roles, helped them gain the confidence to aspire to these roles themselves. 
Diversifying Reading Materials. In ensuring that their students learned through a diverse curriculum, focus group participants provided students with the opportunity to feel represented in the materials they read for class. Participants also shared that they selected and shared diverse reading materials with their children and encouraged them to read books about women and women of color. When the curriculum primarily features a narrow focus on traditional white male voices, everyone who does not fit in that niche has a hard time feeling a sense of belonging or inclusion in the classroom (Appleby, 1992; Greenbaum, 1994). This is meaningful because making women of diverse backgrounds feel welcome and a part of the intellectual conversation throughout each stage of their educations and careers is a vital component in recruiting more women to take on leadership roles and remain within the academy.

Reading and Gender. While some participants tended to read a lot of books by and about women and explained that gender was a key component in their selection of reading material, others shared that their selection was more tied to the plot or the topic of the book. For those that made a concerted effort to choose books which were written by women and explored the experiences of women, this was often in response to their assigned reading materials throughout their education and the bulk of the literature in their field being written by and about men. To fully understand the complexity of the human experience, male and female students both benefit from reading about the experiences of women, reading books by women, and having female literary role models (Zeller Carlson, 1989). This is important because for more women to succeed in higher education leadership roles, women writers and scholars and the experiences of women need to be as integrated into the classroom discussions and the home libraries of women in academia as their male counterparts. 
Exploring Relevant Intersectional Issues Through Reading. Focus group participants also discussed their exploration of intersectional issues, which aided in their understanding of intersectional topics related to their areas of research and also in their personal development whenever an intersectional identity resonated in their own lives. Participants shared their exploration of theory and literature most commonly related to topics such as feminism, racial equity, and LGBTQIA+ issues. Kohn-Wood (2020) explained that having individuals with complex intersectional identities in positions of power within higher education is the only way to bring about real transformation and resolve issues related to representation. This is significant because keeping updated on the latest research in intersectional issues and theories allows women leaders in higher education to apply this knowledge to their fields of expertise, to their understanding of themselves, and to advocate for better representation within their institutions.

Reading for Connection and Community. In addition to personal and professional reading, a third reading category emerged, community reading. Focus group participants shared their experiences connecting with others through their discussions of reading materials through book clubs and book groups, online fanfiction communities, and Little Free Libraries. They connected with professional mentors through reading their work, and bonded with colleagues, friends, and family through sharing reading recommendations. Each of these areas will be discussed in more detail in the sections below. Sharing their love of books takes reading from a solitary practice to one that inspires connection and community.

Understanding and Connecting with Others. Focus group participants shared that one reason they enjoyed reading widely was to explore the lived experiences of individuals who lived lives very different from their own. In reading books which explored the motivations and experiences of different people who grew up in different communities and in other countries, 
participants were able to better understand their motivations and see them in a different light. As Moyer (2007) explained, one of the key reasons given for leisure reading is to learn about different perspectives and about other people, cultures, and countries. This is important in that through reading about and attempting to understand other mindsets and cultures, readers are able to practice empathy and apply the insight that they glean to the variety of different individuals they are exposed to in their personal and professional lives, as well as model this practice for their students.

Book Clubs and Book Groups. Book clubs and book groups are instrumental in instilling a sense of community in the reading lives of women. As focus group participants shared, most of the book groups they participated in were comprised solely of women, which allowed them to keep up social connections and have shared reading experiences with their friends and prompted them to also share with each other about their lived experiences as they related to the book discussions. As Beach and Yussen (2011) shared, once book club members become familiar with each other's experiences and knowledge, they look forward to discussing the books with each other and anticipate which aspects of the books particular book club members may have insight into. This is meaningful in that book clubs can serve as a source of community connection, as well as a means of enforcing time for self-care and balance as they provide a regular deadline for completing leisure reading in order to be able to participate in discussions about the books.

Online Writing Communities. Online fanfiction communities provide a leisure reading experience which is interactive and consistently updated in real time. As Julia shared, she was able to regularly read new content written by amateur writers in the fanfiction community devoted to her favorite television program, The Big Valley, as well as use her teaching skills to provide developing writers with feedback on their writing. As Vinney and Dill-Shackleford 
(2018) explained, fanfiction provides the unique opportunity for readers and writers to delve more deeply into the perspectives of their favorite characters, continue storylines or see plots they wish had originally been included, develop their creative writing skills and provide feedback to others, and explore what is meaningful and important in life. This is a valuable finding because online fanfiction communities can provide women in higher education leadership roles with an engaged leisure activity, providing the unique opportunity to participate in a creative endeavor, engage in community, and consistently read new content. Since this is online and in real time, this can easily fit into their hectic schedules whenever they have a free moment for a break from their professional and personal responsibilities.

Mentors and Models. Women in higher education leadership roles do not always come from backgrounds where they have women in their families or social circles who have succeeded in academia, and that they need to look elsewhere for professional mentors and models. Focus group participants found some of these mentors and models through their reading, and Stephanie in particular connected with two different historians who came from a similar background to her and served as inspirations for how to succeed as women in her field of research. Women in higher education struggle to find female mentors to provide them with examples of how to navigate the challenges they face, as there are few women in leadership positions (Elmuti, Jia, \& Davis, 2009; Kloot, 2004). It is critical for women to locate models and mentors to help guide their path to positions of leadership within their academic fields, and to exemplify how to succeed and live a balanced life in these roles.

Book Recommendations. As the focus group participants shared, they tended to gather book recommendations from a variety of sources, gather reading recommendations shared by public figures like Barack Obama or Oprah, from public radio, and through sites and apps they 
frequent like Amazon, Audible, and Blinkist. The women also frequently read more personalized selections recommended by friends, colleagues, fellow book club members, independent bookstores they patronized, and Little Free Libraries. As Kozak, (2017) explained, Little Free Libraries serve as a space for previously unconnected neighbors to gather and communicate around shared books, and one of the core missions of the organization is to build community. A participant who had a Little Free Library in their front yard shared that their friends and colleagues have used it to stay connected and share books they think they will appreciate. In their stories of the various friends that they relied on for their favorite book recommendations, participants tended to mention female friends as recommenders, and noted that it did not matter how far away they lived from each other, they would continue to share books with each other through the mail from across the country and overseas. This is consistent with the literature which notes that women readers tend to rely on their network of female friends and family for reading recommendations and were likely to read similar types of books to the women they were closest to (Jarvis, 2003). This is significant because women in higher education leadership roles can foster a valuable sense of community in their lives through sharing and discussing favorite books with their social network, while also taking a break from their professional responsibilities.

Reading for Personal Development. When reading during their free time, focus group participants often turned to books for their personal development. Some enjoyed reading up on creative and practical projects such as cooking, quilting, sewing, or knitting. Others turned to books to further develop their skills in navigating the challenges they face in the workplace or in parenting. Each of these areas will be discussed in more detail below. Reading books for 
personal development allowed them an escape from professional reading and a way to further develop skills in their personal lives.

Developing Creative and Practical Skills. Popular choices for personal development reading were cookbooks and books with ideas to further quilting, sewing, and knitting techniques. These offered focus group participants the opportunity to further their technical and creative skills, or in the case of the cookbooks a chance to take a mental break and immerse themselves in the history, culture, and photography associated with the recipes they were interested in potentially making. A literature search did not yield pertinent articles on the subject, so further research and more literature review would be appropriate and this will be further addressed in the section on ideas for future research. This is still a valuable finding because personal development reading offers women in higher education leadership roles who need a break from their professional responsibilities a niche of books that can offer escape without being a work of fiction. For those who prefer nonfiction in their leisure time, these reading choices offer both creative and practical applications.

Developing Skills to Navigate Home and Workplace Roles. Focus group participants also found it useful to spend time reading personal development books related to navigating their busy roles in the home and in the workplace. They gleaned insight into how to be kind to themselves, to strive for egalitarian roles in the home, to navigate their leadership roles at work, to successfully negotiate as a woman. As Scandura (2020) asserted, negotiating is one of the key skills needed by women leaders in higher education, whether it is negotiating positions for a department or school, negotiating salaries, or negotiating disputes between individuals, but it is not often a skill that academics are taught for their roles. This is important because it reveals that 
reading personal development literature is another tool women in higher education leadership roles can use to navigate their work and personal responsibilities and find balance.

Reading for Escape. One of the main reasons they read in their leisure time is to have a brief escape from their hectic lives. Participants shared that they enjoyed escaping in a work of fiction, being transported to another time and place, and having a short respite from the news related to the COVID-19 pandemic, which will be discussed in more detail in the sections below. For women in higher education leadership roles, having an opportunity to escape into a leisure read was a helpful way to add some balance to their busy days.

Escaping Into Leisure Reading. When reading for pleasure, a number of focus group participants turned to fiction to provide an escape from personal and professional responsibilities. We know from the literature that women tend to enjoy reading fiction in their leisure reading which allows them a reprieve from their everyday lives. As Taylor (2020) explained, women are the main readers, buyers, and borrowers of fiction, and "fiction plays an important emotional and therapeutic role in women's lives" (p. 48). Taylor (2020) further noted that women tend to be reflective and interested in exploring the inner lives of other women, which is another reason they are drawn to fiction. This is significant because taking the time to consume fiction in their leisure time can provide a much-needed escape for women leaders in higher education.

Escaping to Another Time and Place. Focus group participants shared that part of the fun of escaping into fiction was immersing themselves in another time and place through the stories. Whether this was travelling to Naples through an Elena Ferrante novel, or visiting a neighborhood outside Philadelphia in an Ann Patchett book, participants enjoyed being able to visualize themselves in locations around the world as they read. As Moyer (2007) shared, a key 
reason readers turn to fiction is to learn more about other cultures, countries, and time periods, making historical fiction and romances popular genre choices for those looking to escape to another time and place through the actions of the characters. This is a meaningful finding as choosing a work of fiction with a vivid and specific setting can provide women in higher education leadership roles with the opportunity to have a brief escape to another time and place through their leisure reading.

Escaping from Reality During the COVID-19 Pandemic. During the COVID-19 pandemic, participants especially utilized leisure reading as a means of escape from the 24-hour news cycle, the added stress of transitioning staff, faculty, and students from in-person to online instruction, and the challenges of maintaining personal and professional responsibilities while in lockdown. As Crabtree, Esteves, and Hemingway (2020) explained, work-life balance deteriorated for women academics during COVID-19, with workloads increasing, emails multiplying, and urgent Zoom or Microsoft Teams virtual meetings filling up the calendar in addition to the changes in domestic responsibilities for those caring for elders or children and homeschooling. Not all changes were negative, as many academics gained back several hours each day during lockdown by not having to commute to work (Crabtree, Esteves, \& Hemingway, 2020). Changed daily habits meant some focus group participants lost their normal audiobook listening time on their commutes to and from the university, but some gained this reading time back by taking more walks where they would listen to books on Audible.

There was a common sense of being overwhelmed by the weight of the news on pandemic protocols and social and political unrest in connection to health guidelines, so participants were eager to escape into light, fun reading materials, many turning to cookbooks to provide a lowkey distraction from the heavier subjects they faced throughout their days. This is 
important because it can provide helpful insight to women facing difficult situations, that taking a small amount of time each day to get outside and walk with an audiobook or sit in their favorite sunny chair with a new cookbook full of history, culture, and flavorful recipes, can provide a welcome escape in stressful times.

\section{How Women Leaders in Higher Education Read}

As we learned through the focus group participants, women in higher education leadership roles had some common reading practices and habits, including having specific places to read different types of materials in their homes, having reading rituals centered around vacation and travel, conducting author studies of favorite writers, and utilizing technology to consume more reading materials throughout their days. This is important because they are leaders in their fields and their organizations, and women in academia or those aspiring to work in academia can learn from their reading rituals and practices. These rituals and practices will be discussed in more detail in the sections below.

Having Specific Places to Read. Focus group participants shared that they had certain areas dedicated to reading in their homes and would often consume different reading materials in different areas. It was common for leisure reading to be done in a comfortable spot, such as in bed or a cushioned chair in a sunny location, while more serious academic reading would be consumed at a desk or kitchen table. Taylor (2020) explained that some readers describe having Upstairs and Downstairs books, reading fiction upstairs and non-fiction downstairs, while others stash different piles of books in various locations throughout their home, depending on the topic, and still others have different types of books they save for different times of the day, designating them appropriate for reading in mornings, afternoons, or evenings. This is an important finding because allocating different areas to different types of reading may help other women in higher 
education leadership roles to balance their personal, professional, and community reading by changing locations as they change tasks.

Reading and Travel. When personal and professional schedules became busy, one time of the year that focus group participants could count on making time to read was while travelling or on vacation. Their reading rituals related to travelling and vacation included choosing reading materials to bring on a trip, purchasing new travel books in airport bookstores, and discovering local bookstores once they reached their destination and purchasing books and bookmarks to commemorate the trip. Taylor (2019) noted that vacations "are a space where many women look forward to reading fiction" (p. 25). This is a meaningful finding because making time to leisure read while travelling or on vacation is a balancing strategy that women leaders in higher education can intentionally integrate into their reading practices to further enjoy their reading experiences and create lasting memories.

Author Studies. Focus group participants shared a tendency to conduct author studies, reading all of the available books written by a favorite author and keeping an eye on the career of living authors so they could read each new book that they released. Author studies was not a term that was familiar to me prior to conducting the focus groups. Subsequent research led me to discover that it is a term commonly used in literature on literacy and K-12 education, which is a background that several focus group participants had, and likely why they shared this term as a description for one of their common reading practices. As Kennedy, (2012) explained, author studies provide students with the opportunity to recognize themes across an author's various books, as well as draw connections between the author's books and their lived experiences. This is significant for adult readers in that conducting author studies is a reading practice that ensures readers will likely enjoy their book selection as they have appreciated the writing of that author 
in the past, ensuring that women in higher education leadership roles with busy schedules do not waste time reading books that they dislike.

Technology Providing More Ways to Consume Reading. Participants embraced technology to find more times and ways in the day to consume reading materials, through listening to audiobooks while driving or walking and easily bringing their books everywhere they travelled on their e-readers or iPads. This has allowed them to continue to be readers even in their busiest times, and easily take a moment to escape into a fiction novel, a book for personal development, or a title in their professional subject while on the go. The literature has revealed that technology has also provided women in higher education leadership roles with more opportunities to work remotely at anytime from anywhere, which in some cases has made it difficult for them to maintain boundaries for their professional and personal time (Penney et al., 2015; Roebuck, Smith, \& El Haddaoui, 2013). Others found that technology was a tool they were able to use to find balance in both their work and family roles (Cheung \& Halpern, 2010). While women in academia were already practiced in using technology to help balance their lives and be able to continue work while at home or handle personal concerns while on campus, the challenges of COVID-19 and the pivot to totally remote work and instruction put work-life balance and the advantages and disadvantages of being able to work anytime from anywhere more prominently into the public conversation. This is important because technology can be both a balancing tool and a means to disrupt work-life balance depending on how it is used.

\section{Reading and Balance}

The focus group discussions revealed that participants had a difficult time finding and creating balance in their busy lives, which is supported by the literature on work-life balance and women leaders in higher education. Women in higher education leadership roles employ an array 
of balancing strategies in their efforts to improve their work-life balance, to varying degrees of success, because finding better balance is integral to their psychological and physical health. Focus group participants shared that they feel improved levels of work-life balance when they gave themselves permission to make time for leisure reading in their lives. Based on their experiences and the literature on work-life balance, reading has the potential to be a useful balancing strategy for women leaders in higher education.

\section{Finding Balance Through Combining and Aligning Reading Interests}

We know from participants that their leisure reading often ends up being related to their professional interests because they are so passionate about their area of research and teaching that they end up seeing how their personal reading can be used for their professional work. Sometimes this means adding a book they originally read for personal enjoyment to their course syllabus or applying things from a book they read for leisure to their professional practices. We know from the literature that sometimes women in higher education leadership roles reframe professional work as a hobby so that they can conduct it during leisure time and see it as taking a break without the usual benefits of doing something completely different in their leisure time for a break (Rafnsdóttir \& Heijstra, 2013. However, based on the information shared by the focus group participants, combining and aligning personal and professional reading interests can be a balancing strategy used when time is scarce and your area of interest is such a big part of your life that you really do enjoy continuing your exploration of the topic in your personal time. This is important because women in higher education leadership roles have a finite amount of time to attend to personal and professional matters, and any ways in which they can save time and energy by combining and aligning reading interests can add to a sense of balance in their lives. 


\section{Balancing Heavy and Light Reading Choices}

Focus group participants shared that rotating between their more heavy and light reading selections was another strategy that helped them maintain balance in their reading lives. Reading a book on a lighter topic allowed them to take a break while continuing to read after completing books on more heavy topics such as racism or the COVID-19 pandemic. As Taylor (2020) explained, in times of stress reading is helpful and helps distract readers from their worries, but they are more selective about their reading topics in such times and avoid anything too upsetting or demanding. While the focus group participants shared that they enjoyed and found it meaningful to read heavier reading material, alternating these choices with lighter reads which provided them with less demanding reading experiences allowed them to feel more balanced in their reading habits.

\section{Finding Work-Life Balance Through Reading}

We know from participants that when they made it a priority to make time to leisure read, they felt like they had their lives together and that they had better work-life balance. We know from the literature that women in academia often give up valuable self-care time in order to make sure that all of their professional obligations are taken care of, which means they cut out or decreased the time they would normally spend sleeping, exercising, and enjoying leisure activities, including reading (Kinman, 2016; McCutcheon \& Morrison, 2017; Rafnsdóttir \& Heijstra, 2013). The drawback to cutting out all of this self-care time to free up more time for work is that women's physical and psychological health deteriorated, and they experienced symptoms such as depression, sleeplessness, burnout, fatigue, and high stress levels (Cherkowski \& Bosetti, 2014; Kinman, 2016; Rafnsdóttir \& Heijstra, 2013). Prioritizing taking time for yourself is an important part of being a female leader in higher education, because the leadership 
role "requires prioritizing the needs of others within the balance of one's own needs" (Coker, 2020, p. 204). While it may seem a small step towards overall wellness, making an effort to read for pleasure on a regular basis can be an impactful step towards improving work-life balance and self-care for women in higher education leadership roles.

\section{Having Time and Permission to Read}

Participants shared that they often had to put leisure time, including time to read for pleasure, at the bottom of their list of priorities when their personal and professional responsibilities began to pile up. They also shared that they felt that whenever they let go of the guilt and allowed themselves the permission to read for enjoyment and carved out time for it, that it helped lighten up their mood and became an important part of their day. The literature revealed that women in higher education leadership roles have to take on the bulk of unpaid labor in their family units, including child and elder care, household maintenance, and other personal responsibilities, in addition to their professional responsibilities (Beddoes \& Pawley, 2014; Dubois-Shaik \& Fusulier, 2017; Kinman, 2016; McCutcheon \& Morrison, 2017; Penney, et. al., 2015; Rafnsdóttir \& Heijstra, 2013; Roebuck, Smith, \& El Haddaoui, 2013; Sallee, 2008a; Sallee, 2008b; Sallee, 2013; Sallee \& Blakewood Pascale, 2012; Toffoletti \& Starr, 2016). Women in academia also feel a sense of guilt whenever they struggle to maintain a balance between their personal and professional duties (Kinman, 2016; Smidt, Pétursdóttir, \& Einarsdóttir, 2017; Toffoletti \& Starr, 2016). This is an important finding because knowing that other women in higher education leadership roles are facing the same challenges and demands on their time and are feeling happier and finding more balance when they make time for personal pursuits like leisure reading, may help other women in academia striving for work-life balance. 
Through finding balance by combining and aligning their reading interests, finding worklife balance through leisure reading, and making time and giving themselves permission to read, women in higher education leadership roles worked towards improving balance in their lives. In the next section, the implications of these findings will be discussed.

\section{Implications}

Through studying the reading experiences, choices, and habits of women in higher education leadership roles, findings about striving for balance through reading were gleaned which will be useful for parents of childhood readers, educators choosing reading materials and designing curriculums, women interested in entering academia and aspiring to higher education leadership, and women in higher education leadership roles. The implications for each of these groups will be discussed in further detail in the sections below.

\section{Parents of Childhood Readers}

We learned that children can be positively impacted by having family members read and discuss books with them and provide them with reading materials, and that childhood readers thrive when given the opportunity to choose their own reading materials. Parents of childhood readers should be taking trips to the library and bookstore with their children and allowing them to make their own reading choices. Taking children to get their own library card and have agency over their reading choices can be a fun and productive family activity that leads to increased positive academic outcomes for young readers. Early agency over reading selection may even lead to children growing up and becoming leaders in higher education like the focus group participants. 


\section{K-12 Through Higher Education Educators}

Children and adults enjoy reading materials that they can identify with, so educators designing curriculums for K-12 through college should do their part to diversify their curriculums and offer reading selections written by and about a wide spectrum of backgrounds and identities and with more gender balance. By incorporating more diverse voices in the curriculum, educators ensure that women and diverse students feel included in the classroom space, which may lead to them continuing their educations and pursuing roles in higher education. In order to have more women and more women of color in higher education leadership roles, we need to make them feel welcome in the academy from the beginning.

\section{Women Interested in Working in Academia}

Women who do not yet have mentors or models to guide them in how to navigate a successful path through academia and to become a leader in higher education can find inspiration in the participants' reading experiences, choices, and habits and how they contributed to their finding balance in their lives. Knowing that reading for pleasure can contribute meaningfully to self-care, relaxation, and establishing more work-life balance is an important finding for women interested in entering academia and aspiring to higher education leadership roles. Establishing these practices early on can help women find more balance between their personal and professional responsibilities.

\section{Women in Higher Education Leadership Roles}

Finally, these findings are particularly important for women already established in higher education leadership roles who are looking for helpful outlets from their everyday responsibilities. Taking time to leisure read can infuse their routine with lightness and creativity and provide them with a much-needed dose of levity and escape. By establishing practices that 
lead to more balance in their personal and professional lives, women leaders in higher education can avoid burnout and continue to find meaning in their academic careers for years to come.

Women in higher education leadership roles can also try balancing their various reading subjects by changing locations when they transition to different reading purposes. Finding a location in their home or office which serves as a productive place to focus and read for professional reading related to teaching, another space which is conducive to consuming reading material related to their research interests, and a more comfortable and inviting space to transition to leisure reading choices to wind down and read for pleasure and escape can all help women to balance their reading choices and mentally transition between reading purposes.

In addition, by modeling balancing practices women leaders in higher education can provide women they are mentoring that are moving up the ranks in academia with examples of how to work towards work-life balance while in a leadership role. Women gain confidence by seeing other women thrive in their sphere. Through more women in leadership positions in higher education making themselves available to mentor others on their campus and in their research field aspiring to similar roles, hopefully we will gain more women in these leadership positions in academia.

\section{Study Limitations}

The COVID-19 pandemic, and complications that arose due to the timing of my study, impacted the data collection process. It would have been preferable to have conducted the focus groups in person, but due to lockdown and social distancing, the focus groups needed to be held virtually. If not for the COVID-19 pandemic and other limiting factors that occurred due to the complications with the timing of this study, I would have also liked to have gone back to the focus group participants for member checking and potential follow up interviews. Some 
grounded theory method literature does warn about balancing member checking with the researcher's iterative analysis of the data. As Birks and Mills (2015) explained, the understandings and beliefs of participants are not fixed and can change or be influenced over time, and that the goal of a grounded theory study is more to "aim for a highly conceptual theorization of process" rather than "provide an accurate representation of individuals' lived experience generated through a process of phenomenological interviewing” (p. 97).

A potential limitation to using focus groups methods was that participants may have chosen to self-edit and not disclose to the other focus group participants any reading choices that they may have been uncomfortable disclosing in a social setting but may have disclosed in an individual interview. Readers, especially women readers, face bias and apologize for enjoying books that may be categorized as less serious or academic; referring to them as "guilty reads." There may have been some reading choices which participants considered to be "guilty reads" that they may not have wanted to mention in a gathering of fellow academics. If not for the pandemic, I could have potentially mitigated this concern through follow up interviews, where participants could have individually disclosed any reading choices they may not have shared in the focus group discussion.

\section{Future Research}

The results of this study provide several interesting lines of inquiry for further research. I would be interested in conducting a wider study, perhaps with a survey component added, so that I could sample a larger group of participants from a wider geographical reach and learn more about how women in higher education leadership roles find and create balance in their lives, and how reading can contribute to that balance. Women in higher education leadership roles who do not consider themselves to be readers could be included in the wider study in order to learn more 
about how they feel about reading. This could add more participants from varied research disciplines such as math and science. I would also be interested in research into whether reading has a positive impact on the work-life balance of men in academia as well, and to what extent.

There were a few topics that did not yield much pertinent literature which may provide an interesting niche for future research. It would be interesting to conduct a deeper literature review and conduct a study about how books to develop practical skills such as cooking, sewing, quilting, and knitting provide women with meaningful leisure reading. I would also be interested in further researching how women choose different locations for different types of reading, and learn more about how they set the stage for their personal, professional, and community reading selections.

It would also be interesting to further study the early reading experiences of children that grew up abroad. For those that grew up with more British reading experiences and had their initial exposure to American culture through books, it would be meaningful to learn more about how reading about American culture in their youth impacted their experiences after moving to the United States.

The timing of my focus groups towards the beginning of the COVID-19 pandemic provided unique data on what women in higher education leadership roles faced during that time, and since there has not yet been much research published on the effects of the pandemic, it would be interesting to conduct future research on how the strategies for women in higher education leadership roles to achieve balance may have changed since going back to more inperson obligations after being fully remote for more than a year during COVID-19. 


\section{Conclusion}

The study of women leaders in higher education revealed that they had reading experiences and developed reading practices that translated to what and how they read in adulthood, and to the choices and habits they made to balance their work for personal, professional, and community connectedness. By exploring what and how focus group participants read in childhood and adulthood as well as the ways they are table to utilize reading rituals and choices to create balance in their lives, and reviewing the literature related to each of these areas, meaningful findings emerged which can be useful to several groups, including parents of childhood readers, educators choosing reading materials and designing curriculums, women interested in entering academia and aspiring to higher education leadership, and women in higher education leadership roles. By applying these findings, women in higher education leadership roles can especially glean useful balancing strategies to apply to their reading choices and habits as they work towards better work-life balance. 


\section{References}

Aiston, S. J., \& Jung, J. (2015). Women academics and research productivity: An international comparison. Gender and Education, 27(3), 205-220.

https://doi.org/10.1080/09540253.2015.1024617

Alsop, R. (2015). A novel alternative. Book groups, women, and workplace networking.

Women's Studies International Forum, 52. 30-38.

https://doi.org/10.1016/j.wsif.2015.07.006

Applebee, A. N. (1992). Stability and change in the high-school canon. The English Journal, 81(5), 27-32. https://doi.org/10.2307/819891

Aronson, P. (2008). The markers and meanings of growing up: Contemporary young women's transition from adolescence to adulthood. Gender \& Society, 22(1). 56-82.

https://doi.org/10.1177/0891243207311420

Bailey, C. A. (2007). A guide to qualitative field research, (2 ${ }^{\text {nd }}$ ed.). SAGE.

Baker, C. E. (2013). Fathers' and mothers' home literacy involvement and children's cognitive and social emotional development: Implications for family literacy programs. Applied Developmental Science, 17(4). 184-197. https://doi.org/10.1080/10888691.2013.836034

Barbour, R. (2007). Doing focus groups. SAGE.

Beach R. \& Yussen, S. (2011). Practices of productive adult book clubs. Journal of Adolescent \& Adult Literacy 55(2). 121-131. https://doi.org/10.1002/JAAL.00015

Beddoes, K., \& Pawley, A. L. (2014). 'Different people have different priorities': Work-family balance, gender, and the discourse of choice. Studies in Higher Education, 39(9), 15731585. https://doi.org/10.1080/03075079.2013.801432 
Bender-Slack, D. (1999). Why do we need to genderize? Women's literature in high school. The English Journal. 88(3), 91-95. https://doi.org/10.2307/821586

Benjamin, B., \& Irwin-DeVitis, L. (1998). Censoring girls’ choices: Continued bias in english language arts classrooms. The English Journal. 87(2), 64-71. https://doi.org/10.2307/821553

Birks, M., \& Mills, J. (2015). Grounded theory: A practical guide. (2nd ed.). SAGE.

Boonk, L., Gijselaers, H. J. M., Ritzen, H., \& Brand-Gruwel, S. (2018). A review of the relationship between parental involvement indicators and academic achievement. Educational Research Review, 24. 10-30. https://doi.org/10.1016/j.edurev.2018.02.001

Bryant, A., \& Charmaz, K. (Eds.). (2007). The SAGE handbook of grounded theory. SAGE.

Bryman, A. (2008). Why do researchers integrate/combine/mesh/blend/mix/merge/fuse quantitative and qualitative research? In M. M. Bergman (Ed.), Advances in mixed methods research (pp. 89-100). SAGE.

Buettner, L., Shattell, M., \& Reber, M. (2011). Working hard to relax: Improving engagement in leisure time activities for a healthier work-life balance. Issues in Mental Health Nursing, 32, 269-270. https://doi.org/10.3109/01612840.2011.553346

Calkins, L. M. (2001). The art of teaching reading. Addison-Wesley Educational Publishers Inc.

Campbell, D. T., \& Fiske, D. W. (1959). Convergent and discriminant validation by the multitrait-multimethod matrix. Psychological Bulletin, 56, 181-105. https://doi.org/10.1037/h0046016

Charmaz, K. (2014). Constructing grounded theory. ( $2^{\text {nd }}$ ed.). SAGE. 
Cherkowski, S., \& Bosetti, L. (2014). Behind the veil: Academic women negotiating demands of femininity. Women's Studies International Forum, 45(1), 19-26. https://doi.org/10.1016/j.ws.if.2014.03.013

Cheung, F. M., \& Halpern, D. M. (2010). Women at the top: Powerful leaders define success as work + family in a culture of gender. American Psychologist, 65(3), 182-193. https://doi.org/10.1037/a0017309

Christman, D., \& McClellan, R. (2008). 'Living on barbed wire': Resilient women administrators in educational leadership programs. Educational Administration Quarterly, 44(1), 3-29. https://doi.org/10.1177/0013161X07309744

Coker, A. L., \& Bush, H. M. (2020). Work-life balance. In C. Rennison \& A. Bonomi (Eds.). Women leading change in academia: Breaking the glass ceiling, cliff, and slipper. (pp. 195-215). Cognella Academic Publishing.

Coles, M. \& Hall, C. (2002). Gendered readings: Learning from children's reading choices. Journal of Research in Reading, 25(1). 96-108. https://doi.org/10.1111/1467-9817.00161

Crabtree, S. A., Esteves, L., \& Hemingway, A. (2020). A 'new (ab)normal'?: Scrutinising the work-life balance of academics under lockdown. Journal of Further and Higher Education. 1-15. https://doi.org/10.1080/0309877X.2020.1853687

Crawford, M., \& Chaffin, R. (1986). The reader's construction of meaning: Cognitive research on gender and comprehension. In E. A. Flynn \& P. P. Schweikart (Eds.), Gender and reading: Essays on readers, text, and contexts. The John Hopkins University Press.

Cresswell, J. W., \& Cresswell, J. D. (2018). Research design: Qualitative, quantitative, and mixed methods approaches, ( $5^{\text {th }}$ ed.). SAGE. 
Crotty, M. (1998). The foundations of social research: Meaning and perspective in the research process, $\left(1^{\text {st }}\right.$ ed.). SAGE.

Cunningham, M., Beutel, A. M., Barber, J. S., \& Thornton, A. (2005). Reciprocal relationships between attitudes about gender and social contexts during young adulthood. Social Science Research, 34(4). 862-892. https://doi.org/10.1016/j.ssresearch.2005.03.001

Danner, M. J. E., Worth Pickering, J., \& Paredes, T. M. (2018). Using focus groups to listen, learn, and lead in higher education. Stylus Publishing, LLC.

Davis, S.N. (2007). Gender ideology construction from adolescence to young adulthood. Social Science Research, 36(3). 1021-1041 doi:10.1016/j.ssresearch.2006.08.001

DeCuir-Gunby, J. T., \& Schultz, P. A. (2017). Developing a mixed methods proposal: A practical guide for beginning researchers, ( $1^{\text {st }} \mathrm{ed}$.). SAGE.

DeVellis, R. F. (2017). Scale development: Theory and applications, ( $4^{\text {th }}$ ed.). SAGE.

Dubois-Shaik, F., \& Fusulier, B. (2017). Understanding gender inequality and the role of the work/family interface in contemporary academia: An introduction. European Educational Research Journal, 16(2-3), 99-105. https://doi.org/10.1177/1474904117701143

Eagly, A. H. (2007). Female leadership advantage and disadvantage: Resolving the contradictions. Psychology of Women Quarterly, 31, 1-12. https://doi.org/10.1007/978-1137-24203-7_20

Eagly, A. H., \& Carli, L. L. (2003). The female leadership advantage: An evaluation of the evidence. The Leadership Quarterly, 14, 807-834. https://doi.org/10.1016/j.leaqua.2003.09.004 
Elmuti, D., Jia, H., \& Davis, H. H. (2009). Challenges women face in leadership positions and organizational effectiveness: An investigation. Journal of Leadership Education, 8(2), 167-186. https://doi.org/10.12806/v8/i2/rf4

Fan, P., \& Marini M. M. (2000). Influences on gender-role attitudes during the transition to adulthood. Social Science Research, 29. 258-283. https://doi.org/10.1006/ssre.1999.0669

Fetters, M. D. (2016). ‘Haven’t we always been doing mixed methods research'?: Lessons learned from the development of the horseless carriage. Journal of Mixed Methods Research, 10(1), 3-11. https://doi.org/10.1177/1558689815620883

Flynn, E. A. (1986). Gender and Reading. In E. A. Flynn \& P. P. Schweikart (Eds.), Gender and reading: Essays on readers, text, and contexts. The John Hopkins University Press.

Fowler Jr., F. J. (2014). Survey research methods, (5 ${ }^{\text {th }}$ ed.). SAGE.

Greenbaum, V. (1994). Expanding the canon: Shaping inclusive reading lists. The English Journal, 83(8), 36-39. https://doi.org/10.2307/820331

Greenbaum, V. (1999). Seeing through the lenses of gender: Beyond male/female polarization. The English Journal, 88(3), 96-99. https://doi.org/10.2307/821587

Greene, J. C., Benjamin, L., \& Goodyear, L. (2001). The merits of mixing methods in evaluation. Evaluation, 7(1), 25-44. https://doi.org/10.1177/13563890122209504

Greene, J. C., Caracelli, V. J., \& Graham, W. F. (1989). Toward a conceptual framework for mixed-method designs. Educational Evaluation and Policy Analysis, 11(3), 225-274. https://doi.org/10.3102/01623737011003255

Griffin, K. A., \& Museus, S. D. (2011). Applications of mixed-methods approaches to higher education and intersectional analyses. New Directions for Institutional Research, 151, 1526. https://doi.org/10.1002/ir.396 
Growe, R., Montgomery, P. (1999). Women and the leadership paradigm: Bridging the gender gap. National Forum of Educational Administration and Supervision Journal,1E(4), 3846. https://www.researchgate.net/publication/242783132_Women_and_the_leadership_parad igm_bridging_the_gender_gap

Harris, E. A. (2021, September 15). Books on race filled best-seller lists last year. Publishers took notice. New York Times. https://www.nytimes.com/2021/09/15/books/new-booksrace-racism-antiracism.html

Heilmann, A., \& Llwellyn, M. (2004). Hystorical fictions: Women (re)writing and (re)reading history. Women: A Cultural Review, 15(2), 137-152.

https://doi.org/10.1080/0957404042000234006

Hertneky, R. P. (2010) The role of balance in women's leadership self-identity. Advancing Women in Leadership Journal, 30(14), 1-12. http://advancingwomen/awl/awl_wordpress/

Hesse-Biber, S. (2012). Feminist approaches to triangulation: Uncovering subjugated knowledge and fostering social change in mixed methods research. Journal of Mixed Methods Research, 6(2), 137-146. https://doi.org/10.1177/1558689812437184

Hesse-Biber, S., \& Griffin, A. J. (2013). Internet-mediated technologies and mixed methods research: Problems and prospects. Journal of Mixed Methods Research, 7(1), 43-61. https://doi.org/10.1177/1558689812451791

Holland, N. N., \& Sherman L. F. (1986). Gothic possibilities. In E. A. Flynn \& P. P. Schweikart (Eds.), Gender and reading: Essays on readers, text, and contexts. The John Hopkins University Press. 
Hopper, R. (2005). What are teenagers reading? Adolescent fiction reading habits and reading choices. Literacy, 39. 113-120. https://doi.org/10.1111/j.1467-9345.2005.00409.x

Ivankova, N. V., Cresswell, J. W., \& Stick, S. L. (2006). Using mixed-methods sequential explanatory design: From theory to practice. Field Methods, 18(1), 3-20. https://doi.org/10.1177/1525822X05282260

Jarvis, C. (2003). Desirable reading: The relationship between women students' lives and their reading practices. Adult Education Quarterly, 53(4). 261-276. https://doi.org/0.1177/07417136032254029

Jarvis, C. (1995). Romancing the curriculum: Empowerment through popular culture. Convergence, 28(3). https://eric.ed.gov/?id=EJ515606

Johansen, E. (2016). The neoliberal gothic: Gone Girl, Broken Harbor, and the terror of everyday life. Contemporary Literature, 57(1), 30-55. https://muse.jhu.edu/article/619446

Johnson, R. B., \& Onwuegbuzie, A. J. (2004). Mixed methods research: A research paradigm whose time has come. Educational Researcher, 33(7), 14-26. https://doi.org/10.3102/0013189x033007014

Kennedy, A. (2012). Author studies: An effective strategy for engaging pre-service teachers in the study of children's literature. Children's Literature in Education, 43. 107-111. https://doi.org/10.1007/s10583-011-9155-y

Kinman, G. (2016). Managing the work-home interface: The experience of women academics. In R. L. Gervais \& P. M. Millear (Eds.) Exploring Resources, Life-Balance and Well-Being of Women Who Work in a Global Context (pp. 127-144). Springer International Publishing. 
Kloot, L. (2004). Women and leadership in universities: A case study of women academic managers. International Journal of Public Sector Management, 17(6), 470-485. https://doi.org/10.1108/09513550410554760

Kohn-Wood, L. (2020). Intersectionality and women leaders in the academy: Race and ethnicity, LGBTQ, differently abled. In C. Rennison \& A. Bonomi (Eds.). Women leading change in academia: Breaking the glass ceiling, cliff, and slipper. (pp. 21-35). Cognella Academic Publishing.

Kozak, N. I. (2017). Building community, breaking barriers: Little free libraries and local action in the United States. Media/Culture Journal, 20(2). https://doi.org/10.5204/mcj.1220

Leavy, P., \& Harris, A. (2019). Contemporary feminist research from theory to practice. The Guilford Press.

Leppänen, U., Anola, K., \& Nurmi, J-E. (2005). Beginning readers' reading performance and reading habits. Journal of Research in Reading, 28(4). 383-399. https://doi.org/10.1111/j.1467-9817.2005.00281.x

Madsen, S. R. (2011). Women and leadership in higher education: Current realities, challenges, and future directions. Advances in Developing Human Resources, 14(2) 131-139. https://doi.org/10.1177/1523422311436299

Madsen, S. R., Longman, K. A., \& Daniels, J. R. (2012). Women's leadership development in higher education: Conclusion and implications for HRD. Advances in Developing Human Resources, 14(1), 113-128. https://doi.org/10.1177/1523422311429734

Marshall, C., \& Rossman, G. B. (2015). Designing qualitative research. $\left(6^{\text {th }}\right.$ ed). SAGE. Maxwell, J. A. (2016) Expanding the history and range of mixed methods research. Journal of Mixed Media Research, 10(1), 12-27. https://doi.org/10.1177/1558689815571132 
McClung, N. A., Barry, E., Neebe, D., Mere-Cook, Y., Wang, Q., \& Gonzalez-Balsam, M. (2019). Choice matters: Equity and literacy achievement. Berkeley Review of Education, 8(2), 147-178. https://doi.org/10.5070/B80037656

McCutcheon, J. M., \& Morrison, M. A. (2017). It's 'like walking on broken glass': PanCanadian reflections on work-family conflict from psychology women faculty and graduate students. Feminism \& Psychology, 28(2), 231-252. https://doi.org/10.1177/0959353517739641

McKim, C. A. (2017). The value of mixed methods research: A mixed methods study. Journal of Mixed Methods Research, 11(2), 202-222. https://doi.org/10.1177/1558689815607096

Merriam, S. B., \& Associates. (2002). Qualitative research in practice: Examples for discussion and analysis, (1 ${ }^{\text {st }}$ ed.). John Wiley \& Sons.

Mertens, D. M., \& Hesse-Biber, S. (2012). Triangulation and mixed methods research: Provocative positions. Journal of Mixed Methods Research, 6(2), 75-79. https://doi.org/10.1177/1558689812437100

Miller, D. (2009). The book whisperer: Awakening the inner reader in every child. Jossey-Bass.

Miller, D. E. (1993). The literature project: Using literature to improve the self-concept of at-risk adolescent females. Journal of Reading, 36(6), 442-448. http://www.jstor.org/stable/40016462

Miller, S. I., \& Gatta, J. L. (2006). The use of mixed methods models and designs in the human sciences: Problems and prospects. Quality \& Quantity, 40(6), 595-610. https://doi.org/10.1007//s11135-005-1099-0 
Morgan, D. L. (2007). Paradigms lost and pragmatism regained: Methodological implications of combining qualitative and quantitative methods. Journal of Mixed Media Research, 1(1), 48-76. https://doi.org/10.1177/2345678906292462

Morgan, D. L. (2019) Basic and advanced focus groups. SAGE.

Moyer, J. E. (2007). Learning from leisure reading: A study of adult public library patrons. Reference \& User Services Quarterly, 46(4). 66-79. https://doi.org/10.5860/rusq.46n4.66

Owen, M. (1997). Re-inventing romance: Reading popular romantic fiction. Women's Studies International Forum, 20(4), 537-546. https://doi.org/10.1016/s0277-5395(97)00042-3

Penney, S., Young, G., Badenhorst, C., Goodnough, K., Hesson, J., Joy, R., McLeod, H., Pickett, S., Stordy, M., Vaandering, D., \& Pelech, S. (2015). Faculty writing groups: A support for women balancing family and career on the academic tightrope. Canadian Journal of Higher Education, 45(4), 457-479. https://eric.ed.gov/?id=EJ1086863

Rafnsdóttir, G. L., \& Heijstra, T. M. (2013). Balancing work-family life in academia: The power of time. Gender, Work, and Organization, 20(3), 283-295. https://doi.org/10.1111/j.14680432.2011.00571.x

Rhode, D. L. (2017). Women and leadership. Oxford University Press.

Risman, B. J., Atkinson, M. P., \& Blackwelder, S. P. (1999). Understanding the juggling act: Gendered preferences and social structural constraints. Sociological Forum, 14(2). 319344. https://doi.org/10.1023/a:1021422930020

Roberts, L. D., \& Allen, P. J. (2015). Exploring ethical issues with using online surveys in educational research. Educational Research and Evaluation, 21(2), 95-108. https://doi.org/10.1080/13803611.2015.1024421 
Roebuck, D. B., Smith, D. N., \& El Haddaoui, T. (2013). Cross-generational perspectives on work-life balance and its impact on women's opportunities for leadership in the workplace. Advancing Women in Leadership, 33, 52-62.

https://doi.org/10.17062/cjil.v2i1.31

Rosser, V. J. (2003). Faculty and staff members perceptions of effective leadership: Are there differences between women and men leaders? Equity \& Excellence in Education, 36(1), 71-81. https://doi.org/10.1080/10665680303501

Russ, J. (1973). Somebody's trying to kill me and I think it's my husband: The modern gothic. Journal of Popular Culture, 6(4), 666-691. https://doi.org/10.1111/j.00223840.1973.00666.x

Sale, J. E. M., Lohfield, L. H., \& Brazil, K. (2002). Revisiting the qualitative-quantitative debate: Implications for mixed-methods research. Quality \& Quantity, 36(1), 43-53. https://doi.org/10.1023/a:1014301607592

Sallee, M. W. (2008a). A feminist perspective on parental leave policies. Innovations in Higher Education, 32, 181-194. https://doi.org/10.1007/s10755-007-9049-5

Sallee, M. W. (2008b). Work and family balance: How community college faculty cope. New Directions for Community Colleges, 142, 81-91. https://doi.org/10/1002/cc.327

Sallee, M. W. (2013). Gender norms and institutional culture: The family-friendly versus the father-friendly university. The Journal of Higher Education, 84(3), 363-396. https://doi.org/10.1153/jhe.2013.0017 
Sallee, M. W., \& Blakewood Pascale, A. (2012). Multiple roles, multiple burdens: The experiences of female scientists with children. Journal of Women and Minorities in Science and Engineering, 18(2), 135-152.

https://doi.org/10.1615/jwomenminorscieneng.2012001669

Scandura, T. A. (2020). Negotiation strategies. In C. Rennison \& A. Bonomi (Eds.). Women leading change in academia: Breaking the glass ceiling, cliff, and slipper. (pp. 217-234). Cognella Academic Publishing.

Schweickart, P. P. (1986). Reading ourselves: Toward a feminist theory of reading. In E. A. Flynn \& P. P. Schweikart (Eds.), Gender and reading: Essays on readers, text, and contexts. The John Hopkins University Press.

Segel, E. (1986). “As the twig is bent..." Gender and childhood reading. In E. A. Flynn \& P. P. Schweikart (Eds.), Gender and reading: Essays on readers, text, and contexts. The John Hopkins University Press.

Seltzer, R. (2015). The coach's guide for women professors. Stylus.

Shannon-Baker, P. (2016). Making paradigms meaningful in mixed methods research. Journal of Mixed Methods Research, 10(4), 319-334. https://doi.org/10.1177/1558689815575861

Shore, Z. L. (2000). Girls learning, women teaching: Dancing to different drummers. Educational Studies, 31(2). p.132-145. https://eds.b.ebscohost.com/ehost/pdfviewer/pdfviewer?sid=47e03694-1a2e-4f97-87b154dc54d9c46b\%40sessionmgr103\&vid=11\&hid=126 
Smidt, T. B., Pétursdóttir, G. M., \& Einarsdóttir, P. (2017). How do you take time? Work-life balance policies versus neoliberal, social and cultural incentive mechanisms in Icelandic higher education. European Educational Research Journal, 16(2-3), 123-140. https://doi.org/10.1177/1474904116673075

Sørensen, S. O. (2017). The performativity of choice: Postfeminist perspectives on work-life balance. Gender, Work and Organization, 24(3), 297-313. https://doi.org/10.1111/gwao.12163

St. Pierre, E. (1999). A historical perspective on gender. The English Journal. 88(3), 29-34. https://doi.org/10.2307/821576

Tashakkori, A. (2009). Are we there yet? The state of the mixed methods community. Journal of Mixed Methods Research, 3(4), 287-291. https://doi.org/10.1177/1558689809346151

Taylor, H. (2020). Why women read fiction: The stories of our lives. Oxford University Press.

Terrell, S. R. (2016). Writing a proposal for your dissertation. The Guildford Press.

The White House Project (2013, August). The White House project report: Benchmarking women's leadership in the United States.

https://womenscollege.du.edu/media/documents/BenchmarkingWomensLeadershipinthe US.pdf

Toffoletti, K., \& Starr, K. (2016). Women academics and work-life balance: Gendered discourses of work and care. Gender, Work \& Organization, 23(5), 489-504. https://doi.org/10.1111/gwao.12133 
Van Voorhis, F. L., Maier, M. F., Epstein, J. L., \& Lloyd, C. M. (2013). The impact of family involvement on the education of children ages 3 to 8: A focus on literacy and math achievement outcomes and social-emotional skills. MDRC. 1-229. https://files.eric.ed.gov/fulltext/ED545474.pdf

Vinney, C., \& Dill-Shackleford, K. E. (2018). Fan fiction as a vehicle for meaning making: Eudaimonic appreciation, hedonic enjoyment, and other perspectives on fan engagement with television. Psychology of Popular Media Culture, 7(1) 18-32. http://dx.doi.org/10.1037/ppm0000106

Watanabe, M., \& Falci, C. (2017). Workplace faculty friendships and work-family culture. Innovative Higher Education, 42(1), 113-125.https://doi.org/10.1007/s10755-016-9373-8

Wheatley, K. (2002). Gender politics and the gothic in Alfred Hitchcock's Rebecca. Gothic Studies, 4(2), 133-144. https://doi.org/10.7227/gs.4.2.4

Wheeldon, J. (2010). Mapping mixed methods research: Methods, measures, and meaning. Journal of Mixed Media Research, 4(2), 87-102. https://doi.org/10.1177/1558689809358755

Willingham, D. T. (2017). The reading mind: A cognitive approach to understanding how the mind reads. Jossey-Bass.

Wisker, G. (1999). Don't look now! The compulsions and revelations of Daphne du Maurier's horror writing. Journal of Gender Studies, 8(1), 19-33. https://doi.org/10.1080/095892399102797

Zeller Carlson, M. A. (1989). Guidelines for a gender-balanced curriculum in english, grades 712. The English Journal, 78(6), 30-33. https://doi.org/10.2307/817920 


\section{APPENDIX A \\ Recruitment Email Distributed to Potential Participants}

Subject line: Love to read?

Do you love to read? Looking for women in academic administrative roles to participate in an hour-long virtual focus group. Please respond to this e-mail if you are interested and see below for more details.

Good evening,

My name is Laura Burns and I am a Ph.D. in Education Candidate with an emphasis in Leadership Studies through the Attallah College of Educational Studies at Chapman University. I am writing to invite you to participate in my dissertation research study about the reading choices and habits of women in higher education leadership roles. I am looking for female participants that hold higher education leadership roles and like to read for professional development as well as for leisure purposes.

If you decide to participate in this study, you will participate in a focus group session for approximately one hour and will be asked to provide feedback on emergent issues. I will be recording the focus group discussion.

I would be very grateful if you would be willing to take part in my study. If you are interested in participating, or have any questions about the study, please contact me at the address below. If you do so, you will have the chance to find out more about the study before coming to any decision. Participation is voluntary, and you would be under no obligation to take part.

Thank you,

\section{Laura Burns, M.A.}

Ph.D. in Education Candidate, Leadership Studies

Administrative Coordinator, Master of Arts in Leadership Development \& Extended Education Attallah College of Educational Studies

\section{Chapman University}

(714) 628-7263

Student: burns178@mail.chapman.edu

Work: laburns@chapman.edu 


\section{APPENDIX B}

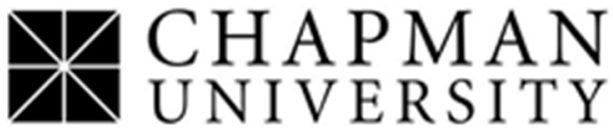

\section{ADULT INFORMED CONSENT TO PARTICIPATE IN RESEARCH}

\section{Title of Study:}

\section{Reading Choices and Habits of Women in Higher Education Leadership Roles}

\section{Members of the Research Team}

Student Researcher: Laura Burns, M.A.

Mobile: (714) 931-4054

Lead Researcher: Whitney McIntyre Miller, Ph.D.

Office: (714) 744-2134

\section{Key Information}

You are being asked to take part in a research study. Research studies include only people who choose to take part. A member of the research team will explain the study to you and will answer any questions you might have. You should take your time in deciding whether or not you want to participate.

If you agree to participate in this study, the project will involve:

- Individuals who self-identify as women

- Procedures will include answering questions within a focus group

- There is one visit

- The visit will take approximately one hour total

- There are not risks associated with this study that exceed what would typically be encountered in daily life

- You will be provided a copy of this consent form

\section{Invitation}

You are invited to take part in this research study. The information in this form is meant to help you decide whether or not to participate. If you have any questions, please ask.

\section{Why are you being asked to be in this research study?}

You are being asked to be in this study because you are a woman holding a higher education leadership position in a university in Orange County, CA. You must be 18 years of age or older to participate. 
What is the reason for doing this research study?

This research is designed to better understand the ways that reading impacts the personal and professional lives of women in higher education leadership roles, which may potentially inform what it takes to aspire to these roles and what should be included in reading curriculums to prepare individuals for these positions.

\section{What will be done during this research study?}

You will be asked to participate in a focus group that will include questions about your reading choices and habits. The focus group discussion will take approximately 1 hour to complete.

\section{What are the possible risks of being in this research study?}

As with any study involving collection of data, there is the possibility of breach of confidentiality of data. Other risks in this research include possible emotional and/or psychological distress due to topics introduced by other participants in the group discussion.

It is possible that other rare side effects could occur that are not described in this consent form. It is also possible that you could have a side effect that has not occurred before.

\section{What are the possible benefits to you?}

You will potentially gain insight into how literature has influenced your personal and professional life and shaped you as a leader. However, you may not get any benefit from being in this research study.

\section{What are the possible benefits to other people?}

The benefits to science and/or society may include insight into the literature that impacts women leaders in higher education, how this literature has influenced their personal and professional lives, as well as illuminate what it takes to shape future leaders and how to improve literature curriculums to better prepare women for leadership roles.

\section{What will participating in this research study cost you?}

There is no cost to you to be in this research study.

\section{Will you be compensated for being in this research study?}

You will not be compensated for your participation in this research study. 
What should you do if you have a problem during this research study?

Your welfare is the major concern of every member of the research team. If you have a problem as a direct result of being in this study, you should immediately contact one of the people listed at the beginning of this consent form.

\section{How will information about you be protected?}

Reasonable steps will be taken to protect your privacy and the confidentiality of your study data.

The data will be stored in a locked cabinet in the investigator's office and will only be seen by the research team during the study and for one year after the study is complete.

The data will also be stored electronically on the investigator's personal computer and will only be seen by the research team during the study and for one year after the study is complete.

The only people who will have access to your research records are the members of the research team, the Institutional Review Board (IRB), and any other person, agency, or sponsor as required by law. Information from this study may be published in scientific journals or presented at scientific meetings but the data will be reported as group or summarized data and your identity will be kept strictly confidential.

\section{What are your rights as a research subject?}

You may ask any questions about this research and have those questions answered before agreeing to participate in the study or during the study.

For study related questions, please contact the investigator(s) listed at the beginning of this form.

For questions concerning your rights or complaints about the research, contact the Institutional Review Board (IRB) at (714) 628-2833 or irb@chapman.edu.

\section{What will happen if you decide not to be in this research study or decide to stop participating once you start?}

You can decide not to be in this research study, or you can stop being in this research study (i.e., "withdraw") at any time before, during, or after the research begins for any reason. Deciding not to be in this research study or deciding to withdraw will not affect your relationship with the investigator or with Chapman University. You will not lose any benefits to which you are entitled. 


\section{CHAPMAN}

\section{Documentation of informed consent}

You are voluntarily deciding whether or not to be in this research study. Signing this form means that (1) you have read and understood this consent form, (2) you have had the consent form explained to you, (3) you have had your questions answered, and (4) you have decided to be in the research study. You will be given a copy of this consent form to keep.

$\overline{\text { Printed Name of Participant or Legal Guardian }}$

Signature of Participant or Legal Guardian

Date

\section{AUDIO \\ RECORDING:}

I have received an adequate description of the purpose and procedures for audio recording sessions during the course of the proposed research. I give my consent to allow myself to be audio recorded during participation in this study, and for those records to be reviewed by persons involved in the study, as well as for other professional purposes as described to me.

Yes, I agree to allow the research team to audio record my interview(s).

No, I do not wish to have my interview(s) audio recorded.

Signature of Participant or Legal Guardian
Date 


\section{APPENDIX C \\ Semi-Structured Interview Guide}

\section{Past Experiences:}

1) Can you please speak about when your love of reading began?

2) What books do you remember reading as part of the curriculum in K-12, college, and graduate school that made an impact on you?

a. What kind of impact did these books make?

b. Why did they make this impact?

3) Did the literature that you read as part of the curriculum in K-12, college, and graduate school influence your path to becoming a leader?
a. If so, how?
b. If not, why not?

4) What books do you remember reading on your own time during those years that made an impact on you?

a. What kind of impact did these books make?

b. Why did they make this impact?

5) Did the literature that you read on your own time during those years influence your path to becoming a leader?
a. If so, how?
b. If not, why not?

\section{Current Experiences:}

6) Do you currently consume literature for your professional reading?

a. If so, what literature do you currently consume for your professional reading? 
7) Do you currently consume literature for your leisure reading?

a. If so, what literature do you currently consume for your leisure reading?

8) Do you find that you balance pleasure reading and professional reading?

a. If so, how do you do so?

9) How does reading for pleasure contribute to your work-life balance?

a. How has the current pandemic impacted your reading habits?

b. Has reading become an outlet during these stressful times?

\section{Recommendations:}

10) Where do you get book recommendations from?

11) Does the gender of the author or the protagonist make an impact on your choice of books?

12) What books would you recommend adding to the literature curriculum to help young women prepare to enter leadership roles?

13) Is there anything else you would like to share about this topic? 


\section{APPENDIX D}

\section{Concept Maps}

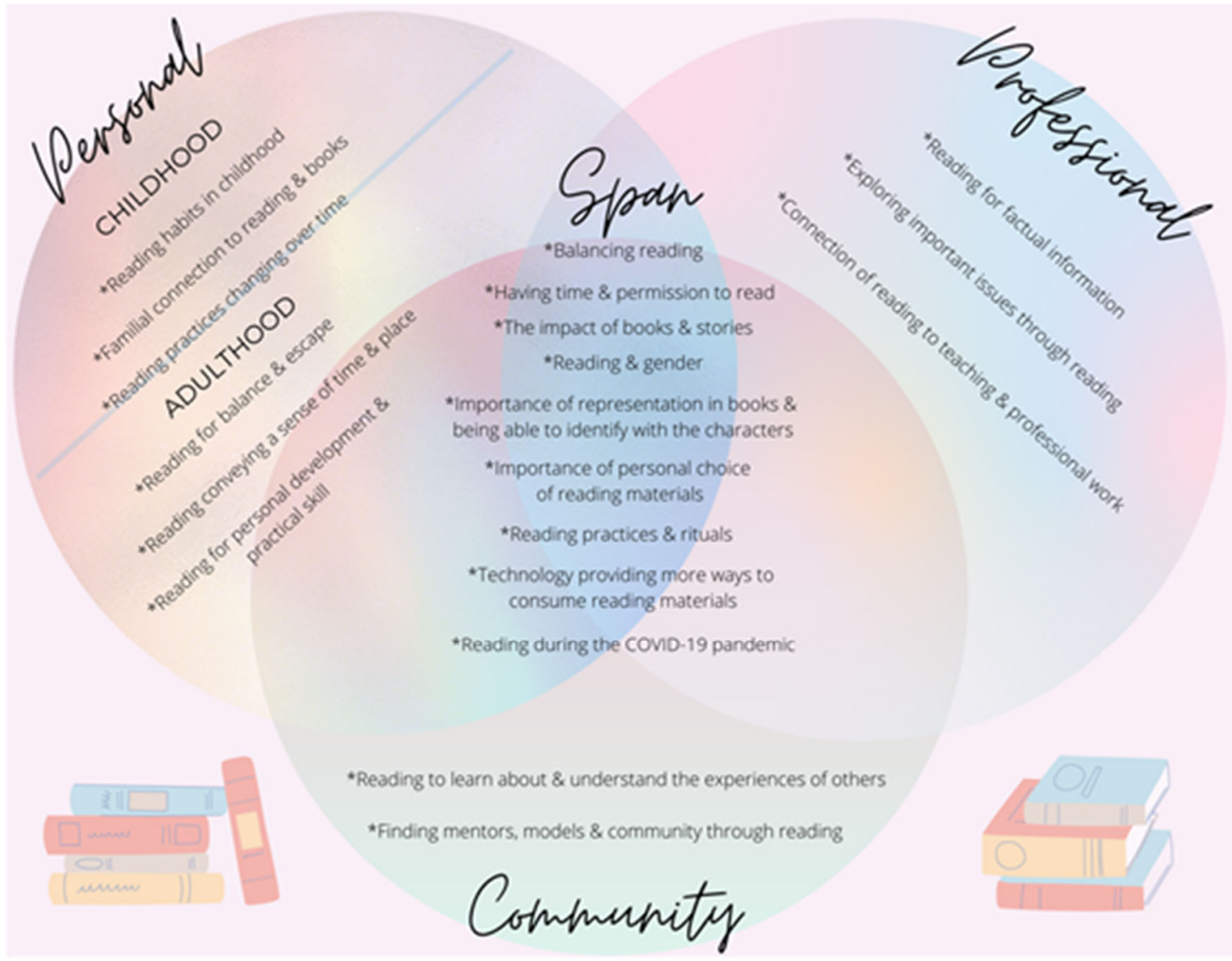

Professional

Childhaad ......... Hhat? Haw? ........... Balance

Personal Community

Adulthaad 